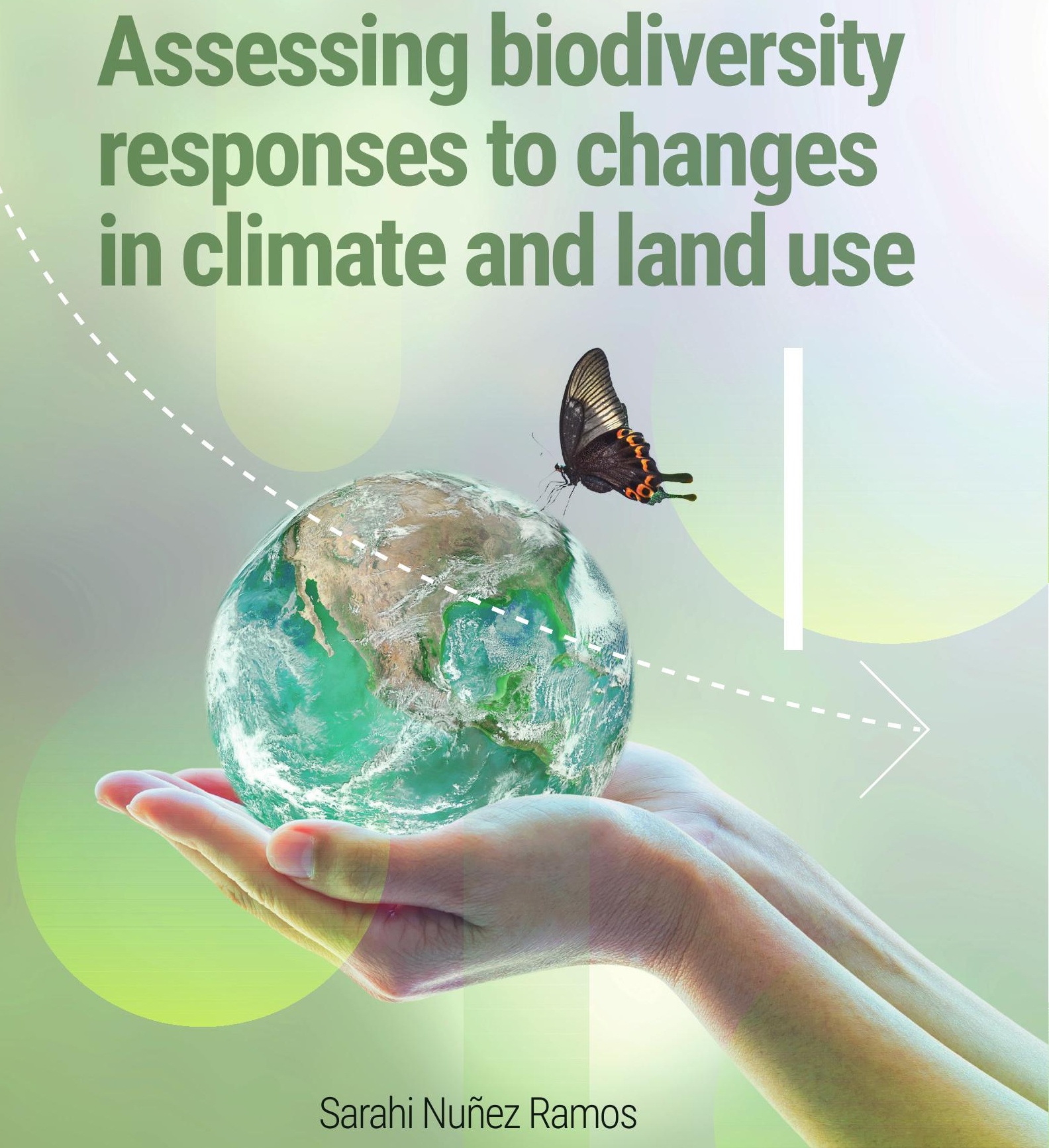

Sarahi Nuñez Ramos 



\section{Propositions}

1. Achieving any climate-protection target will not reduce the pace of biodiversity loss. (this thesis)

2. Land-based mitigation options determine the fate of future biodiversity. (this thesis)

3. Depletion of natural resources is the 'traveling companion' of renewable energy.

4. The price tag of fossil fuels should be set to conserve these resources rather than consume them.

5. The last stretch of the $\mathrm{PhD}$ journey is not overwhelming if other 'once-in-a-life' milestones are planned simultaneously.

6. The circular economy is the best way to happiness in a modern society.

Propositions belonging to the thesis of Sarahi Nuñez Ramos

'Assessing biodiversity responses to changes in climate and land use'

Wageningen, 09 October 2019 



\section{Assessing biodiversity responses to changes in climate and land use}




\section{Thesis committee}

\section{Promotors}

Prof. Dr R. Leemans

Professor of Environmental Systems Analysis

Wageningen University \& Research

Prof. Dr R. Alkemade

Special professor Global Biodiversity and Ecosystem Services Modelling

Wageningen University \& Research

\section{Co-Promotor}

Dr K. Kok

Assistant Professor, Soil Geography and Landscape Group

Wageningen University \& Research

\section{Other members}

Prof. Dr Marielos Peña Claros

Wageningen University and Research

Prof. Dr Wolfgang Cramer

Institut Méditerranéen de Biodiversité et d'Ecologie marine et continentale, Aix en Provence,

France

Prof. Dr Martina Flörke

Ruhr-Universität Bochum, Germany

Dr Pita Verweij

Utrecht University

This research was conducted under the auspices of the Graduate School for Socio-Economic and Natural Sciences of the Environment (SENSE). 


\title{
Assessing biodiversity responses to changes in climate and land use
}

\author{
Sarahi Nuñez Ramos
}

Thesis

submitted in fulfilment of the requirements for the degree of doctor at Wageningen University

by the authority of the Rector Magnificus

Prof. Dr A.P.J. Mol, in the presence of the

Thesis Committee appointed by the Academic Board to be defended in public

on Wednesday 9 October 2019

at 1.30 p.m. in the Aula. 
Sarahi Nuñez Ramos

Assessing biodiversity responses to changes in climate and land use 143 pages.

PhD Thesis, Wageningen University, Wageningen, NL (2019)

With references, with summaries in English and Spanish

ISBN 978-94-6395-042-8

DOI: $10.18174 / 496549$ 


\section{Contents}

Chapter 1 Introduction 1

Chapter 2 Assessing the impacts of climate change on biodiversity: Is below $2^{\circ} \mathrm{C}$ enough? 11

Chapter 3 Increasing biodiversity loss in the Central Asian grasslands as a result of changes in climate and land use 29

Chapter 4 Exploring interactions between climate and land-use change effects on biodiversity 51

Chapter 5 Assessing implications of land-based mitigation on biodiversity 73

Chapter 6 Synthesis, discussion and conclusions 95

$\begin{array}{lr}\text { References } & 109\end{array}$

$\begin{array}{ll}\text { Summary } & 127\end{array}$

$\begin{array}{ll}\text { Resumen } & 131\end{array}$

$\begin{array}{ll}\text { Acknowledgements } & 135\end{array}$

$\begin{array}{ll}\text { About the author } & 137\end{array}$

$\begin{array}{ll}\text { List of publications } & 139\end{array}$

SENSE Diploma 



\section{Chapter 1}

\section{Introduction}

"Biological diversity must be treated more seriously as a global resource, to be indexed, used, and above all, preserved." E.O. Wilson, 1988 


\subsection{Background}

The message from E.O. Wilson in his book Biodiversity (Wilson, 1988) was clear: the diversity of plant and animal species was declining at a much faster rate than generally was realized. $\mathrm{He}$ attributed this decline to increasing human population and destruction of natural habitats to fulfil the demands of economic development. In his book, he also stressed the need to acquire knowledge on biodiversity conservation. Three decades later, however, the urgent need to preserve and maintain global biodiversity still prevails.

The term 'biodiversity' (i.e. 'biological diversity') was first used in 1988 by E.O. Wilson. Years later, biodiversity was defined by the Convention on Biological Diversity (CBD) during the 1992 United Nations Conference on Environment and Development as "the variability among living organisms from all sources including, inter alia, terrestrial, marine and other aquatic ecosystems and the ecological complexes of which they are part; this includes diversity within species, between species and between species and as well as that of ecosystems" (CBD, 1992). In other words, biodiversity concerns all living organisms, the interactions they have with each other and with the environment in which they live. Since then, many definitions for biodiversity have been adopted and used. This has resulted in many studies with different measures and indicators that assess the state of biodiversity. Already in 1988, discussions on the current extinction crisis reached importance among the scientific community (Heywood and Watson, 1995). Back then, monitoring biodiversity loss was a challenge and projections were usually estimated using principles of biogeography such as area-species relationship (e.g. Blake and Karr, 1987; Rydin and Borgegard, 1988). However, data on the rates and direction of biodiversity loss remained sparse and uncertain.

The CBD represented an important step forward in the conservation of biodiversity. When the 'Strategic Plan for Biodiversity 2011-2020' was adopted by the parties to the CBD in 2010, increasing societal responses and important efforts targeted to halve the rate of biodiversity loss. However, biodiversity continues to decline (CBD, 2014) and the progress has been insufficient to achieve this target. The most recently released Global Assessment Report from the Intergovernmental SciencePolicy Platform on Biodiversity and Ecosystem Services (IPBES, 2019) estimated that "up to one million species are threatened with extinction". This is undoubtedly an overwhelming message.

The threats to biodiversity are due to multiple anthropogenic and environmental drivers with climate change and land-use change being amongst the most prominent ones (IPBES, 2019). Changes in climate and land use affect biodiversity in many ways (Sala et al., 2000; Settele et al., 2014; UNEP, 2014; Visconti et al., 2015; Newbold, 2018), affect overall ecosystems' functioning (Cardinale et al., 2012) and consequently human well-being (Díaz et al., 2006). Both climate change and land-use change pose immediate threats to biodiversity. I now shortly introduce those two drivers. 
Climate change has been defined by the Intergovernmental Panel on Climate Change (IPCC) as "any change in the state of the climate over time, whether due to natural variability or as a result of human activity". This definition differs from that in the United Nations Framework Convention on Climate Change (UNFCCC), where climate change refers to "a change of climate that is attributed directly or indirectly to human activity that alters the composition of the global atmosphere and that is in addition to natural climate variability observed over comparable time periods".

Climate change results from increased atmospheric greenhouse gas concentrations (e.g. carbon dioxide $\left[\mathrm{CO}_{2}\right]$, methane $\left[\mathrm{CH}_{4}\right]$ and nitrous oxide $\left[\mathrm{N}_{2} \mathrm{O}\right]$ ) that lead to rising global temperatures (IPCC, 2013b). $\mathrm{CO}_{2}$ concentrations have increased by $40 \%$ since pre-industrial times, primarily due to emissions from burning fossil fuels and cement production, and secondarily from net land-use change emissions. Increasing atmospheric $\mathrm{CO}_{2}$ concentrations since pre-industrial times have resulted in an average global temperature rise of $0.8^{\circ} \mathrm{C}$ (NASA, 2019). Such changes in climate have large effects upon species and ecosystems. Climate, for example, largely determines the geographical distributions of species (Cramer and Leemans, 1993; Pearson and Dawson, 2003), drive phenological (e.g. timing) and physiological changes (Walther et al., 2002; Parmesan and Yohe, 2003) and influence evolutionary (i.e. genetic) responses (Hoffmann and Sgrò, 2011). Climate change is also increasingly exacerbating the impact of other drivers on biodiversity, including landuse change (IPBES, 2019).

The IPCC defined land use as "the total of arrangements, activities and inputs undertaken in a certain land cover type (a set of human actions)", and land-use change as "a change in the use or management of land by humans, which may lead to a change in land cover" (IPCC, 2014a). In this thesis, land use refers to the human use of land (e.g. croplands and pastures). Land use can change over time by changing its land cover or altering its management (e.g. more fertilizer or irrigation). Land-use change is driven by multiple factors from interacting sectors, including agriculture and forestry, and trends urbanization, infrastructure development and more energy production (UNCCD, 2017). Land-use change has large local and regional environmental and human well-being consequences (Verburg et al., 2015). Although land-use change offers a powerful potential for mitigation of and adaptation to climate change, it often entails the conversion of pristine, carbon-rich systems to a land use with lower carbon storage potential (e.g. forests to croplands or pastures) (UNCCD, 2017). Such conversion of natural ecosystems results in biodiversity loss as it affects spatial patterns of species' habitats and limits dispersal (Fahrig, 2003; Opdam and Wascher, 2004), for instance, through habitat fragmentation.

Previous assessments of projected climate and land-use change impacts indicated strong biodiversity reductions. These reductions, however, vary widely. For example, species extinction risks from climate change ranged from $8 \%$ (Urban, 2015) and 37\% (Thomas et al., 2004) to 57\% (Warren et al., 2013). The average reductions of within-sample species richness from land-use change ranged from $14 \%$ to $17 \%$ (Newbold et al., 2015) and the combined effect of both drivers was projected to range from $16 \%$ to about $54 \%$ (Newbold, 2018). Birds are particularly sensitive to both climate and 
land-use changes (Jetz et al., 2007). Species from dryland ecosystems (e.g. grasslands) will be particularly vulnerable to land conversion (Sala et al., 2000; Alkemade et al., 2009) because their habitats will be reduced or lost. Biodiversity projections for other species groups and different ecosystems have been synthesized in review studies (e.g. Bellard et al., 2012) and model and scenario studies (e.g. Pereira et al., 2010). These studies consistently indicated alarming consequences for biodiversity over the 21 st century.

The Fifth Assessment Report from IPCC (IPCC AR5) introduced the Shared Socio-economic Pathways (SSPs: O'Neill et al., 2014) and the Representative Concentration Pathways (RCPs:van Vuuren et al., 2011) (i.e. the SSP-RCP scenario framework), which provide an improved integrated assessment of climate change impacts and adaptation and mitigation needs under a range of climate and socio-economic scenarios, and adaptation and mitigation policy assumptions. This SSP-RCP scenario framework is an integral part of this thesis.

The latest IPBES regional assessments on biodiversity and ecosystem services (IPBES, 2018a; IPBES, 2018b; IPBES, 2018c; IPBES, 2018d) reported that changes in climate and land use will likely act synergistically and accelerate the rate of biodiversity loss. Although these reports underpin the findings on the unprecedented global biodiversity loss, they highlight ambiguous or poorly studied trends for some regions and ecosystems (e.g. Central Asian grasslands) and critical knowledge gaps, including more comprehensively understanding of drivers interactions and biodiversity status.

Alongside the IPBES biodiversity reports, the IPCC special report on Global Warming of $1.5^{\circ} \mathrm{C}$ (IPCC, 2018) provided insights on the climate-change impacts on biodiversity and ecosystems. This IPCC special report assessed available scientific evidence relevant to the recently adopted Paris Agreement of the UN Framework Convention on Climate Change. This agreement aims at "holding the increase in the global average temperature to well-below $2^{\circ} \mathrm{C}$ ", and "to pursue efforts to limit the temperature increase to $1.5^{\circ} \mathrm{C}^{\prime}$. To achieve these targets, global efforts to combat climate change will require large mitigation commitments from different sectors, particularly the land sector, with both positive and negative implications on biodiversity. The IPCC special report presented mitigation options that are consistent with limiting warming to $1.5^{\circ} \mathrm{C}$ above pre-industrial levels, including land-based mitigation. The implications of land-based mitigation on biodiversity, however, were not fully assessed and this can easily be improved.

Recent international efforts ranging from small-scale projects in remote communities aiming to improve their climate change resilience and land use, to regional and global initiatives that build the knowledge base, develop capacity and guide climate and agricultural policies, must quantify and explain the consequences of unmitigated 'high-end' scenarios for society at large, and for biodiversity in particular. This is especially useful for decision-makers who are responsible for designing climate change adaptation, mitigation and development strategies (IMPRESSIONS, 2014). Such efforts report robust findings generally accompanied by a series of challenges and risks that need to be addressed. The Impacts and Risks from High-End Scenarios: Strategies for 
Innovative Solutions (IMPRESSIONS) project proposed a novel methodology to explore impacts and risks from high-end scenarios for climate adaptation (Box 1.1). Whilst this methodology created an integrated set of high-end scenarios covering multiple scales and key social, economic and environmental sectors, where climate change and land use play fundamental roles, many challenges were simultaneously reported. Part of the research carried out for my $\mathrm{PhD}$ thesis took place within the IMPRESSIONS project. I contributed to advance the development of integrated high-end climate and more extreme socio-economic scenarios for the international case study in Central Asia. $\mathrm{My} \mathrm{PhD}$ thesis expands on the context of the likely impacts on biodiversity of projected changes in climate and land use, and the implications from land-based mitigation options. These options should be consistent with limiting warming to $1.5^{\circ} \mathrm{C}$ above pre-industrial levels. In my thesis, biodiversity refers to the local abundance of terrestrial species in areas with suitable climate.

I now first address two most important biodiversity-related research subjects: biodiversity responses and measuring biodiversity loss. These subjects are central to my research but need further explanation. Thereafter I introduce some major research gaps and the general research objective and research questions of my thesis.

\subsection{Biodiversity response to projected changes in climate and land use}

Biodiversity is strongly affected by climate change and this has large impacts on human well-being (Díaz et al., 2006). This changing climate strongly influences the impacts of land use on biodiversity (Titeux et al., 2016). This is a complex interaction on what the IPBES conceptual framework calls the 'links between nature and people' (Díaz et al., 2015). In the context of IPBES, 'nature' refers to the natural world with an emphasis on the diversity of living organisms (i.e. biodiversity) and their interactions among themselves and with their environment (i.e. in ecosystems). Climate change and land-use change are drivers that affect nature directly, at various temporal and spatial scales. Projected changes in climate and land use anticipate that maintaining locations with favourable climate and land-use patterns is critical to protect biodiversity because the loss of either can reduce the biodiversity that an area supports (Higgins, 2007). These projections, however, are based on different global climate and land-use change scenarios. Getting a clear picture of the future biodiversity is therefore problematic (Pereira et al., 2010).

Climate and land-use change effects on biodiversity can be quantified and monitored by different indicators, which showed a dramatic increase over the past few decades (Butchart et al., 2010). The many available indicators allow to characterize reversed, improved or deteriorated trends in biodiversity (Butchart et al., 2010). Few studies have shown a positive biodiversity response to climate change, especially for local-scale plant biodiversity (Vellend et al., 2013; Dornelas et al., 2014; Vellend et al., 2017). However, a consistent pattern commonly emerges from the majority of 
biodiversity assessments (Parmesan and Yohe, 2003; Thomas et al., 2004; Warren et al., 2011; Urban, 2015): loss of species and habitats. This means that despite efforts to substantially reduce the rate of biodiversity loss as agreed by CBD's parties, trends of continuous biodiversity decline show that most of the Aichi targets cannot be achieved (CBD, 2014; Tittensor et al., 2014).

Understanding the biodiversity response to changes in climate and land use is challenged by all the different environmental and anthropogenic drivers. These drivers include direct exploitation of organisms, pollution and invasive alien species (IPBES, 2019). These drivers are also likely to vary considerably among different geographic regions and species (Newbold et al., 2019) and this adds to the complexity. However, recent studies that assessed the global biodiversity change (e.g. Jantz et al., 2015; Rondinini and Visconti, 2015; Visconti et al., 2015; Segan et al., 2016; Newbold, 2018), showed a consistent pattern of biodiversity loss, strongly driven by changes in climate and land use. Although few assessments on biodiversity responses to projected climate and land-use change show an increase in local biodiversity, such as, for example, increases in widespread habitat generalists and exotic or invasive species (Vellend et al., 2013), most assessments show substantial habitat range contractions and species extinctions (e.g. Malcolm et al., 2006; Jetz et al., 2007). However, most of these assessments focus on single species or taxonomic groups and specific biodiversity hotspots. This limits the extent to understand biodiversity responses world-wide.

\subsection{Measuring biodiversity loss}

Biodiversity can be quantified and monitored by different indicators (Walpole et al., 2009; Butchart et al., 2010; Heink and Kowarik, 2010; UNEP, 2012). A single indicator to measure biodiversity loss can never cover all relevant aspects or drivers (Scholes and Biggs, 2005). The actual selected measure for biodiversity loss will depend on the (type of) question that is addressed, or what aspect needs to be emphasised. Indicators are thus crucial to project future biodiversity responses to climate and land-use change effects (Balmford et al., 2005; Mace and Baillie, 2007).

The CBD identified and developed a comprehensive set of indicators to assess progress to attain the Aichi Biodiversity Targets. This set includes both generic indicators, which identify types of clearly observable and discernible issues, and specific indicators that can be used to monitor changing trends in these issues (CBD, 2016). For example, generic indicators are 'trends in natural habitat' and 'trend in species extinction risk and populations impacted by climate change', and their specific indicators are 'natural habitat extent' and the 'Red List Index', respectively. Specific indicators largely describe species diversity (i.e. richness, abundance and evenness) in a particular area. 


\section{Box 1.1: Impacts and Risks from High-End Scenarios: Strategies for Innovative Solutions (IMPRESSIONS)}

IMPRESSIONS was a research project funded by the European Union from 2013 to 2018 . The project aimed to provide a scientifically robust and policy-relevant understanding of the nature and scale of more extreme and long-term consequences (i.e. high-end scenarios) of climate change, and support the use of this knowledge by decision-makers working on adaptation, mitigation and sustainability (Harrison et al., 2019). The IMPRESSIONS project combined modelled high-end climate change impact projections (Harrison et al., 2019a) with participatory methods and stakeholder determined socio-economic scenarios (Pedde et al., 2019) to provide a unique set of comparable, yet stakeholder-relevant multiscale scenarios (Figure 1.1). This multi-scale modelling framework, developed in seven work packages, helped to analyse the complex interactions, synergies and trade-offs between different sectors, such as agriculture, forestry, biodiversity, urban development and health and tourism as they compete for resources under the impaired climate and socio-economic scenarios. This was done in five case studies from the local to the international scale. Novel approaches allowed to downscale SSPs, while ensuring consistency with existing scenarios (e.g. Europe; Kok et al., 2019).

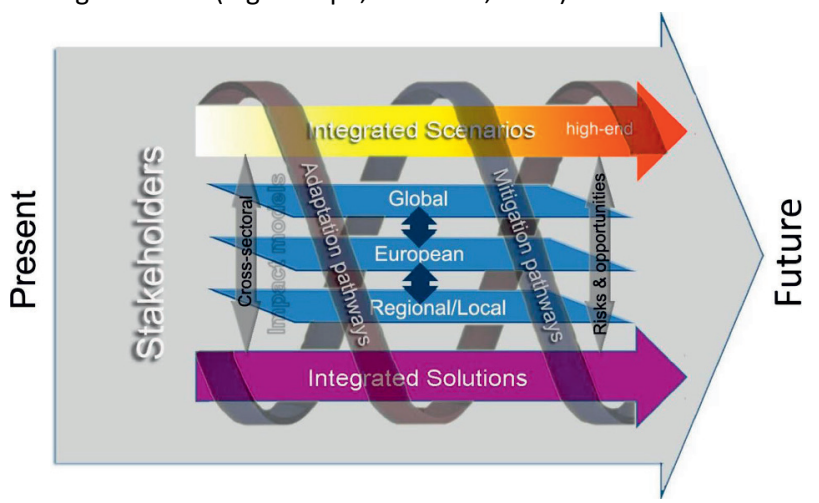

Figure 1.1 Overview of the conceptual framework of IMPRESSIONS project

In IMPRESSIONS, 'high-end' scenarios are those that describe climate change levels at the upper end of the range of possible futures (i.e. beyond the $2^{\circ} \mathrm{C}$ Paris target). This included, for example, a scenario consistent with a potential revised policy target of $3^{\circ} \mathrm{C}$, and worlds of $4^{\circ} \mathrm{C}$ and higher (i.e. RCP8.5)bounded only by what is physically plausible according to the current set of available models (IMPRESSIONS, 2014). The scenarios' underlying socio-economic storylines (i.e. SSPs) act both as the drivers of emissions (and other contextual factors) and as consistent narratives. These narratives capture a range of plausible societal challenges to mitigation and adaptation, and establish the ability of society to cope with the impacts of climate change.

The main findings of IMPRESSIONS included: i) the considerably greater impact under high-end than low-end climate change in this century and the need to include this information as well as from stakeholder engagement in decision-making processes; ii) the challenges and risks in developing highend scenarios, including loss of detail, specific uncertainties and degree of subjectivity; iii) the potential high-end climate change together with socio-economic changes will require transformative solutions; and iv) adaptation and mitigation pathways that are robust to climate and socio-economic uncertainty are unlikely to be sufficient to fully enable Europe to achieve the vision of a sustainable future. 
Research on indicators that assess biodiversity change in the new generation of studies, that explore the impacts of climate and socio-economic changes based on the latest SSP-RCP scenario framework, is needed. This SSP-RCP scenario framework better allows to assess (trends in) major causes and effects of climate change (van Vuuren et al., 2011; van Vuuren et al., 2012; O'Neill et al., 2014) and land-use change (Popp et al., 2017). Recent studies (e.g. Newbold, 2018) showed that direct indicators such as species richness which is a relatively simple indicator, can predict effects of climate and land-use change on terrestrial vertebrate communities under SSP-RCP scenarios. Previous assessments that projected the impacts of different drivers of change on biodiversity (Alkemade et al., 2009; Pereira et al., 2010; Visconti et al., 2015), used the Mean Species Abundance (MSA) indicator. MSA measures the abundance of original species relative to their abundance in undisturbed ecosystems, indicating naturalness or biodiversity intactness (Alkemade et al., 2009). MSA ranges between 0 in areas where original biodiversity has completely disappeared, to 1 in areas where species composition and abundance is fully original. The scientific, policy and conservationmanagement communities needs to deal with the many approaches to measure and monitor biodiversity change. Indicators such as MSA approximate trends in species abundance in local, regional or global assessments under both sparse and ample data availability conditions, and are thus an appropriate start to further develop an adequate, and urgently needed indicator set.

\subsection{Research gaps}

From the above review, I identified four main research gaps that limit the projection of a biodiversity response to changes in climate and land use. Firstly, a consolidated body of knowledge to assess the response of biodiversity to a global mean temperature increase well-below $2^{\circ} \mathrm{C}$ (i.e. the target of the Paris Agreement) is mostly lacking. Although many studies assess the multiple impacts of climate change on species and habitats at higher temperature increases, a clear response to the target of the Paris Agreement is still needed. This is also reported in Chapter 3 of the IPCC special report on Global Warming of $1.5^{\circ} \mathrm{C}$ in which research gaps on regional changes, impacts and consequences on terrestrial systems at $1.5^{\circ} \mathrm{C}$ and $2^{\circ} \mathrm{C}$ of warming were identified (Hoegh-Guldberg et al., 2018). Synthesising and attributing observed impacts can help to fill these gaps (IPCC, 2014b) but a consistent modelling approach that is compatible with the earlier approaches (i.e. at higher temperature increases) is also urgently needed. Secondly, global and regional biodiversity studies have poorly assessed the climate and land-use change impacts in regions or biomes of high importance for biodiversity, such as the central Asian grasslands, which is the largest grassland region of the world. Thus, an integrated assessment of climate and land-use change impacts on biodiversity for these grasslands complements other regional assessments and perfects global assessments. Thirdly, the interactions between climate and land-use change impacts on biodiversity are poorly understood and in most cases ignored. Often only the individual effects are accumulated and this result is reported. Thus, important interaction mechanisms must be addressed. Lastly, the 
implications on biodiversity of land-based mitigation options in the context of the Paris Target needs to be better understood. These four research gaps limit the further development of strategies to reduce biodiversity loss.

\subsection{Overall research objective and research questions}

$\mathrm{My} \mathrm{PhD}$ research therefore aims to address the four abovementioned research gaps. The overall research objective is to explore future biodiversity trends under projected direct and synergistic changes in climate and land use and to advance understanding of climate-change mitigation consequences for biodiversity. To achieve this objective I formulated four research questions (RQs):

RQ1 Is the well-below $2^{\circ} \mathrm{C}$ climate target adequate to protect biodiversity?

RQ2 How do projected changes in climate and land use affect biodiversity in a grassland ecosystem?

RQ3 How will interaction mechanisms between changes in climate and land use affect biodiversity?

RQ4 What are the implications on biodiversity of land-based mitigation?

\subsection{Thesis outline}

This $\mathrm{PhD}$ thesis consists of six chapters, including this introductory chapter. Figure 1.2 shows the outline of the different $\mathrm{PhD}$ chapters.

In Chapter 2, I assessed the magnitude of expected changes of biodiversity by performing a metaanalysis of the responses of species distributions to climate change. I estimated the proportion of local remaining species and areas with suitable climate for different taxonomic groups and ecosystems. This is a review chapter that highlights biodiversity responses to different intervals of global mean temperature increase, including the climate target of keeping global temperature wellbelow $2^{\circ} \mathrm{C}$.

In Chapter 3, I developed climate and land-use scenarios based on the SSP-RCP scenario framework to explore biodiversity change in the Central Asian grasslands. I used climate-change estimates derived in Chapter 2, model outputs from integrated assessment models, regression analyses and existing gridded datasets on grazing. This is a methodological chapter that translates relevant information of socio-economic and climate-change drivers of biodiversity change.

In Chapter 4, I explored interactions between climate change and land-use change, which are the two major drivers of biodiversity loss. This review chapter expands the findings of Chapter 3 and validates interaction mechanisms with evidence from a literature review of studies that used bioclimatic models and climate-change scenarios in modified landscapes under different dispersal assumptions. This review resulted in a comprehensive database of changes, interactions and responses. 
In Chapter 5, I assessed the world-wide implications of climate-change mitigation on biodiversity. The land sector plays a crucial role in ambitious mitigation scenarios. Thus, I focus on land-based mitigation options consistent with the $1.5^{\circ} \mathrm{C}$ climate target from the Paris Agreement.

In Chapter 6, I summarised the main outcomes and take-home message of my thesis based on the state-of-the-art knowledge generated for the scientific community and policy-makers. I discussed on the expected gradual continuous biodiversity decrease an showed that, although a climate target of well-below $2^{\circ} \mathrm{C}$ is insufficient to protect biodiversity, limiting global mean temperature increase to the lowest possible is desired to reduce biodiversity losses.

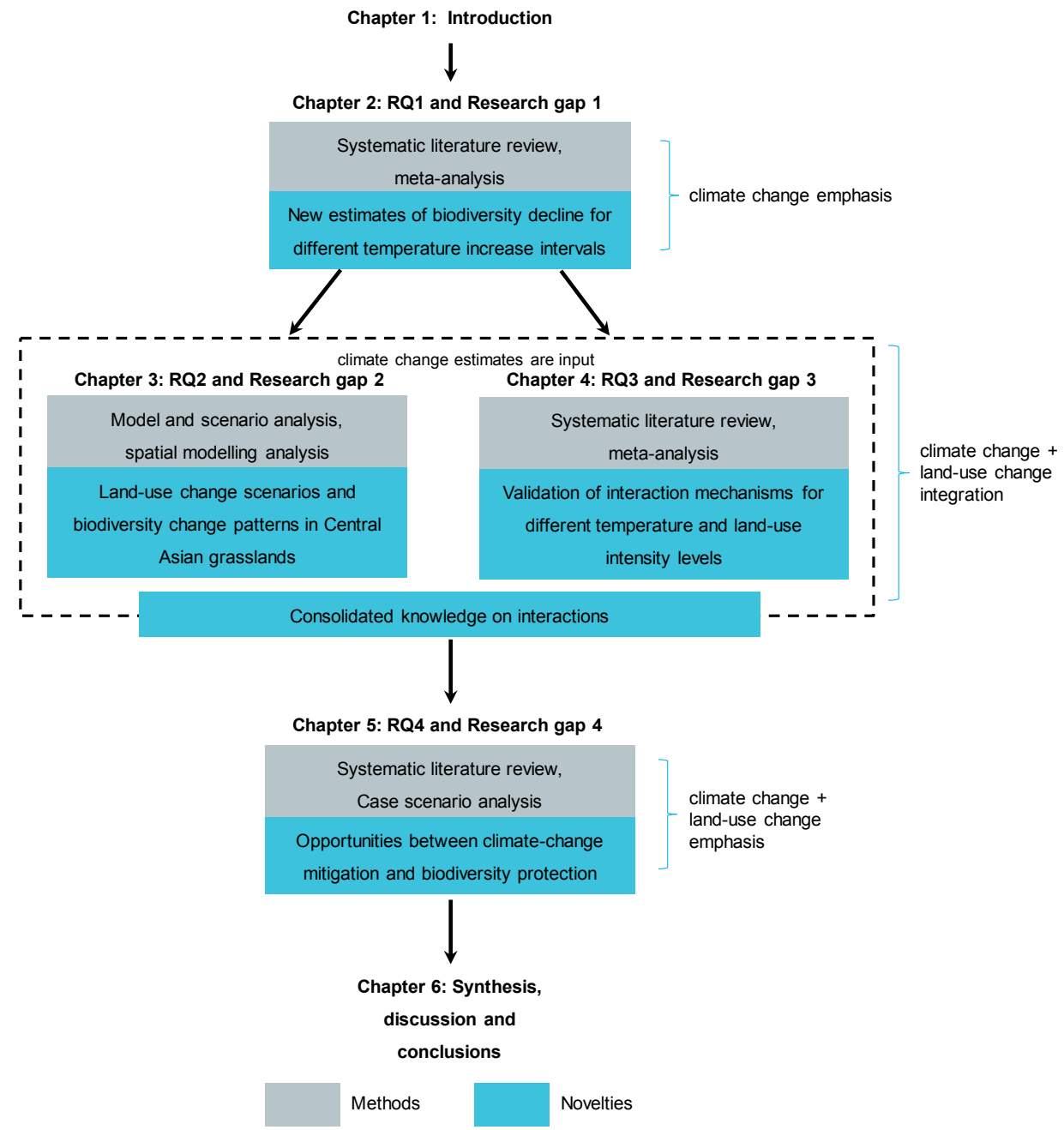

Figure 1.2. Outline of the $\mathrm{PhD}$ thesis chapters with the focus on research questions, methods and the main outputs. 


\section{Chapter 2}

\section{Assessing the impacts of climate change on biodiversity: Is below $2^{\circ} \mathrm{C}$ enough?}

This chapter is based on:

Nunez, S., Arets, E., Alkemade, R., Verwer, C. and Leemans, R. (2019) Assessing the impacts of climate change on biodiversity: Is below $2^{\circ} \mathrm{C}$ enough? Climatic Change 154, 351-365.

Supplementary materials to this chapter can be found in the online publication. 


\section{Abstract}

Large changes in biodiversity are expected to occur if climate change continues at its current pace. Adverse effects include changes in species habitats and compositions, and consequently changes in ecosystem functioning. We assessed the magnitude of expected changes of biodiversity by performing a meta-analysis of the responses of species distributions to climate change. We focused on the proportion of local remaining species and their habitats. We summarized 97 studies and calculated two effect-size metrics from their results to quantify changes in biodiversity. These metrics were the fraction of remaining species (FRS) and the fraction of remaining area (FRA) with suitable climate for each species. Both metrics calculate deviations from the original biodiversity state and together they indicate biodiversity intactness. We found an expected gradual decrease in both FRS and FRA with significant reductions of $14 \%$ and $35 \%$ between $1{ }^{\circ} \mathrm{C}$ and $2{ }^{\circ} \mathrm{C}$ increase in global mean temperatures. Strong impacts were projected for both mammals and plants with FRS reductions of $19 \%$. The climate-change response of biodiversity varied strongly among taxonomic groups and biomes. For some taxonomic groups the FRA declined strongly beyond $3^{\circ} \mathrm{C}$ of temperature increase. Although these estimates are conservative, as we assume that species are unable to disperse or adapt, we conclude that already at moderate levels (i.e. $1-2^{\circ} \mathrm{C}$ ) of temperature increase a significant decrease of original biodiversity is projected. Our research supports the pledge to limit climate change to $1.5^{\circ} \mathrm{C}$ and preferably lower to protect biodiversity. 


\subsection{Introduction}

Biodiversity is under increasing threats by many anthropogenic pressures (Alkemade et al., 2009; Leadley et al., 2014; Tittensor et al., 2014; Visconti et al., 2015; Johnson et al., 2017; Ripple et al., 2017). A major pressure of biodiversity decline in this century is climate change (Parmesan and Yohe, 2003; Thomas et al., 2004; Warren et al., 2011; Bellard et al., 2012; Pacifici et al., 2015; Urban, 2015). Climate change affects biodiversity as climate variables largely determine the geographical distribution ranges of species (i.e. species' climate envelopes; Box, 1981; Guisan and Zimmermann, 2000; Pearson and Dawson, 2003). Hence, in areas where climate is less suitable, species shift their geographical ranges and go extinct locally, depending on their dispersal capacities (Guisan and Zimmermann, 2000; Bellard et al., 2012). Species' phenology and physiology, and community structures and ecosystem functions are also affected (Bellard et al., 2012). All these negative impacts exacerbate the challenge to manage and conserve biodiversity (CBD, 2019).

The average global temperature has increased by almost $1^{\circ} \mathrm{C}$ since 1880 and the adverse effects of such increase on biodiversity are already witnessed and documented by many studies (Thomas et al., 2004; Parmesan, 2006; Butchart et al., 2010; Cardinale et al., 2012; Cook et al., 2012; IPCC, 2013b; Peñuelas et al., 2013; CBD, 2014; Pacifici et al., 2017; Pecl et al., 2017). They all showed that the decline of biodiversity continues worldwide as many ecosystems lose suitable conditions for the survival of a proportion of their species. Some studies projected the already observed negative impacts on species (e.g. Parmesan et al., 2013; Warren et al., 2013) and their results feed into the ongoing debate of constraining the increase of global temperatures (e.g. by the climate-change target to keep global temperature increase well-below $2{ }^{\circ} \mathrm{C}$ above pre-industrial levels in the Paris Agreement; (UNFCCC, 2015; Rogelj et al., 2018a). Yet, how biodiversity will respond to a global mean temperature increase of $2^{\circ} \mathrm{C}$, or any increase close to this target, is not yet clear and represents a fundamental research challenge.

The primary objective of this study was to quantify the response of terrestrial biodiversity to climate change covering global mean temperature-increase up to $6^{\circ} \mathrm{C}$ in 2100 (and implicitly considering associated climate variables, such as precipitation change) above the pre-industrial level. For this purpose, we performed a meta-analysis of studies that used bioclimatic models and climate-change scenarios. These studies reported climate-change effects on contemporary ecosystems and different taxonomic groups around the world. The climate-change level in these studies was indicated by their scenario's global mean temperature increase. Most climate-change scenarios project that global mean temperature continues to increase to between $2^{\circ} \mathrm{C}$ and over $5^{\circ} \mathrm{C}$ in 2100 (Kintisch, 2009; Moss et al., 2010; IPCC, 2013b; Rogelj et al., 2018a). Similar to previous modelling studies that assessed the overall decline of biodiversity (e.g. Alkemade et al., 2009), we focused on the proportion of remaining biodiversity. We calculated two effect metrics: the fraction of remaining (i.e. persisting) species (FRS) at a location and the fraction of remaining area (FRA) with suitable climate for species. These metrics assess the changes of species richness over a region compared to the original 
situation in the selected study. Both metrics indicate a deviation from the original biodiversity state and indicate biodiversity intactness (Scholes and Biggs, 2005; Alkemade et al., 2009). FRS indicates a decrease of species within the study region. FRA indicates a suitable climate-area (e.g. habitat) contraction within the study region. A potential increase of species or extending its geographical range is excluded from these metrics. As a result, FRS and FRA generally indicate a decline regardless of the global temperature interval. The changes in species composition can also indicate consequences for ecosystem's functioning, but we do not address this. The results of our metaanalysis allow to generalise projected trends and to assess effects across a broad range of climatechange projections. The established meta-regression models can be used in models, such as the GLOBIO model (Alkemade et al., 2009; Alkemade et al., 2011), to assess biodiversity change in scenario studies in combination with other pressures of global biodiversity loss.

\subsection{Methods and materials}

\subsubsection{Systematic literature review}

In June 2016, we queried the ISI Web-of-Science database to identify bioclimatic modelling studies that assess the effects of global mean temperature increase on terrestrial biodiversity. We reviewed all studies following the guidelines provided by the Collaboration for Environmental Evidence (CEE) (CEE, 2013) (Section 1.1 in Online Resource 1). The guidelines indicate the stages for conducting a systematic research in environmental science, and these stages were combined into three main steps.

Firstly, we defined several search terms and classified them into four main search strings to conduct the review: i) Climate change elements: (climat* SAME change*) OR (temperature SAME change*) OR (temperature SAME increase) OR (global SAME warming) OR (climat* SAME warming); ii) Biodiversity elements: (biodiversity) OR (diversity SAME species) OR (species SAME richness*) OR (species SAME distribution*) OR (species SAME abundance*) OR (species SAME occurrence*) OR (species SAME turnover) OR (species SAME loss*) OR (species SAME gain*) OR (species SAME composition) OR (species SAME assemblage*); iii) Bioclimatic modelling elements: (bioclimat* model $^{*}$ ) OR (niche* model $^{*}$ ) OR (climat* model*) OR (distribution model ${ }^{*}$ ) OR (habitat model $\left.^{\star}\right)$ OR (ecologic* model*) OR (occurrence model*) OR (species distribution model ${ }^{*}$ ) OR (model* distribution*) OR (model* ${ }^{*}$ range*) OR (climat* envelope*) OR (envelope* model*); and iv) Modelling projections elements: (future SAME distribution*) OR (climat* SAME scenario*) OR (climat* SAME projection) OR (climat* SAME prediction) OR (climat* SAME pathway*). Additionally, we defined seven inclusion criteria to determine the pertinence of the studies (Section 1.1 in Online Resource 1). These criteria allowed to further restrict the selection by rejecting those studies that did not support our objective. All studies were screened by title for their relevance to the purpose of our study. Those studies selected were then screened by abstract and, when providing 
limited information in their abstracts, were fully screened, both in content and supporting material. Secondly, the potentially relevant studies were critically revised to select those fulfilling the inclusion criteria. Finally, the relevant data were extracted from all selected studies and synthesized in a biodiversity-impact database. These data included number of species and their area with suitable climate in the original and the projected climate situations, taxonomic group, study location, spatial resolution and the used global mean temperature increase. Many studies that reported climate effects on single species or exotic species (particularly weeds and insect pests, and aquatic species), were excluded from the database. These studies do not provide data on the original species composition or do not consider terrestrial species.

\subsubsection{Calculation of effect sizes}

We calculated the effect sizes, which are measures commonly used in meta-analyses, for each selected study. For studies that assessed the number of species affected by increasing temperatures, we used the fraction of species remaining at a location (Fraction Remaining Species, FRS) as the effect size; for studies assessing the loss of area with suitable climate for a species, we used the fraction of remaining area with suitable climate (Fraction Remaining Area, FRA) under a projected increase of global mean temperature (Figure 2.1). Both FRS and FRA are effect sizes compared to the original situation in the selected study. The original situation refers to the ecosystem's condition before its climate changed (i.e. original area with suitable climate). Results from multiple climatechange scenarios and time periods, or different bioclimatic modelling algorithms (e.g. Generalized Linear Model, Generalized Additive Model, Maximum Entropy Modelling) that are reported in a study, were all included as separate effect sizes in our database.

We specifically estimated the proportion of remaining biodiversity (i.e. a conservative option assuming that species are unable to disperse or adapt) for three main reasons: i) on average, the projected climate distributions of species are closer to projections without dispersal than projections with full dispersal (Midgley et al., 2006; Hellmann et al., 2016); ii) uncertainty associated to the capacity of species to disperse (Pearson and Dawson, 2003; Pearson et al., 2006) or adapt (Berry et al., 2013) under climate change is reduced; and iii) FRS and FRA fit into the domain of the GLOBIO3 model, more specifically, they relate to the relative Mean Species Abundance (MSA) indicator from GLOBIO3 (Alkemade et al., 2009) and the Biodiversity Intactness Index (BII) (Scholes and Biggs, 2005; Newbold et al., 2016) of the local remaining biodiversity. 
FRS is calculated as average of ratios between the remaining number of species and the original number of species within each locality (e.g. a grid cell) of the study area's map after projected climate change:

$$
F R S=\frac{1}{n} \cdot \sum_{i=1}^{n} \frac{S_{d i}}{S_{o i}}
$$

where $S_{d i}$ is the expected number of remaining species in grid cell $i$ after climate change as characterized by global mean temperature increase $\left({ }^{\circ} \mathrm{C}\right)$, and $S_{o i}$ is the number of species in grid cell $i$ in the original situation. $n$ is the total number of grid cells. FRS is a relative index between 0 (no original species present) and 1 (all original species present). FRS decreases if the climate is not suitable anymore for a species at one of the grid cells within the study area. FRS represents the local response of species to climate change (e.g. in a specific grid cell).

FRA is calculated per species as the ratio between the original suitable climate area and the remaining suitable climate area:

$$
F R A=\frac{1}{S} \cdot \sum_{j=1}^{S} \frac{A_{d j}}{A_{o j}}
$$

where $A_{d j}$ is the remaining suitable climate area for species $j$ after climate change, $A_{o j}$ is the suitable climate area for species $j$ in original situation without climate change and $S$ is the number of species. FRA is also a relative index between 0 (no original suitable climate area) and 1 (suitable climate area unchanged).

We estimated sampling variances for both effect sizes FRS and FRA to determine the weight to be assigned during the meta-analysis (Section 1.2 in Online Resource 1). 


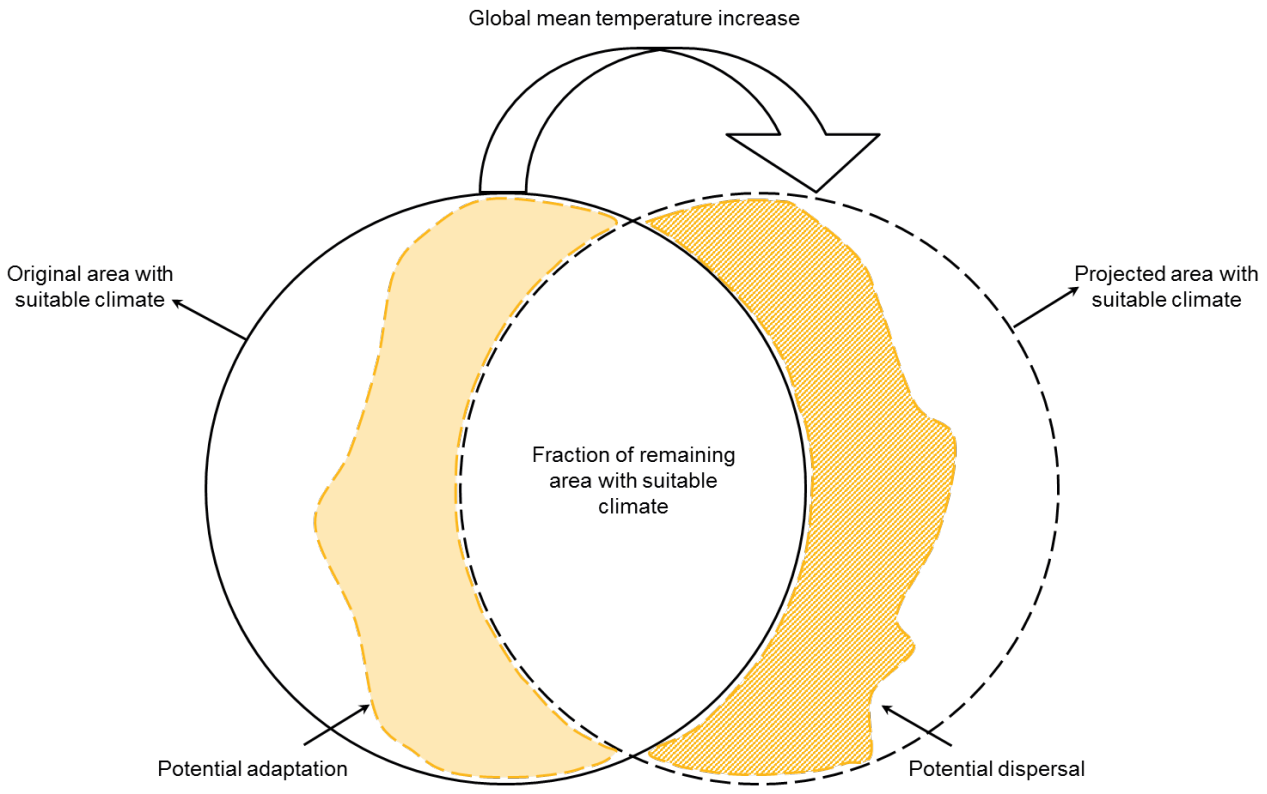

Figure 2.1. Schematic illustration to indicate the fraction of remaining area (FRA) with suitable climate under projected global mean temperature increase.

\subsubsection{Harmonization of climate-change effects}

All studies reported their baseline and projected climate conditions. Following Warren et al. (2011), we converted projected temperatures from the climate-change scenarios for each study to a common pre-industrial reference (approximately 1880) (Equation 2.3). To this end, the assumed temperature increase between pre-industrial and the $1961-1990$ climatic normal was $0.3^{\circ} \mathrm{C}$, between pre-industrial and $1981-1990$ was $0.5^{\circ} \mathrm{C}$ and between pre-industrial and 1990 was $0.6^{\circ} \mathrm{C}$. These are the baseline conditions often reported by the selected studies.

$$
G M T I_{n}=T_{\text {scen }}+\Delta T_{\text {pre-ref }}
$$

where $G M T I_{n}$ is global mean temperature increase converted to a common pre-industrial reference point for study $n, T_{\text {scen }}$ is the projected temperature and $\Delta T_{\text {preref }}$ is the assumed temperature increase between the pre-industrial and the baseline conditions, which are both driven by (or based on) climate-change scenarios. We defined four intervals of temperature increase for the meta-analysis: $1-2^{\circ} \mathrm{C}, 2-3^{\circ} \mathrm{C}, 3-4^{\circ} \mathrm{C}$ and $\geq 4^{\circ} \mathrm{C}$. Temperature increases between $0-1^{\circ} \mathrm{C}$ usually correspond to shortterm climate-change scenarios depicting low carbon emissions and/or stringent mitigation policies. 


\subsubsection{Meta-analysis}

We conducted a meta-analysis to derive the pooled effect for all effect sizes as a response to global mean temperature increase. We used the package 'Metafor' in the R-3.2.2 software (Viechtbauer, 2010) and the rma.mv() function assuming independence between the effect size and sampling variance. The included studies are a selection from a larger population of bioclimatic modelling studies.

We ran mixed-effects models with random-effects structures (Section 1.3 in Online Resource 1). We compared them using the Bayesian Information Criterion (BIC). We then fitted random-effects meta-models with restricted maximum likelihood (REML) to different taxa subsets. These are 'all species', 'plants', 'vertebrates', 'birds', 'mammals', 'herptiles' and 'insects', for the effect sizes FRS and FRA, and for all four intervals of global mean temperature increase. We introduced the variable 'biomes' as a moderator to determine sources of heterogeneity (Table OR1.1 in Online Resource 1). For the meta-analyses and the meta-regression analyses ratios are often transformed using logit or log transformations to reach normality assumption for the effects sizes (Urban, 2015; Benítez-López et al., 2017). We ran the mixed-effects models separately for the untransformed effect sizes FRS and FRA, the logit-transformed and the $\log _{10}$-transformed FRS and FRA, and checked the results for robustness (Table OR1.2 in Online Resource 1). In addition, meta-regression analyses were used to relate pooled effect sizes FRS and FRA to global mean temperature increase.

We visually inspected the funnel plots of asymmetry to explore the possibility of publication bias (Viechtbauer, 2010; Kuiper et al., 2014). We assessed heterogeneity by the formal test of heterogeneity 'Q' (Borenstein et al., 2009; Viechtbauer, 2010). Variability among the effect sizes was expected due to differential characteristics of the studies (e.g. different taxonomic groups, biomes and temperature-change intervals).

\subsection{Results}

The systematic literature search yielded 302 relevant studies after the title screening. These studies were screened by abstract, out of which 138 fulfilled the criteria for full text screening. We finally selected 97 studies that assessed species composition of the originally occurring species at a location spanning publication dates between 1992 and 2015. Figure 2.2 shows the location and number of selected studies from the systematic literature review. The selected studies allowed the calculation of 370 effect sizes for FRS (data from 60 studies) and 146 for FRA (data from 50 studies). The studies and the relevant information extracted are provided in the Online Resource 2. The types of bioclimatic models in the selected studies cover, in some cases, the entire distribution of each species studied. For instance, these models were derived for a continental species distribution or for endemic species. In other studies the models do not cover the entire range of all species and this likely slightly overestimates the effects of climate change. 
The meta-analyses showed similar results for untransformed, logit-transformed and log transformed effect sizes, suggesting robustness of these results. Here we present the results of $\log _{10}$-tranformed FRS and FRA, which is the most commonly used transformation. Results for untransformed effect sizes and logit-transformed FRS and FRA are provided in Tables OR3.5- OR3.8 in the Online Resource 3. We retained the random-effects structures (1 | Study ID + 1 | Extent) for the metaanalysis of FRS (BIC = -502.4888) and ( 1 | Extent) for the meta-analysis of FRA (BIC = 14.8613) (Table OR3.1 in Online Resource 3).

Results from the meta-regressions to estimate the response changes of FRS and FRA to global mean temperature increase are shown in Figure 2.3. The effect sizes decrease with increasing climate change - the rate of decrease is generally larger for FRA than for FRS.

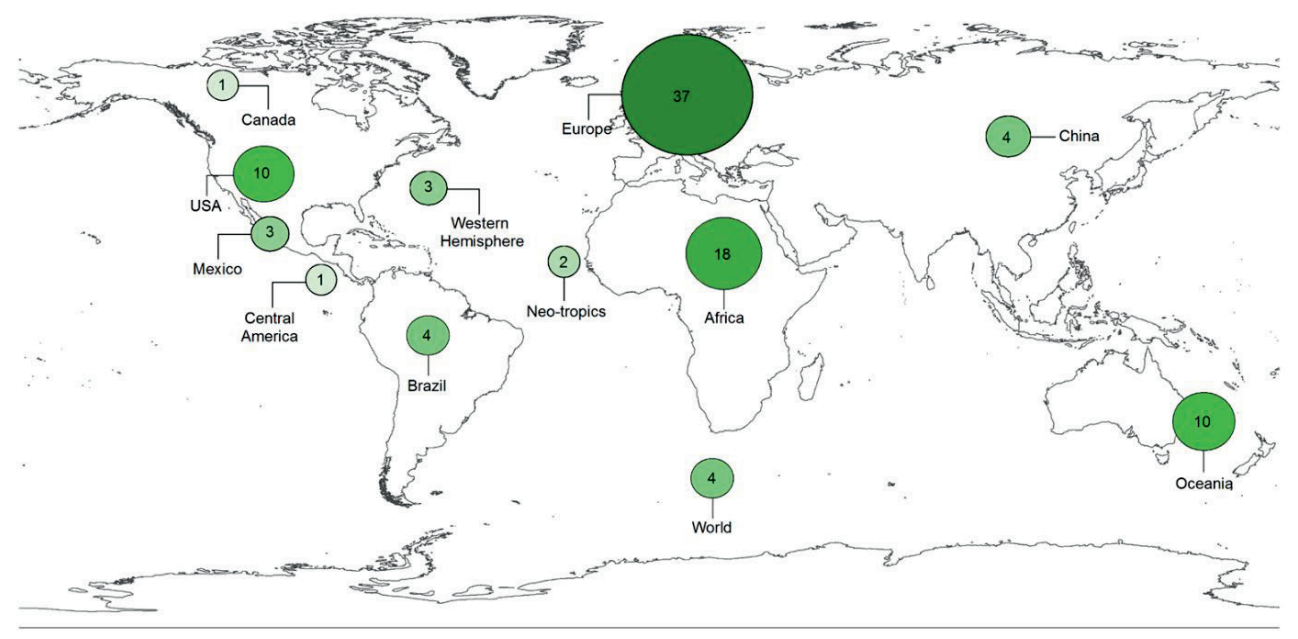

Figure 2.2. Locations and number of selected bioclimatic studies.

Table 2.1 provides the results of the random-effects meta-models for FRS and FRA for 'all species'. FRS and FRA were significantly lower under each global mean temperature increase interval. Overall, the FRS and FRA were reduced by $19 \%$ (95\% confidence interval: $14-23 \%$ ) and $47 \%$ (95\% confidence interval: 37-55\%), respectively (Figure OR3.1 in Online Resource 3).

The first interval $1-2^{\circ} \mathrm{C}$ for the 'all species' group results in a FRS of $86 \%$ (95\% confidence interval: $79-93 \%$ ) and a FRA of $65 \%$ (95\% confidence interval: 56-75\%). These estimates imply that under a global mean temperature increase of up to $2^{\circ} \mathrm{C}$, terrestrial ecosystems could lose on average $14 \%$ of their current local species and that species could lose on average $35 \%$ of their suitable climate area. The intervals $2-3^{\circ} \mathrm{C}$ and $3-4^{\circ} \mathrm{C}$ result in larger reductions of FRS and FRA compared to the first interval: FRS is projected to reduce to $83 \%$ (95\% confidence interval: $78-88 \%$ ) and $78 \%$ (95\% confidence interval: $72-86 \%$ ), and FRA to $50 \%$ (95\% confidence interval: $39-64 \%$ ) and $46 \%$ (95\% confidence interval: $34-63 \%$ ), respectively. However, the largest reductions occur under a global 
mean temperature increase beyond $4^{\circ} \mathrm{C}$ : only $68 \%$ of the local current species are projected to remain on average across the Earth's terrestrial ecosystems (95\% confidence interval: $57-80 \%$ ) and their suitable climate area will likely be reduced to less than $46 \%$ (95\% confidence interval: $25-85 \%$ ). These responses are based on a wide range of climate projections with up to $6^{\circ} \mathrm{C}$ increase in bioclimatic studies assessing distributions for birds and plants species (e.g. Shoo et al., 2005; Sekercioglu et al., 2008; Meyer et al., 2016).

FRS and FRA responses differ among taxonomic groups. The responses of the taxonomic group 'plants' are lower than for 'vertebrates' in all temperature-increase intervals (Figure 2.4; Table OR3.2 in Online Resource 3). In the interval of $1-2^{\circ} \mathrm{C}$, the fraction of local originally occurring plant species is reduced by $18 \%$, whereas the vertebrate species' fraction is reduced by $10 \%$. Under a more extreme temperature-increase interval (e.g. $3-4^{\circ} \mathrm{C}$ ), the suitable climate area for plant species is reduced by $53 \%$ and for vertebrate species by $50 \%$. These results differ significantly from the original situation (see Table 2.1). The visual inspection of the funnel plots of asymmetry for FRS and FRA (Figure OR3.2 and Figure OR.3.3 in Online Resource 3) indicates that a bias is absent.

We found that mammals show the largest reduction in FRS, which quickly declines beyond $2^{\circ} \mathrm{C}$. Contrary to this FRS case, FRA for birds reduces to a larger extent under all intervals (Figure OR3.4 and Table OR3.3 in Online Resource 3). 

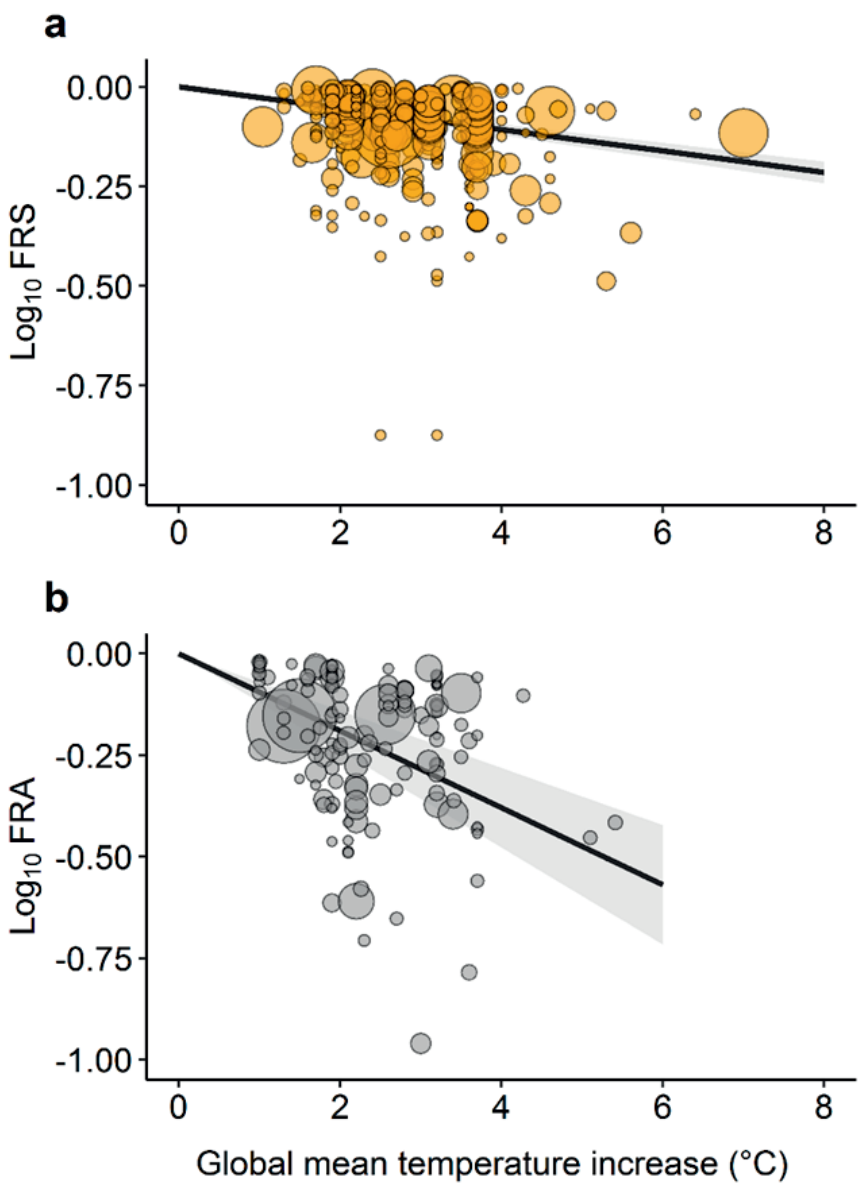

Figure 2.3. Meta-regressions on global mean temperature increase for $\log _{10}$ effect sizes (a) Fraction of Remaining Species (FRS) and (b) Fraction of Remaining Area (FRA) with suitable climate. Confidence intervals (CI 95\%) are shown by the shadowed line. Each effect size is represented by a circle, and the size of the circle indicates the number of species in the original study. 


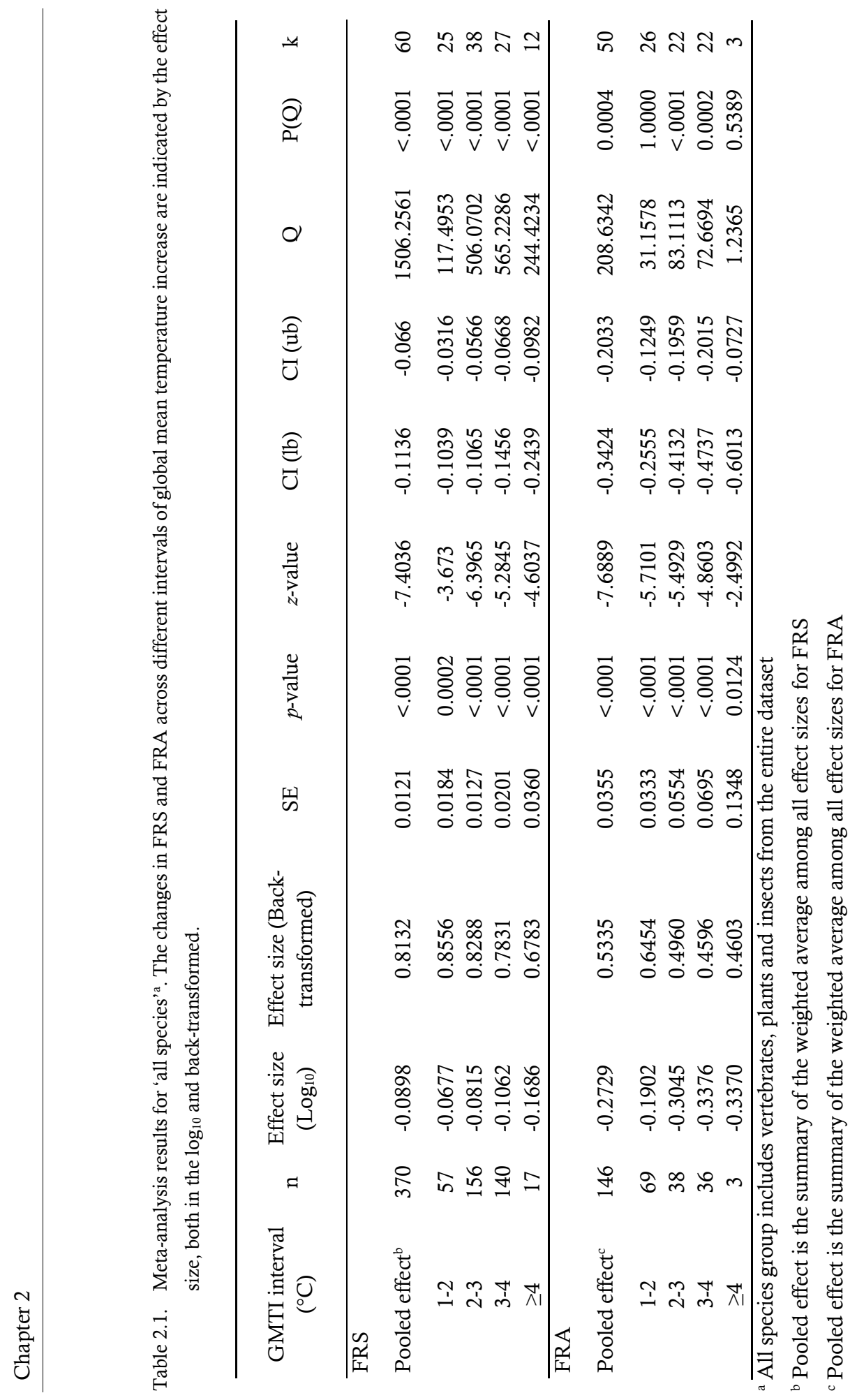




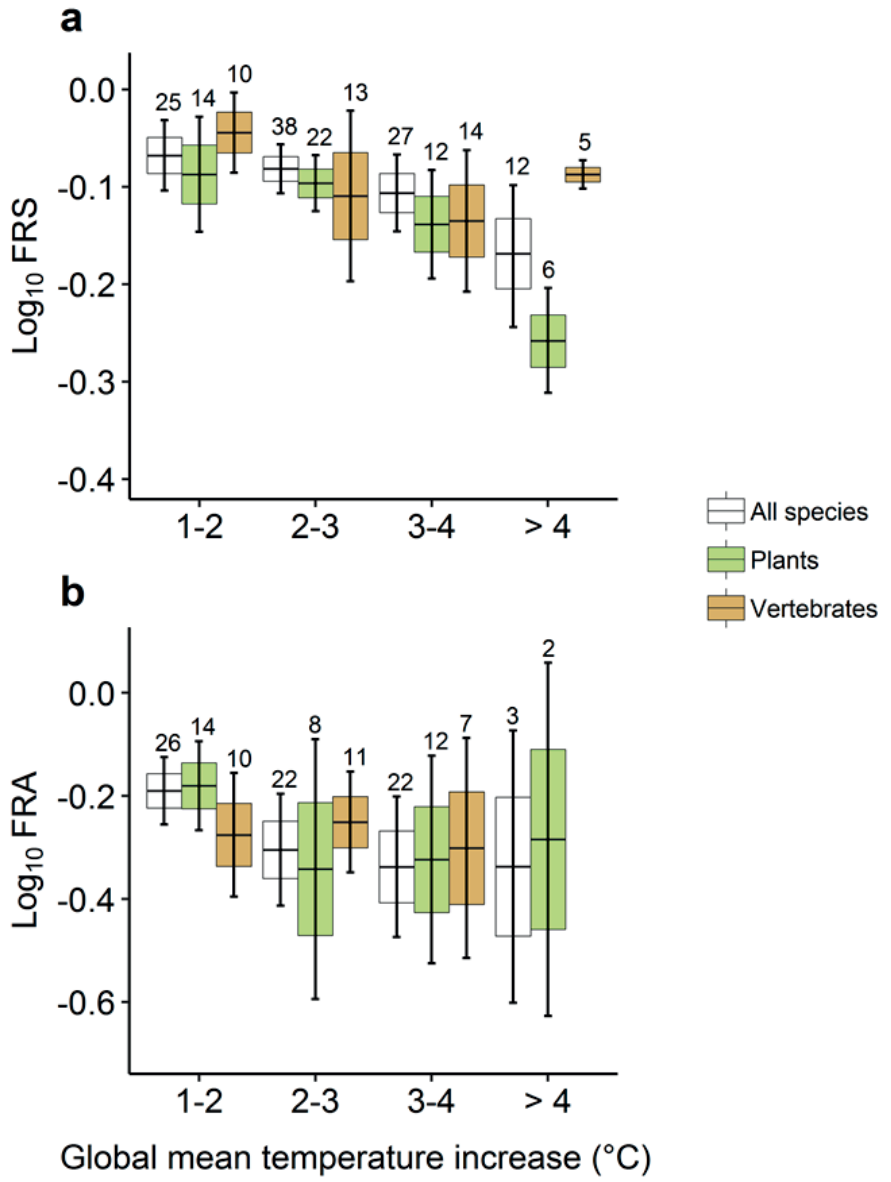

Figure 2.4. Mixed-effects model results per taxonomic group plants and vertebrates for (a) Fraction of Remaining Species and (b) Fraction of Remaining Area with Suitable Climate. Whiskers indicate confidence intervals (CI 95\%) and boxes demarcate standard errors. Top numbers indicate the number of studies (k) providing data for each group. 
Estimates of FRS and FRA can also be used to rank biomes to indicate sensitivities to climate change. The resulting effect-size estimates from our mixed-effects models were used to run metaregressions to assess the response of biomes to global mean temperature increase (Figure 2.5 and Figure OR3.5 in Online Resource 3 for the FRA results). We found that deserts, temperate forests and shrublands experience the largest reductions in FRS and tropical and boreal forests in FRA. These are thus likely the most sensitive biomes to increasing global temperatures.
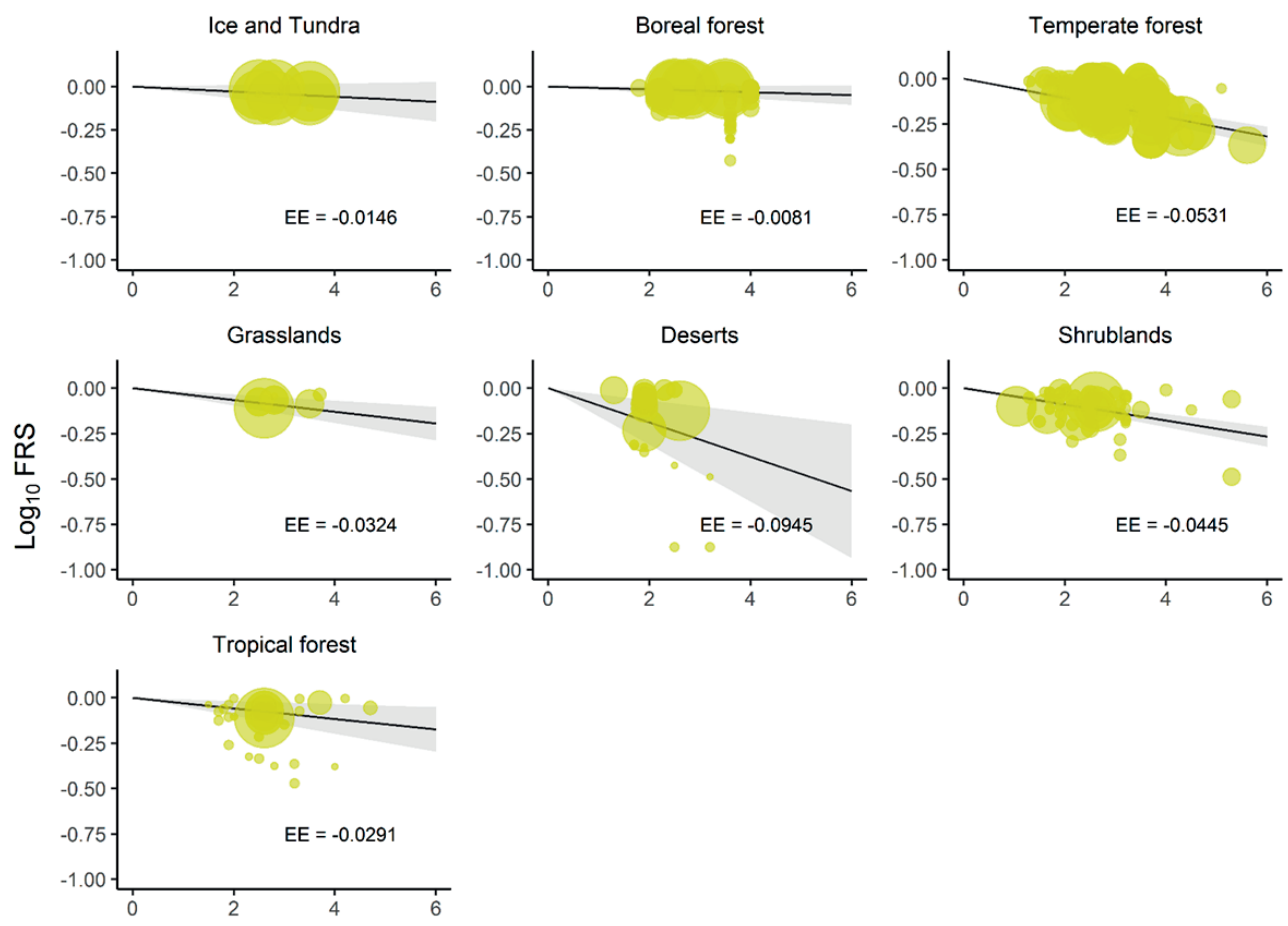

Global mean temperature increase $\left({ }^{\circ} \mathrm{C}\right)$

Figure 2.5. Mixed-effects model - meta-regressions on global mean temperature increase for different terrestrial biomes. Circles indicate the $\log _{10}$ effect sizes Fraction of Remaining Species, and the size of the circles corresponds to the number of species in the original study. Results obtained with meta-regression and $95 \%$ confidence. 


\subsection{Discussion and conclusions}

The projections of both the FRS and the FRA overall showed continuous decreases. This indicates losses of local species richness (on average by $14 \%$ at $2{ }^{\circ} \mathrm{C}$ of global mean temperature increase) and losses of suitable climate area of many species (on average by $35 \%$ at $2^{\circ} \mathrm{C}$ of global mean temperature increase). These results indicated that many species will be extirpated locally and disappear from areas where they now occur. This finding is supported by other studies (e.g. Wiens, 2016) and will certainly challenge species conservation in many places (Johnson et al., 2017; Warren et al., 2018). However, this does not mean that total species richness will necessary decrease as new species can potentially expand their ranges and establish, depending on their ability to disperse (Hellmann et al., 2016), but such emerging species are ignored in our effect sizes.

We estimated that reductions exacerbate as global mean temperature goes beyond $2^{\circ} \mathrm{C}$. For example, at $3^{\circ} \mathrm{C}$ of global mean temperature increase the local species richness decreased on average by $17 \%$ and the suitable climate area of species by $50 \%$. In addition, these effects are expected not only to increase biodiversity losses but also to accelerate for every degree rise in global mean temperature. As a result, all the local decreases will likely lead to global extinctions.

The results of FRS and FRA varied among taxonomic groups and biomes. This means that the species responses are closely related to their individual sensitivities and exposures to changes in temperature (Urban et al., 2016). For example, the response of vertebrates species to increases in global mean temperature was a decrease in both FRS (on average $10 \%$ at $2^{\circ} \mathrm{C}$ of global mean temperature increase) and FRA (on average $47 \%$ at $2^{\circ} \mathrm{C}$ of global mean temperature increase). We found that within the vertebrates group, mammals are projected to undergo the largest local species reduction (i.e. overall FRS reduced by $22 \%$ ). Our finding is consistent with previous studies (Pacifici et al., 2017), which conclude that many threatened mammals are also negatively affected by climate change. For plant species, the projected FRS and FRA decreased by $18 \%$ and $34 \%$ respectively at $2^{\circ} \mathrm{C}$ of global mean temperature increase. The lower plant species' FRS response probably resulted from a higher variability among effect sizes (Q-test for heterogeneity in Table OR3.2 and funnel plots of asymmetry in Figure OR3.1 in Online Resource 3) than the variability for vertebrate species' FRS. This high variability likely relates to methodological issues (e.g. different modelling algorithms) that are inherent to bioclimatic modelling and that affect species-range shifts and abundances. Although exotic and aquatic species were excluded from our study, the different climate-change responses of these groups (e.g. Schnitzler et al., 2007; Kalwij et al., 2015) contribute to the challenge of setting a climate-protection target. Our analysis with the mixed-effects model with biomes as a moderator, resulted in a lower heterogeneity in effect sizes compared to plants and vertebrates species. This indicates that 'biomes' is an important explanatory variable when assessing the projected effect of global mean temperature increase on biodiversity.

FRS and FRA focus on assessing the remaining proportion of biodiversity under the conservative assumption of no dispersal. On average, no dispersal is close to reality for most species (Midgley et 
al., 2006; Hellmann et al., 2016). This implies that FRS and FRA generally indicate decreases. FRS is consistent with indices that estimate the naturalness or intactness, such as the BII (Scholes and Biggs, 2005) or the MSA (Alkemade et al., 2009; Alkemade et al., 2011). As these indices are officially accepted by the Convention on Biologically Diversity to indicate the expected responses of original occurring species, our outcomes can also be used in international assessments of biodiversity change, such as the Global Biodiversity Outlook (CBD, 2014) and other global studies (e.g. PBL, 2012; Kok et al., 2018). FRS, however, differs from other biodiversity indices, such as the Species Richness Index (Newbold et al., 2014), because FRS ignores new species for which the future climate becomes suitable. FRA accounts for suitable climate-area reduction of local species. Previous studies that analysed suitable habitat of species to estimate global species richness patterns (e.g. Visconti et al., 2015) and/or the average proportional change in species distributions to estimate species extinction risks (e.g. Thomas et al., 2004), used similar approaches as our FRA. These studies inform developing goals for local biodiversity conservation and designing protected areas (Newbold et al., 2014; Virkkala et al., 2014). However, such studies also ignore reductions in areas with suitable climate of the originally occurring local species and the local community compositions. Contrary to the instant loss of biodiversity caused by some non-climatic anthropogenic pressures, climate change triggers more gradual and long-term effects on species (Bertrand et al., 2011) and such temporal dynamics must be considered to interpret the FRS and FRA results. In this study, we estimated the effects of global mean temperature increase assuming that any increase materialises simultaneously, but in reality higher increases in temperature are projected to occur at the end of this century, whereas increases of $2^{\circ} \mathrm{C}$ are possible already in 2050 (van Vuuren et al., 2011; IPCC, 2013b). Although our results support the notion that higher impacts of climate change will occur with higher temperatures, our results do not demonstrate that a climate target of keeping global temperature well-below $2^{\circ} \mathrm{C}$ protects all biodiversity. Therefore, we support the pledge to keep climate change below $1.5^{\circ} \mathrm{C}$ and preferably lower, as this helps to maintain the composition of local communities and their climatically suitable areas.

Understanding the climate-change impacts on biodiversity helps to prioritize biodiversity conservation strategies (Gärdenfors, 2001; Broennimann et al., 2006). Our results generically relate climate change and biodiversity loss. This relationship is useful to assess relative adverse effects of different climate-change scenarios and to stress the importance of holding climate change well-below $2^{\circ} \mathrm{C}$. Furthermore, our results can be used to explore interactions between climate change and other biodiversity-loss pressures, and estimate interactive effects. This implies that reducing the rate of biodiversity loss is critical and only possible if all pressures are reduced or eliminated (CBD, 2014). This means that, it would be helpful if the UN Conventions on Biological Diversity and Climate Change closely collaborate to address multiple urgent environmental challenges. 


\subsection{Acknowledgements}

We acknowledge the "Impacts and Risks from High-End Scenarios: Strategies for Innovative Solutions (IMPRESSIONS)" project (Grant Agreement 603416) from the EU FP7 programme for providing financial support to conduct this research. 



\section{Chapter 3}

\section{Increasing biodiversity loss in the Central}

\section{Asian grasslands as a result of changes in climate and land use}

This chapter is based on:

Nunez, S., Alkemade, R., Kok, K. and Leemans, R. Increasing biodiversity loss in the Central Asian grasslands as a result of changes in land use and climate. (Under review) 


\section{Abstract}

Arid and semiarid natural grasslands in Central Asia are extensively used for pastoral livestock grazing. This traditional land use is nowadays characterized by intensifying grasslands into more productive pastures. This change affects biodiversity and diminishes grasslands' ecological role. Biodiversity impacts are probably also exacerbated by climate change. These changes in biodiversity are poorly studied in Central Asia. Here we estimated how biodiversity changes in the Central Asian grasslands using the latest Shared Socio-economic Pathways and the Representative Concentration Pathways (i.e. SSP-RCP scenario framework). We selected scenarios with contrasting socioeconomic and climate conditions (i.e. SSP1-RCP4.5, SSP3-RCP8.5, SSP4-RCP4.5 and SSP5RCP8.5) and further detailed the land-use scenarios for the region. We indicated future biodiversity by the Mean Species Abundance indicator. The contrasting scenario combinations showed that grasslands' biodiversity will decline under each scenario. The strongest impact on biodiversity is expected in SSP5-RCP8.5, where half of the grasslands are likely to lose most of their local originally occurring species by 2100. The lowest impact is expected in SSP4-RCP4.5. Our study stresses the potential vulnerability of this region to increasing land-use intensity and climate change. These impact projections can help regional decision makers to develop and implement better biodiversityconservation and sustainable management policies for these grasslands. 


\subsection{Introduction}

Grasslands of Central Asia are located in a large land-locked region comprising five post-Soviet independent republics of Kazakhstan, Kyrgyzstan, Tajikistan, Turkmenistan and Uzbekistan. This region extents over an area of 4 million $\mathrm{km}^{2}$ and grasslands occupy nearly $65 \%$ of this extent, covering considerable areas of Kazakhstan, Tajikistan and Kyrgyzstan (Figure 3.1). Most grasslands are arid and semiarid (Gintzburger et al., 2005; FAO, 2007) and provide important habitats for many species that are of global and regional conservation concern (IUCN, 2019a), including steppe birds (Kamp et al., 2011), large ungulates such as the Saiga tatarica (Mallon and Zhigang, 2009), and diverse plant communities (Kamp et al., 2016). These grasslands also provide livelihoods for pastoral and agro-pastoral communities that lived in this region for centuries (Mirzabaev, 2013; Mirzabaev et al., 2015). The resulting socio-ecological systems have strongly contributed to the regional stability (Chen et al., 2019).

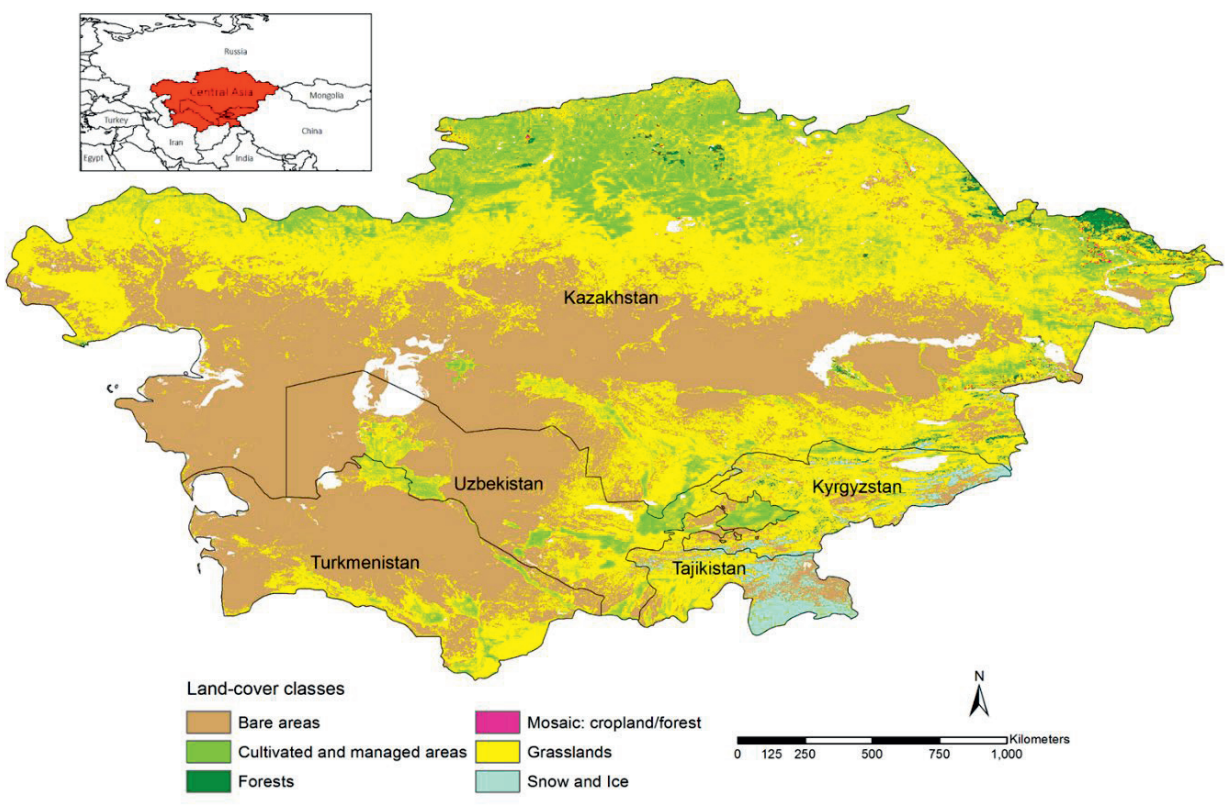

Figure 3.1. Map of Central Asia and main land-cover classes (adapted from GLC2000, Global Land Cover Network). 
The Central Asian grasslands are nowadays transformed by changes in land use (Suleimenov, 2014) and climate (Zhang et al., 2018a). These changes diminish the grasslands' ecological and socioeconomical roles and this ultimately leads to biodiversity loss. Traditionally, the Central Asian grasslands were used for extensive livestock production with high livestock mobility (FAO, 2007), which was a key element to sustainably manage grasslands. This helped to conserve and improve biodiversity. However, this traditional mobile pastoralism is recently replaced by a collective and sedentary grazing systems. This intensified grazing negatively affects biodiversity (e.g. habitat degradation) (Mallon and Zhigang, 2009; Singh et al., 2010; Kamp et al., 2016), especially in areas near settlements (Suleimenov, 2014; de Beurs et al., 2015; Mirzabaev et al., 2015). Future changes in land use likely pose considerable additional threats to Central Asia's biodiversity. These changes stem, for example, from the governmental support to enhance the livestock industry (Suleimenov, 2014) or from an increasing future demand for livestock products (Herrero et al., 2009; Thornton, 2010; Alkemade et al., 2013). Both factors are driven by population growth, economic development and politics (Popp et al., 2017).

Such land-use change has been accompanied by a decadal temperature increase of $0.4^{\circ} \mathrm{C}$ since 1970 (Chen et al., 2009; Hu et al., 2014). This temperature increase already substantially decreased grassland extent in the neighbouring Xinjiang province in China since the start of this century (Zhang et al., 2018a). Climate change is expected to further exacerbate the land-use change impacts as the temperature in the region is projected to increase between $3^{\circ} \mathrm{C}$ and $5^{\circ} \mathrm{C}$ by 2080 , relative to the average temperature over the period from 1961 to 1990 (Lioubimtseva and Henebry, 2009). Additionally, less water will be available (i.e. changed precipitation patterns and more evapotranspiration).

Central Asia is also a region with large information gaps of past and current biodiversity trends, including habitat extent and intactness, and species conservation status (Hamidov et al., 2016; IPBES, 2018c). These knowledge gaps exist mainly because available assessments poorly represent this extensive grassland area. Global assessments inadequately depict the more subtle changes in grasslands, such as increasing land-use intensities (that are driven by socio-economic factors). Furthermore, these assessments generally ignore interaction mechanisms between land-use and climate effects, and consequently fail to accurately project biodiversity change. Thus, a new approach that fills in these knowledge gaps and improves future projections is clearly needed. The region has also been challenged socially, economically and politically since the collapse of the Soviet Union in 1991 (Yu et al., 2019), and neighbouring countries such as Russia and China have much at stake in Central Asia in terms of security and access to natural resources. These complex regional conditions suggests that Central Asia will remain relatively unstable in the future and also this makes future projections difficult and uncertain. 
Our study aimed to estimate future biodiversity change in the Central Asian grasslands as a result of socio-economic trends and the consequent projections of land-use and climate-change effects. Our approach included the use of scenarios that are based on the Shared Socio-economic Pathways (SSPs: O'Neill et al., 2014) and the Representative Concentration Pathways (RCPs: van Vuuren et al., 2011), to quantify the possible range of future biodiversity changes. Scenarios have been widely used to assess global biodiversity change (e.g. Thomas et al., 2004; Malcolm et al., 2006; Pereira et al., 2010; IPBES, 2018c). They describe plausible futures based on a coherent and internally consistent set of assumptions about the drivers of change (MA, 2005). These drivers are input to models that quantify and simulate projections of biodiversity change (IPBES, 2016). We used the relative Mean Species Abundance (MSA) of original species as compared to their original abundance to indicate biodiversity change (c.f. Alkemade et al., 2009). Below, we describe our stepwise study approach and data sources, present scenario and modelling results and finally present and discuss the main findings. The projected continuous decline in biodiversity has consequences for current and future grassland management and conservation.

\subsection{Methodology}

\subsubsection{Study approach}

We developed a stepwise study approach to assess biodiversity change in grasslands (Figure 3.2). This approach combined outcomes from the SSP-RCP scenario framework, outputs from integrated assessment models, regression analyses and existing gridded datasets on land-use change (i.e. grazing intensity). Below we describe the four steps and data sources in more detail.

Step 1. Developing land-use scenarios for Central Asia

We developed a set of four land-use scenarios based on the Central Asian socio-economic narratives from the IMPRESSIONS project (Harrison et al., 2019b). These socio-economic narratives are plausible 'high-end' qualitative narratives, which contain additional, more detailed information about regional socio-economic drivers of change (i.e. population and gross domestic product: GDP) for 2010 to 2100. Our land-use scenarios described the impact of these socio-economic drivers and model assumptions (i.e. technological agricultural developments) on grasslands. Land-use change was indicated by the extent and intensity of grassland use (i.e. grazing intensity).

The scenario selection made within the IMPRESSIONS project covered SSP1 (Sustainability) and SSP4 (Game of Elites) combined with RCP4.5, and SSP3 (Regional Rivalry) and SSP5 (Fossilfuelled Development) combined with RCP8.5 (Figure 3.3). SSP1 represented low and constant population growth and moderate economic growth. SSP4 represented low population growth and economic stagnation. Climate change was moderate in both SSP1 and SSP4. SSP3 and SSP5 scenarios represented high population growth, with economic stagnation and high economic 
growth, respectively. Both SSP3 and SSP5 were challenged by high climate change. Technological agricultural development was indicated by the management factor which is derived from the IMAGE model (Stehfest et al., 2014). This factor slightly improved in SSP1 and remained constant in SSP3, whereas in SSP4 declined and in SSP5 only improved in the second half of the century. Our land-use scenarios thus showed different levels of demand for agricultural products (e.g. livestock) and agricultural production which were both reflected on grazing intensity.

Step 2. Quantifying grazing intensity projections

We quantified changes in grazing intensity at a grid cell level in ArcGIS 10.5 for each SSP for three periods (i.e. 2010-2040, 2040-2070 and 2070-2100) as follows:

$$
\operatorname{GrazInt}_{i, t}=\operatorname{GrazInt}_{i, 0} \cdot \Delta \operatorname{Pop}_{i, t} \cdot \Delta G D P_{i, t} \cdot \Delta M F_{i, t}
$$

(Equation 3.1)

where: GrazInt $\mathrm{i}_{\mathrm{i}, \mathrm{t}}$ is the grazing intensity in grid cell $\mathrm{i}$ at time $\mathrm{t}, \mathrm{GrazInt}_{\mathrm{i}, 0}$ is the current grazing intensity in grid $\mathrm{i}, \Delta \mathrm{Pop}_{\mathrm{i}, \mathrm{t}}$ and $\Delta \mathrm{GDP}_{\mathrm{i}, \mathrm{t}}$ are the relative increases of population and GDP per capita in grid cell $i$ at time $t$, and the relative increase change in the management factor $\left(\Delta M F_{i, t}\right)$ in grid cell $i$ at time $t$. We assumed a multiplicative relationship between these four factors and grazing intensity. Grazing intensity ranges from 0 to 1 . We classified the resulting grazing intensity as low (i.e. 0.0 to 0.4 ), moderate (i.e. 0.4 to 0.6 ), high (i.e. 0.6 to 1.0 ) and land that is converted. Such converted land corresponded to grasslands that exceed their grazing capacity (i.e. GrazInt $>1.0$ ).

Step 3. Quantifying grazing and climate-change effects on biodiversity Grazing and climate-change effects were indicated by the MSA indicator. MSA indicates biodiversity intactness and ranges between 0 in areas where original biodiversity has completely disappeared, to 1 in areas where species composition and abundance is fully original. We quantified biodiversity change from changes in grazing intensity (i.e. MSA $\mathrm{LU}_{\mathrm{U}}$ based on the relationship between MSA and grazing intensity (Alkemade et al, 2013; Petz et al., 2014). Here, the MSA $A_{L U}$ described the biodiversity loss with increasing grazing intensities resulting in changing plant-species composition, soil compaction by trampling, outcompeting and hunting of wildlife, homogenization of landscapes and habitat destruction.

The climate-change effect on biodiversity (i.e. $\mathrm{MSA}_{\mathrm{CC}}$ ) was estimated using the relationship between global mean temperature increase and the fraction of remaining species (FRS), which is derived from a meta-analysis of projected species shifts in different species-envelope models (Nunez et al., 2019). We related the projected global mean temperature increase for RCP4.5 and RCP8.5 for three periods and the FRS estimate for grasslands (FRS $=-0.0324,95 \%$ confidence interval: $-0.0478--0.0170$ ). This relationship determined changes of species richness in grasslands compared to the original biodiversity state. 


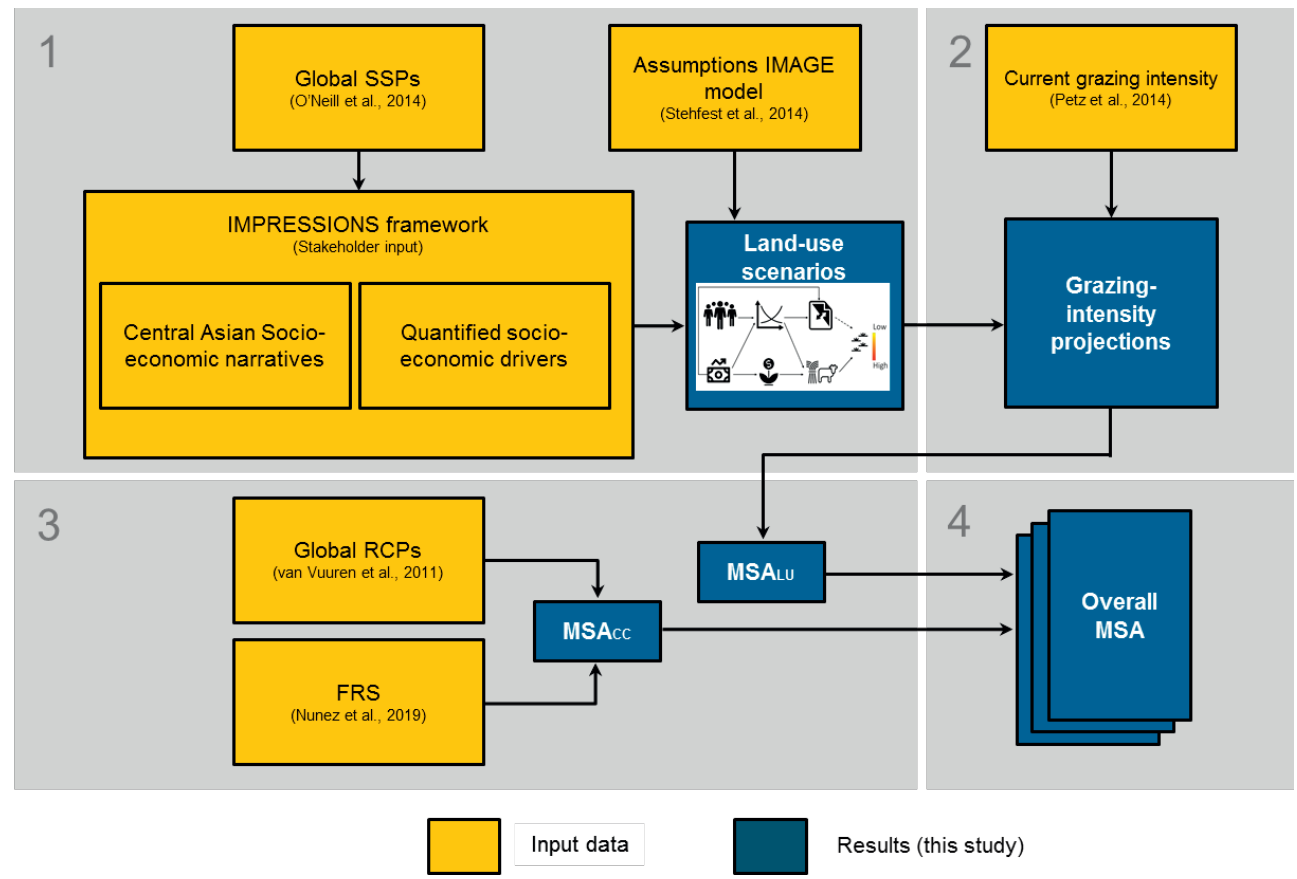

Figure 3.2. Schematic illustration of the study approach to assess biodiversity change in grasslands. Global Shared Socio-economic Pathways (SSPs) and assumptions from IMAGE model are input to develop land-use scenarios that indicate the impact of land-use change on Mean Species Abundance $\left(\mathrm{MSA}_{\mathrm{LU}}\right)$. Projected global mean temperature increase based on the Representative Concentration Pathways (RCPs) and the Fraction of Remaining Species (FRS) are correlated to indicate the impact of climate change on Mean Species Abundance (MSA $\mathrm{CC}_{\mathrm{CC}}$ ). The overall biodiversity change $\left(\mathrm{MSA}_{\mathrm{LU}-\mathrm{CC}}\right)$ is the product of $\mathrm{MSA}_{\mathrm{LU}}$ and $\mathrm{MSA}_{\mathrm{CC}}$.

Step 4. Analysis of biodiversity change in the SSP-RCP scenario matrix

The overall biodiversity change (MSA $\mathrm{LU}_{\mathrm{LC}}$ ) was estimated by multiplying the individual effects of land-use $\left(\mathrm{MSA}_{\mathrm{LU}}\right)$ and climate change $\left(\mathrm{MSA}_{\mathrm{CC}}\right)$ in ArcGIS 10.5. We visually compared the spatial patterns of biodiversity change in grasslands. We analysed these patterns by calculating the grassland proportion under each MSA category for each scenario for three periods to indicate the resulting biodiversity change. 


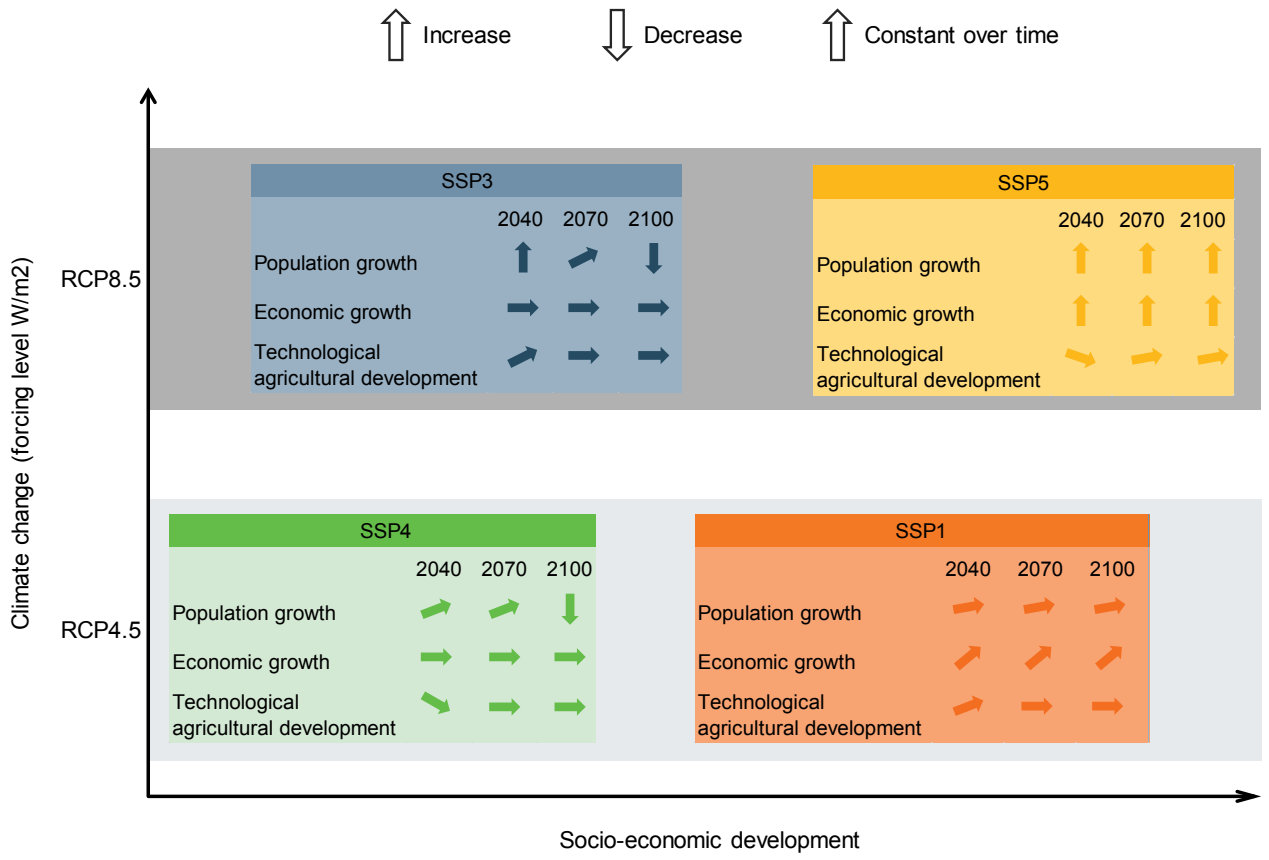

Figure 3.3. SSP-RCP scenario matrix and the characteristics of major socio-economic drivers.

\subsubsection{Data sources}

In this study, we used various datasets (qualitative and gridded) to explore land-use and climatechange effects on the biodiversity of grasslands. We describe these sources below (see Appendix 3.A.1 for more detail).

Population and GDP projections were quantified within the IMPRESSIONS project. Population projections are gridded datasets of $0.125 \times 0.125^{\circ}$ resolution (Jones and O'Neill, 2013). GDP projections are datasets for each country derived from The World Bank DataBank (2016).

Technological development was based on the management factor from the IMAGE model. This management factor described the actual yield per crop group (i.e. grass) for Central Asia region as a proportion of the maximum potential yield and depends on the regional GDP (Stehfest et al., 2014). Projected global mean temperature increases for the late 21st century relative to the 1986-2005 period for RCP4.5 $\left(1.8^{\circ} \mathrm{C}\right)$ and $\mathrm{RCP} 8.5\left(3.7^{\circ} \mathrm{C}\right)$ were used to indicate climate change (IPCC, 2013b). Projected temperatures for the years 2040 and 2070 were derived from Table AII.7.5 (Annex II; IPCC, 2013b). The IPCC 5th Assessment Report used 1850-1900 as a historical baseline, and estimated the warming from then to $1986-2005$ at $0.6^{\circ} \mathrm{C}$. 
Spatial data on grazing intensity (Petz et al., 2014) was used to define the initial grazing situation. We distinguished three grazing intensity categories (1 indicates maximum carrying capacity): low (0.0-0.4), moderate (0.4-0.6) and high (0.6-1.0). The Land cover database GCL2000 (Bartholomé and Belward, 2005) and the terrestrial biomes database (Olson et al., 2001) were used to delineate grasslands and other land-use classes in the region.

\subsection{Results}

Our land-use scenarios showed that grazing intensification will trigger large biodiversity losses in the region over the course of this century. SSP1 and SSP5 depicted the larger increases in grazing intensity by 2100 , while the other two scenarios featured moderate losses. These changes in grazing intensity translate into a decrease in the $\mathrm{MSA}_{\mathrm{LU}}$ (Figure 3.4). The MSA 'high' corresponded to nearly pristine grasslands where the proportion of originally occurring species was projected to be $70-100 \%$ after land-use change, 'moderate' to grasslands areas that lost between $30-50 \%$ of the originally occurring species, 'low' to areas that lost more than half of their originally occurring species and 'critical' indicated that areas lost almost entirely their local originally occurring species.

In SSP1, Central Asian countries followed a path of sustainable development with steady economic growth (see land-use scenarios in Appendix 3.A.2). However, the extent of natural grasslands that contain the highest biodiversity (i.e. low-intensity grazed), decreased by $8 \%$ between 2010 and 2100 (Table 3.1). Between 2040 and 2070, 10\% of the total grasslands likely converted, for example, into pastures, due to irrigation efficiency improvements. In SSP5, the highly intensively grazed areas increased by $6 \%$ between 2010 and 2100 and the moderate grazing areas by $9 \%$ (Table 3.1). By 2100 , the extent of natural grasslands was highly reduced and possibly converted into other categories. Changes resulted from high economic and population growth. By the end of the century, the total population in Central Asia increased from 63.0 million in 2010 to 74.5 million and the annual GDP was over twenty times higher than in 2010. SSP3 was characterised by both an exclusive economic development and limited cooperation between countries that limit the economic growth in the region. Between 2040 and 2070, population dynamics powered a moderate grazing intensification that decreased low-intensity grazed areas by $4 \%$ (Table 3.1). In 2100, however, grazing intensification decreased due to a limited economic growth and out-migration from the region. By then, the population size in SSP3 was the lowest among all scenarios. In SSP4, Central Asia was a highly unequal heterogeneous region with an agricultural sector that focused on realising the food demand by local populations. Grazing intensity only increased slightly as a result of low population and economic growth, and therefore did not show substantial impacts on the MSA $A_{L U}$. On the contrary, the high intensity grasslands slightly decreased. This reduced the pressure on grasslands and slightly increased the MSA $\mathrm{LU}_{\mathrm{LU}}$. Here, livestock production probably expanded into other areas (e.g. croplands or forest). The grazing intensity in grid cells without population was assumed to remain constant (i.e. no changes in GDP per capita and the management factor). 
Table 3.1. Changes in grazing intensity (\%) for all scenarios for 2040, 2070 and 2100.

\begin{tabular}{lcccccccccccccc}
\hline Grazing & \multirow{2}{*}{$\begin{array}{l}2 \\
\text { intensity }\end{array}$} & 2010 & \multicolumn{3}{c}{ SSP1 } & \multicolumn{3}{c}{ SSP3 } & \multicolumn{3}{c}{ SSP4 } & \multicolumn{3}{c}{ SSP5 } \\
\cline { 2 - 14 } & 2040 & 2070 & 2100 & 2040 & 2070 & 2100 & 2040 & 2070 & 2100 & 2040 & 2070 & 2100 \\
\hline Low & 94.4 & 85.0 & 84.9 & 86.3 & 91.1 & 90.1 & 94.5 & 97.3 & 97.9 & 98.1 & 83.1 & 71.0 & 59.3 \\
Moderate & 2.2 & 2.8 & 2.3 & 2.4 & 2.6 & 2.6 & 2.2 & 2.2 & 1.6 & 1.4 & 3.6 & 8.2 & 11.6 \\
High & 3.4 & 3.6 & 3.2 & 2.7 & 2.8 & 3.0 & 2.5 & 0.5 & 0.4 & 0.4 & 3.0 & 6.0 & 9.8 \\
Converted & 0.0 & 8.5 & 9.6 & 8.7 & 3.5 & 4.3 & 0.8 & 0.0 & 0.1 & 0.2 & 10.3 & 14.7 & 19.3 \\
\hline
\end{tabular}

RCP4.5 projected a global mean temperature increase of $2.4^{\circ} \mathrm{C}$ relative to pre-industrial. This increase resulted in the $\mathrm{MSA}_{\mathrm{CC}}$ in grasslands decreasing from 2010 to 2100 by $16 \%$ (95\% confidence interval: 9-23\%). For RCP8.5 the global mean temperature increase was $4.3^{\circ} \mathrm{C}$ relative to preindustrial and the $\mathrm{MSA}_{\mathrm{CC}}$ was projected to decrease by $27 \%$ (95\% confidence interval: $16 \%-38 \%$ ). We estimated that the MSA $\mathrm{LU}_{\text {-CC }}$ in grasslands decreased dramatically between 2010 to 2100 (Figure 3.5). In 2100, only half of the natural grasslands of Central Asia was projected to remain undisturbed by land-use and climate changes for all SSPs. 

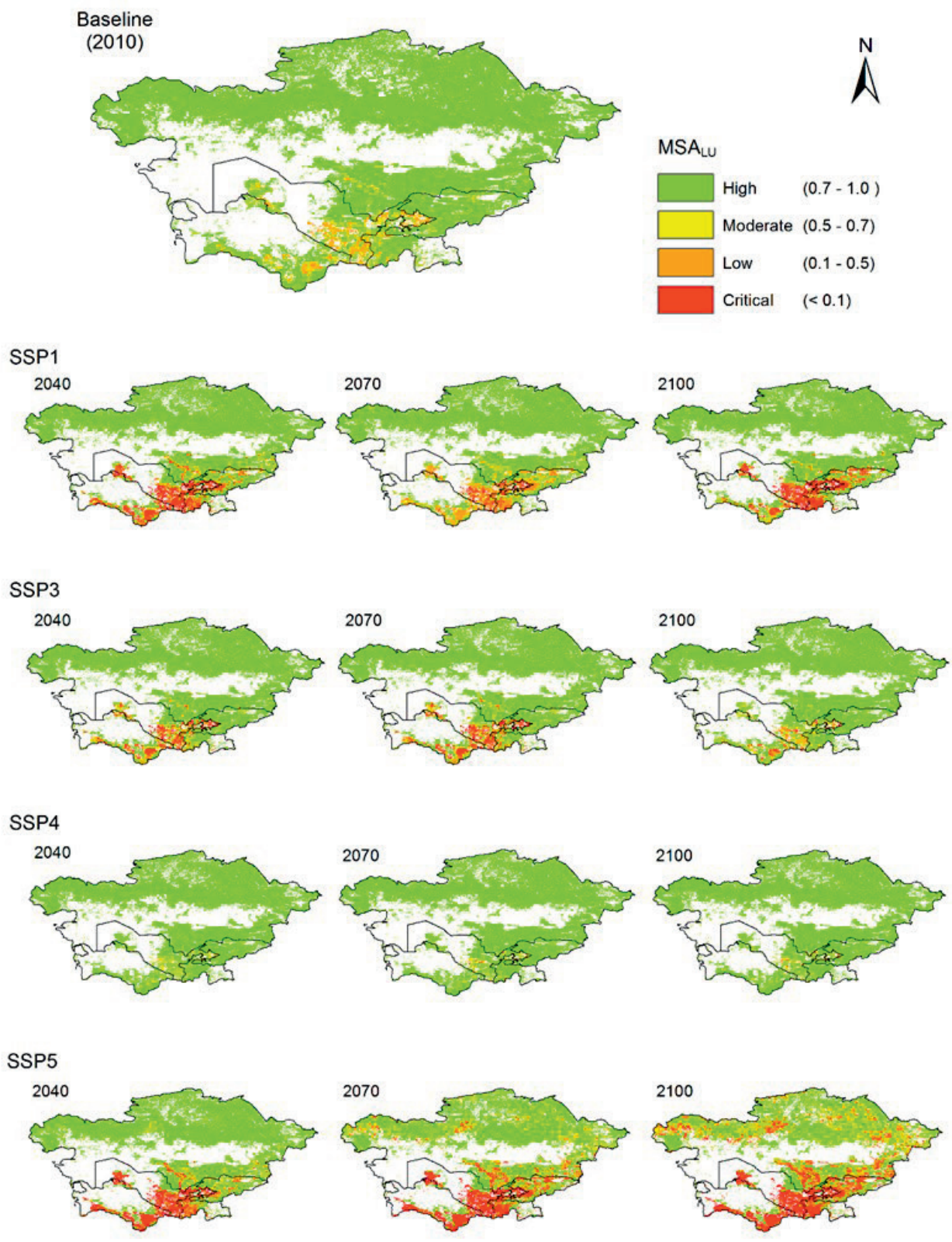

Figure 3.4. Estimated changes in Mean Species Abundance $\left(\mathrm{MSA}_{\mathrm{LU}}\right)$ in the grasslands of Central Asia between 2010 and 2100 for different futures. 


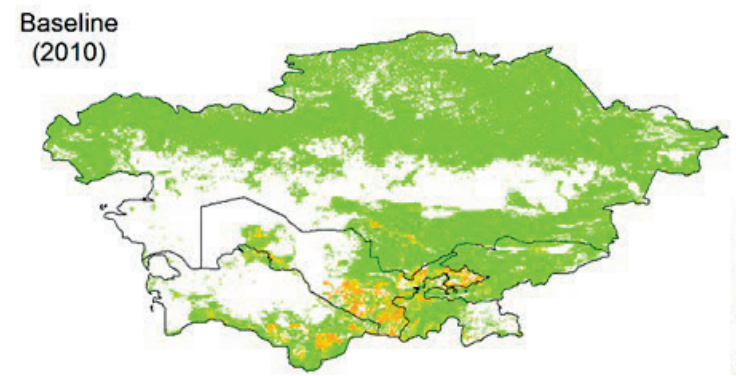

SSP1 - RCP4.5
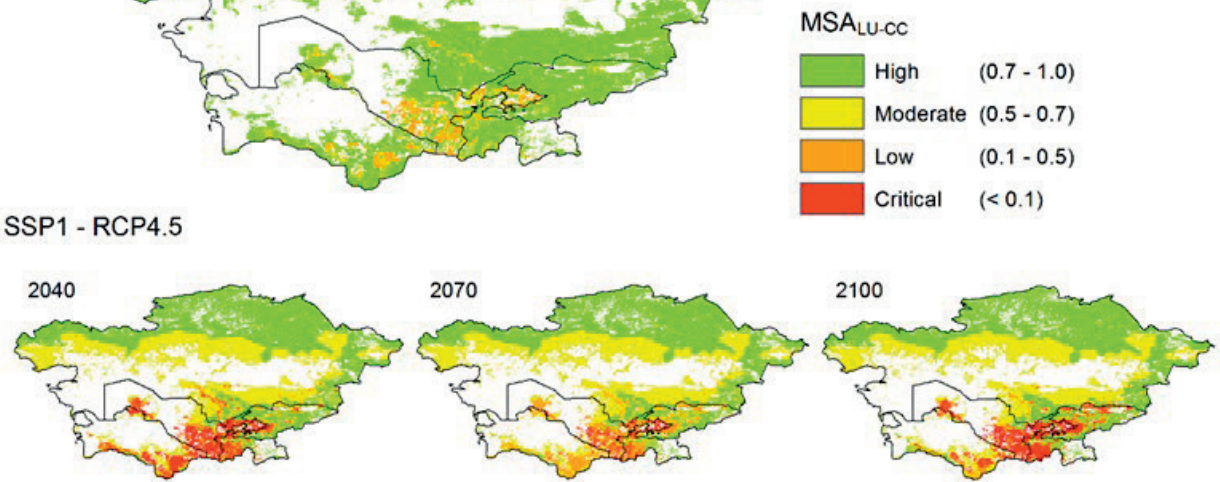

\section{SSP3 - RCP8.5}
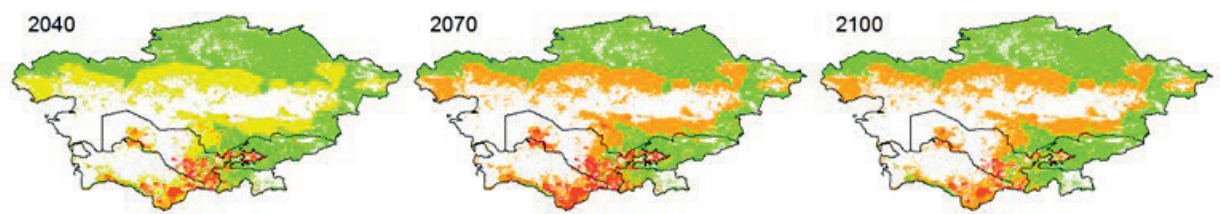

\section{SSP4 - RCP4.5}
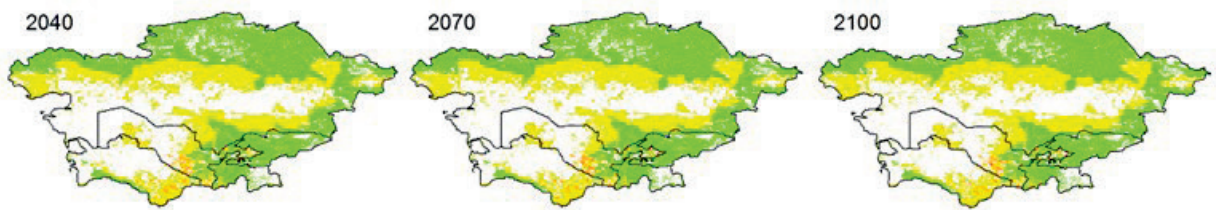

\section{SSP5 - RCP8.5}
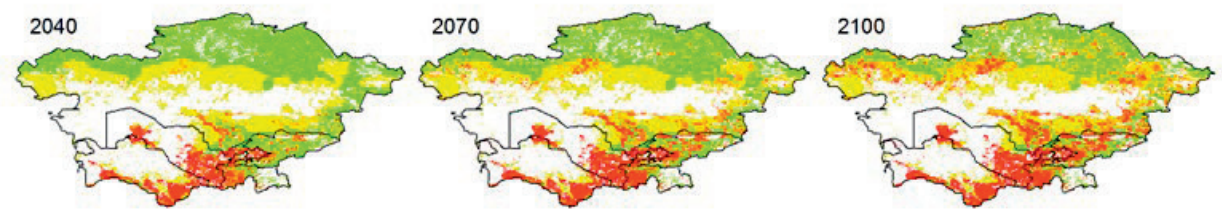

Figure 3.5. Estimated changes in Mean Species Abundance (MSA $\mathrm{Lu}_{\mathrm{LC}}$ ) in the grasslands of Central Asia between 2010 and 2100 for different futures. 
The largest decrease in biodiversity occurred in SSP5-RCP8.5. By 2100, half of the grasslands were likely to lose more than $70 \%$ of their local originally occurring species. This scenario projected the largest grassland conversion (i.e. 19\%) that implied a strong decline of more than $90 \%$ in the local originally occurring species (Figure 3.6). In SSP3-RCP8.5, biodiversity loss occurred already in the first half of the century. This was mainly driven by population growth and food demand peaking in 2040. The high climate-change impact exacerbated biodiversity loss in these two scenarios. Moderate changes in biodiversity in SSP1-RC4.5 were mostly driven by the increasing population and economic development. Last, the scenario SSP4-RCP4.5 projected the smallest decrease in biodiversity by the end of the century. In this scenario, most grasslands (98\%) retained more than half of their original occurring species, while less than $1 \%$ fell into a critical category. SSP 1 and SSP4 were influenced by a less stringent climate-change impact on grasslands.

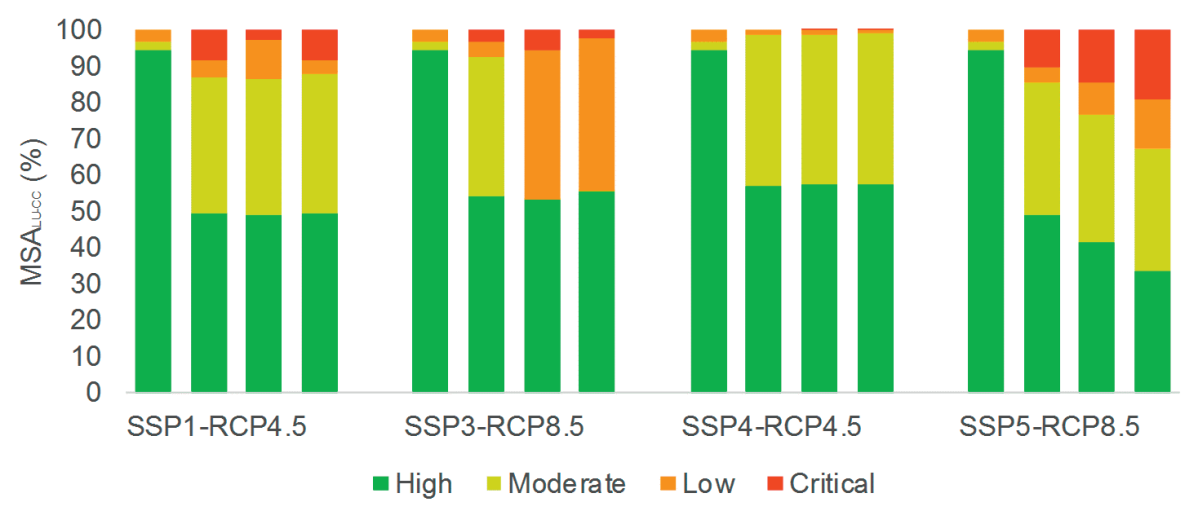

Figure 3.6. Estimated changes (\%) in Mean Species Abundance (MSA $\mathrm{Lu}_{\mathrm{LU}}$ ) for different SSPs-RCPs. The left bar in each scenario indicates the year 2010, followed by 2040, 2070 and 2100.

\subsection{Discussion and conclusions}

Our analysis showed that biodiversity in the Central Asian grasslands will decline in all scenarios. The strongest impact on biodiversity was expected in SSP5-RCP8.5. This was a high-end climatechange scenario with high economic growth that intensively develops the agricultural sector. This finding is consistent with the recent IPBES report (IPBES, 2019) that projects land-use and climatechange impacts on biodiversity. This IPBES report indicates that species richness more strongly decreases in all SSPs-RCPs scenarios (with SSP5-RCP8.5 the strongest) for Central Asia in comparison to most other regions. Our results showed that the lowest impact will occur in Central Asia in SSP4-RCP4.5. 
SSP1-RCP4.5 depicted a remarkably large biodiversity loss driven by the moderate economic and high demographic growth that lead to rapid grazing intensification. This result, however, contrasts the IPBES projections and its intuitive assumption that this scenario will protect biodiversity. Here, SSP1 showed that a world with high affluence and population growth will continue to put pressure on biodiversity, regardless of the efforts to pursue sustainability.

The extent of (nearly) pristine natural grasslands that contain the highest biodiversity, was projected to be halved in all scenarios, already by 2040. In terms of impacts on biodiversity, this means that the abundance of original occurring species decreases to less than $70 \%$ in half of the total grassland area. The remaining proportion of natural grasslands was projected to slightly change over the course of the century, with consequent implications in ecosystem functioning. This is consistent with previous studies (Christensen et al., 2004; Zhang et al., 2018b) that showed that small temperature increase (i.e. $1-2^{\circ} \mathrm{C}$ ) and moderate grazing level in steppe will affect native grasses (e.g. bunch-grass steppe) and result in decreasing above ground net primary production.

Critical levels of biodiversity loss were mainly projected around population settlements. This is because land-use change is increasingly dynamic in response to population growth (Verburg et al., 2015) and economic development, influenced by people's preferences for agricultural production and technological development (Kok et al., 2018). Thus, spatial patterns of the relative change in land use that drive great losses of biodiversity occurred mainly around urban areas. For example, scenarios with steep technological developments (i.e. SSP1 and SSP5) showed an increasing management intensity of grasslands, with possibly habitat conversion and eventually land degradation (Popp et al., 2017). In other words, natural grasslands that decreased will likely convert into moderate or even high intensively used grasslands, and these eventually into other land use (e.g. permanent pastures). This will typically cause a decrease of biodiversity (Alkemade et al., 2013; Hamidov et al., 2016). In contrast, scenarios that assumed gentle technological developments (i.e. SSP4), will likely result in less pressure on the habitats of species.

The extreme climate impact from RCP8.5 projected an increased biodiversity loss in the region. This associated impact is in line with recent studies that reported the negative effect of temperature increase on arid and semi-arid grasslands worldwide (Warren et al., 2011; Dangal et al., 2016). SSP5-RCP8.5 projected continuously increasing greenhouse-gas emissions over the entire century (Riahi et al., 2011) and a global mean temperature that likely exceeded $2^{\circ} \mathrm{C}$ (IPCC, 2014). In the absence of climate policy, this scenario is very unlikely to limit the global mean temperature increase to well-below $2^{\circ} \mathrm{C}$ above pre-industrial levels (i.e. Paris Agreement; UNFCCC, 2015). Hence, the biodiversity losses in SSP3-RCP8.5 and SSP5-RCP8.5 that result from climate change, are an urgent call to limit greenhouse-gas emissions worldwide to the lowest possible level.

Our study relied highly on qualitative assumptions from integrated assessment models and socioeconomic scenarios to explore the future implications of land-use and climate changes on extensively used grasslands, which are part of one of the most common land-use classes in the world. Socioeconomic scenarios in our analysis were based on detailed insights from regional stakeholders. 
Stakeholders' input results in more realistic regional scenario elements than the assumption based on global scenario studies. This likely catered for a more robust analysis. Previous studies that assessed global land-use change in the SSPs (Popp et al., 2017; Riahi et al., 2017; Doelman et al., 2018) included additional socio-economic elements, such as land allocation of grassland or cropland expansion, consumer preferences and food price sensitivities. Their results, however, showed similar trends in losses of natural land. This means that the main elements that are selected in our study, drive the larger changes in the land-use system. While the SSPs are not specifically designed to explore grassland systems, our relatively simple approach allowed to explore changes in this system. Other assumptions on land-use intensification or the effects of GDP growth could derive different biodiversity trends. Thus the underlying assumptions and scenarios are crucial to assess consequences in grassland systems .

Previous studies that reported the effects of land-use change (Alkemade et al., 2013; Petz et al., 2014; Newbold et al., 2015) and climate change (Alkemade et al., 2009; Bütof et al., 2012; White et al., 2014) in other grassland regions, concluded that biodiversity is projected to decline. Our study supports this notion but also hints at the potentially large biodiversity losses in the Central Asian grasslands across all scenarios. These grasslands seem more vulnerable.

While our results translate relevant information of socio-economic and climate-change drivers, more research is urgently needed to translate our findings into better management strategies for Central Asia's grasslands. We estimated biodiversity loss in the Central Asian grasslands using a simple biodiversity model that assumed a linear relationship between socio-economic drivers and grazing intensification. The resulting trends clearly demonstrate the need for better land-use and biodiversity-conservation planning.

\subsection{Acknowledgements}

We acknowledge the "Impacts and Risks from High-End Scenarios: Strategies for Innovative Solutions (IMPRESSIONS)" project (Grant Agreement 603416) from the EU FP7 programme for providing financial support to conduct this research. 


\section{A Appendix}

\section{A.1 Datasets used in the study}

Table 3.A.1. Summary of qualitative and gridded datasets used as input in our study.

\begin{tabular}{|c|c|c|c|}
\hline Data description & $\begin{array}{l}\text { Resolution } \\
\text { (geographical) }\end{array}$ & $\begin{array}{l}\text { Resolution } \\
\text { (spatial) }\end{array}$ & Source \\
\hline Grazing intensity & Global & $0.05^{\circ} \times 0.05^{\circ}$ & Petz et al. (2014) \\
\hline $\begin{array}{l}\text { Global Land Cover } \\
\text { (GLC2000) }\end{array}$ & Global & $0.0089^{\circ} \times 0.0089^{\circ}$ & Joint Research Centre (2003) \\
\hline Terrestrial ecoregions & Global & $0.05^{\circ} \times 0.05^{\circ}$ & $\begin{array}{l}\text { Olson et al. (2001); TNC } \\
\text { (2009) }\end{array}$ \\
\hline $\begin{array}{l}\text { Shared Socio-economic } \\
\text { Pathways (SSPs) }\end{array}$ & Global & n.a. & Riahi et al. (2017) \\
\hline $\begin{array}{l}\text { Central Asian Socio- } \\
\text { Economic Narratives }\end{array}$ & Regional & n.a. & $\begin{array}{l}\text { IMPRESSIONS Socio- } \\
\text { economic scenarios (Kok and } \\
\text { Pedde, 2016) }\end{array}$ \\
\hline Total Population & Per country & $0.125^{\circ} \times 0.125^{\circ}$ & Jones and O’Neill (2013) \\
\hline $\begin{array}{l}\text { Gross Domestic } \\
\text { Product (GDP) }\end{array}$ & Per country & n.a. & The World Bank DataBank \\
\hline Management factor & Regional & n.a. & $\begin{array}{l}\text { IMAGE model (Stehfest et } \\
\text { al., 2014) }\end{array}$ \\
\hline $\begin{array}{l}\text { Representative } \\
\text { Concentration } \\
\text { Pathways (RCPs) }\end{array}$ & Global & n.a. & $\operatorname{IPCC}(2013 b)$ \\
\hline $\begin{array}{l}\text { Fraction of Remaining } \\
\text { Species (FRS) }\end{array}$ & Biome & n.a. & (Nunez et al., 2019) \\
\hline
\end{tabular}




\section{A.1.1 Socio-economic drivers}

\section{Population}

Population data consists of ESRI Shapefile (SHP) Feature Class in Geographic Coordinate System: GCS_WGS_1984 and Datum: D_WGS_1984 for SSP1, SSP3, SSP4, and SSP5 for each 10-year interval over the period 2010-2100.

This file contains gridded population projections for Central Asia (Kazakhstan, Kyrgyzstan, Turkmenistan, Tajikistan, Uzbekistan) for the period 2010-2100. Projections are constructed by downscaling stakeholder-developed aggregate country-level projections to $1 / 8^{\text {th }}$ degree resolution using the NCAR spatial population downscaling model. Urban, rural, and total population projections are reported in 10-year intervals for SSP1, SSP3, SSP4, and SSP5. SSP-specific projections of urbanization are taken from the SSP database (URL) and applied to stakeholderdeveloped aggregate projections to produce country-specific projections of the urban and rural population for each ten-year time-step. For more information on the NCAR spatial downscaling methodology see: Jones, B. \& O'Neill, B. C. Historically grounded spatial population projections for the continental United States, Environ. Res. Lett. 8, 044021 (2013).

The 2010 population distribution is derived from the 2.5" Gridded Population of the World (GPWv3), scaled to meet the observed 2010 population for each country and aggregated to $1 / 8^{\text {th }}$ degree (7.5").

Table 3.A.2. Population data for Central Asia used as input in our study.

\begin{tabular}{|c|c|c|c|c|c|c|c|c|}
\hline \multirow[t]{2}{*}{ Year } & \multicolumn{2}{|l|}{ SSP1 } & \multicolumn{2}{|l|}{ SSP3 } & \multicolumn{2}{|l|}{ SSP4 } & \multicolumn{2}{|l|}{ SSP5 } \\
\hline & $\begin{array}{l}\text { Million } \\
\text { persons }\end{array}$ & $\begin{array}{l}\text { Growth } \\
\text { factor } \\
\text { relative } \\
\text { to } 2010\end{array}$ & $\begin{array}{l}\text { Million } \\
\text { persons }\end{array}$ & $\begin{array}{l}\text { Growth } \\
\text { factor } \\
\text { relative } \\
\text { to } 2010\end{array}$ & $\begin{array}{l}\text { Million } \\
\text { persons }\end{array}$ & $\begin{array}{l}\text { Growth } \\
\text { factor } \\
\text { relative } \\
\text { to } 2010\end{array}$ & $\begin{array}{l}\text { Million } \\
\text { persons }\end{array}$ & $\begin{array}{l}\text { Growth } \\
\text { factor } \\
\text { relative } \\
\text { to } 2010\end{array}$ \\
\hline 2010 & 63.00 & 1.00 & 63.00 & 1.00 & 63.00 & 1.00 & 63.00 & 1.00 \\
\hline 2020 & 63.82 & 1.01 & 73.62 & 1.17 & 64.23 & 1.02 & 64.28 & 1.02 \\
\hline 2030 & 64.64 & 1.03 & 84.23 & 1.34 & 65.46 & 1.04 & 65.57 & 1.04 \\
\hline 2040 & 65.46 & 1.04 & 75.46 & 1.20 & 66.69 & 1.06 & 66.85 & 1.06 \\
\hline 2050 & 66.28 & 1.05 & 66.69 & 1.06 & 67.91 & 1.08 & 68.13 & 1.08 \\
\hline 2060 & 67.10 & 1.07 & 70.23 & 1.11 & 69.14 & 1.10 & 69.42 & 1.10 \\
\hline 2070 & 67.91 & 1.08 & 73.76 & 1.17 & 70.37 & 1.12 & 70.70 & 1.12 \\
\hline 2080 & 68.73 & 1.09 & 77.30 & 1.23 & 67.91 & 1.08 & 71.98 & 1.14 \\
\hline 2090 & 69.55 & 1.10 & 67.00 & 1.06 & 65.46 & 1.04 & 73.27 & 1.16 \\
\hline 2100 & 70.37 & 1.12 & 56.70 & 0.90 & 63.00 & 1.00 & 74.55 & 1.18 \\
\hline
\end{tabular}


Economic development (GDP)

Table 3.A.3. Annual gross domestic product data for Central Asia used as input in our study.

\begin{tabular}{lllllllll}
\hline Year & SSP1 & & SSP3 & & SSP4 & \multicolumn{3}{l}{ SSP5 } \\
\cline { 2 - 9 } & Billion & Growth & Billion & Growth & Billion & Growth & Billion & Growth \\
& 2005 US & factor & 2005 & factor & 2005 & factor & 2005 US & factor \\
& \$ PPP & relative & US \$ & relative & US \$ & relative & \$ PPP & relative \\
& & to 2010 & PPP & to 2010 & PPP & to 2010 & & to 2010 \\
\hline 2010 & 318.52 & 1.00 & 219.96 & 1.00 & 219.96 & 1.00 & 219.96 & 1.00 \\
2020 & 587.57 & 1.84 & 314.03 & 1.43 & 185.30 & 0.84 & 397.24 & 1.81 \\
2030 & 1035.19 & 3.25 & 348.68 & 1.59 & 171.61 & 0.78 & 710.13 & 3.23 \\
2040 & 1555.25 & 4.88 & 293.74 & 1.34 & 174.55 & 0.79 & 1236.20 & 5.62 \\
2050 & 1974.19 & 6.20 & 277.51 & 1.26 & 177.54 & 0.81 & 1895.43 & 8.62 \\
2060 & 2280.63 & 7.16 & 293.65 & 1.33 & 180.58 & 0.82 & 2555.56 & 11.62 \\
2070 & 2555.54 & 8.02 & 347.56 & 1.58 & 183.67 & 0.84 & 3024.79 & 13.75 \\
2080 & 2722.39 & 8.55 & 335.03 & 1.52 & 186.82 & 0.85 & 3580.18 & 16.28 \\
2090 & 2828.17 & 8.88 & 261.88 & 1.19 & 190.02 & 0.86 & 4237.54 & 19.26 \\
2100 & 2893.74 & 9.08 & 165.25 & 0.75 & 193.27 & 0.88 & 5015.61 & 22.80 \\
\hline
\end{tabular}


Technological development

Table 3.A.4. Management factor data for Central Asia used as input in our study

\begin{tabular}{|c|c|c|c|c|c|c|c|c|c|}
\hline \multirow[t]{2}{*}{ Year } & \multirow[t]{2}{*}{ Category } & \multicolumn{2}{|l|}{ SSP1 } & \multicolumn{2}{|l|}{ SSP3 } & \multicolumn{2}{|c|}{ SSP4 } & \multicolumn{2}{|l|}{ SSP5 } \\
\hline & & MF & $\begin{array}{l}\text { Growth } \\
\text { factor } \\
\text { relative } \\
\text { to } 2010\end{array}$ & & $\begin{array}{l}\text { Growth } \\
\text { factor } \\
\text { relative } \\
\text { to } 2010\end{array}$ & & $\begin{array}{l}\text { Growth } \\
\text { factor } \\
\text { relative } \\
\text { to } 2010\end{array}$ & & $\begin{array}{l}\text { Growth } \\
\text { factor } \\
\text { relative } \\
\text { to } 2010\end{array}$ \\
\hline 2010 & Grass and fodder & 0.06 & 6.20 & 0.06 & 6.20 & 0.06 & 5.70 & 0.06 & 5.70 \\
\hline 2020 & Grass and fodder & 0.06 & 6.20 & 0.07 & 6.60 & 0.05 & 5.45 & 0.05 & 5.37 \\
\hline 2030 & Grass and fodder & 0.06 & 6.40 & 0.07 & 7.00 & 0.05 & 5.26 & 0.05 & 5.15 \\
\hline 2040 & Grass and fodder & 0.06 & 6.20 & 0.07 & 6.90 & 0.05 & 5.07 & 0.05 & 5.04 \\
\hline 2050 & Grass and fodder & 0.06 & 6.00 & 0.07 & 6.80 & 0.05 & 5.01 & 0.05 & 4.92 \\
\hline 2060 & Grass and fodder & 0.06 & 6.00 & 0.07 & 6.76 & 0.05 & 5.04 & 0.05 & 4.88 \\
\hline 2070 & Grass and fodder & 0.06 & 6.00 & 0.07 & 6.72 & 0.05 & 5.10 & 0.05 & 4.83 \\
\hline 2080 & Grass and fodder & 0.06 & 6.00 & 0.07 & 6.68 & 0.05 & 5.16 & 0.05 & 4.80 \\
\hline 2090 & Grass and fodder & 0.06 & 6.00 & 0.07 & 6.64 & 0.05 & 5.21 & 0.05 & 4.84 \\
\hline 2100 & Grass and fodder & 0.06 & 6.00 & 0.07 & 6.60 & 0.05 & 5.27 & 0.05 & 4.88 \\
\hline
\end{tabular}


Land use

Land-use data was derived from a linear regression between grazed biomass and the Mean Species Abundance (MSA) (Petz et al., 2014). This regression is based on the relationship from GLOBIO3 between MSA and livestock grazing intensity for biodiversity estimates (Alkemade et al., 2009).

Table 3.A.5. Grazing intensities per country. Percentages under each category.

\begin{tabular}{llll}
\hline \multirow{2}{*}{ Country } & \multicolumn{2}{l}{ Grazing intensity } & \\
\cline { 2 - 4 } & Low & Moderate & High \\
\hline Kazakhstan & 99.4 & 0.3 & 0.3 \\
Kyrgyzstan & 94.9 & 2.9 & 2.2 \\
Tajikistan & 80.0 & 8.8 & 11.2 \\
Turkmenistan & 80.3 & 9.1 & 10.6 \\
Uzbekistan & 62.1 & 11.7 & 26.1 \\
\hline
\end{tabular}

Low grazing intensity means nearly pristine natural rangeland with marginal grazing-based livestock production system and minimal human intervention and livestock production is far below the natural production capacity; MSA values corresponding to this category range from 0.7-1.0 (high and very high). Moderate grazing intensity means natural rangeland with grazing-based production system, human intervention is restricted to low external input (e.g. manure) and livestock production is slightly below the natural production capacity; MSA values corresponding to this category range from $0.5-0.7$. High grazing intensity means intensively used and (partly) modified natural rangelands with mixed production system, management heavily depends on external inputs and high resource extractions from the original ecosystems and livestock production approaches or exceeds the natural production capacity and grazing is supplemented with feed application; MSA values corresponding to this category range from $0.14-0.5$. 


\section{A.1.2. Climate change}

The effect of climate change on the biodiversity of grasslands was taken from the cause-effect relationship between global mean temperature increase and the relative MSA in GLOBIO3 (Alkemade et al., 2009):

$$
M S A_{C C}=b \cdot G M T I
$$

(Equation A.3.1)

where $\mathrm{MSA}_{\mathrm{CC}}$ is the relative mean abundance of species after climate change, $\mathrm{b}$ is the regression coefficient for a specific biome and GMTI is the global mean temperature increase corresponding to the different climate scenarios.

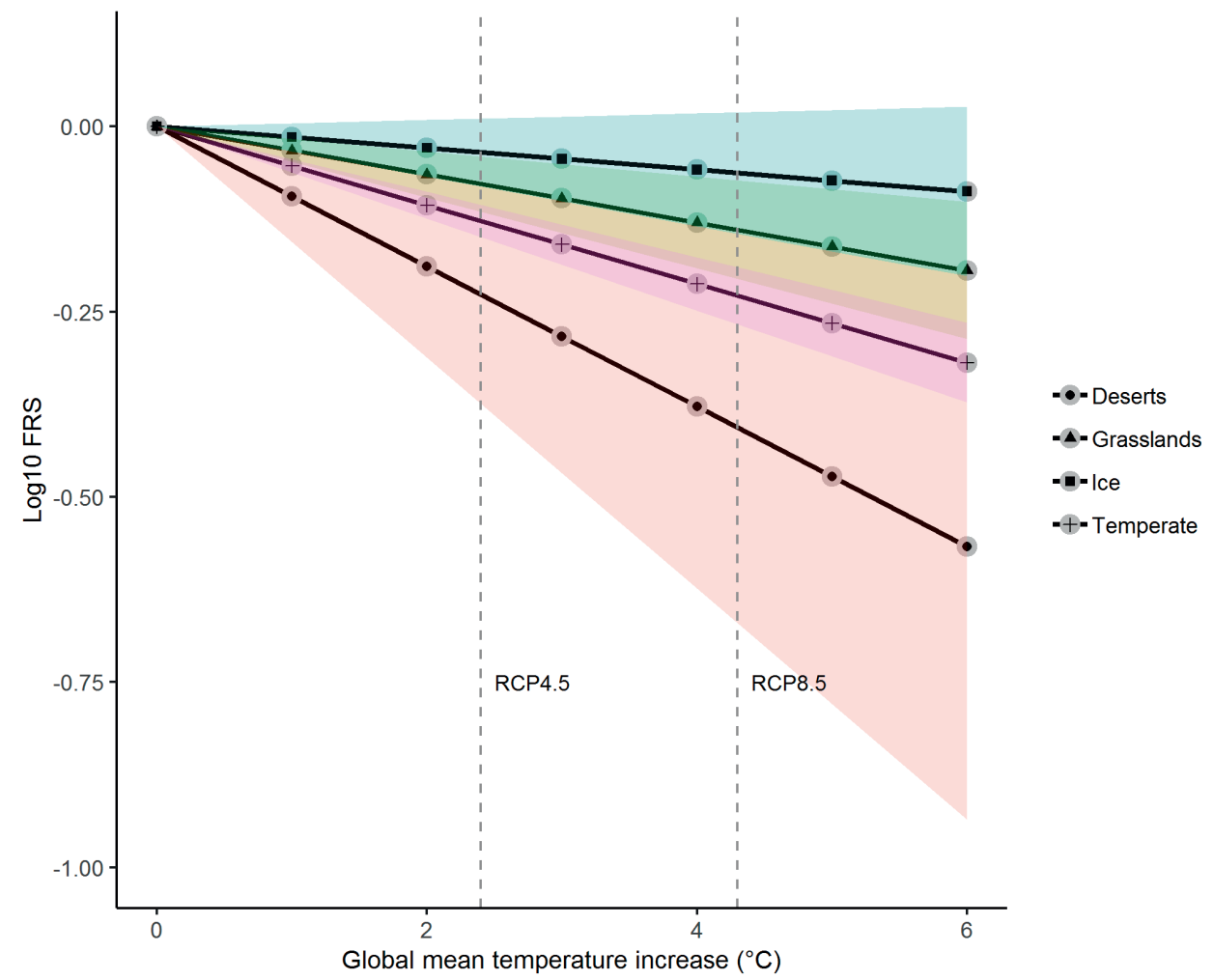

Figure 3.A.1. Projected global mean temperature increase for RCP4.5 and RCP8.5

Data for global mean temperature increase is derived from Table AII.7.5 from the Fifth Assessment Report of the Intergovernmental Panel on Climate Change (IPCC, 2013a). The global mean surface temperature change $\left({ }^{\circ} \mathrm{C}\right)$ relative to $1986-2005$ reference period, thus I added $0.6^{\circ} \mathrm{C}$ to make it relative to pre-industrial level. 


\section{A.2 Land-use scenarios}

\section{Central Asia SSP1 - Sustainability}

Central Asian countries follow a path of sustainable development. Their governments invest in the economy, particularly in the energy sector by promoting green technology development. Central Asian values and commonalities (e.g. culinary traditions) across these countries are also promoted. The agricultural sector intensifies to feed a growing population. The expansion of agricultural land is strongly regulated and countries see high improvements in agricultural productivity. Even though food production is ensured by a strong agricultural sector, the demand for livestock products put grasslands under pressure to an increased grazing intensity. The steady economic growth boosts an increased cooperation between the governments in Central Asia. This cooperation stimulates stability in the region, allowing that most food demand is met through internal supply.

Central Asia SSP3 - Regional Rivalry

Exclusive economic development leads to food insecurity, because priority is given to resource use for export, which supports external competition. The inexistent cooperation between countries limits the economic growth in the region. Land-use change is hardly regulated. The investment possibilities in agricultural technology to improve the productivity of agricultural land are low. Thus agriculture expands under bad irrigation practices deteriorating soil quality in agricultural areas. Livestock production remains far below its actual potential. Difficulties exist to supply food to upstream countries. This leads to an increasing out-migration from the region.

SSP4 - Game of elites

Central Asia is a highly unequal region, with governments gradually increasing their own power by concentrating wealth in the upper class. The elite mostly aim at increasing (economic) power, but there is increasing interest to address certain environmental problems (e.g. water and energy issues). The high level of environmental awareness results in an effective collaboration for the management of protected areas and exploitation of natural resources. The agricultural sector focus on fulfilling the food demand from the population. Agricultural technological development is low and Central Asian countries remain relatively unproductive in agriculture.

SSP5 - Fossil Fuelled Development

The Central Asian governments collaborate closely in order to compete on the global market. Economic growth derived from foreign investments (e.g. oil and gas industries) is very high. Population growth is also high. The agricultural sector sees a good increase in its productivity, partly due to improved technologies within this sector not only to supply the internal food demand but also to take part in international competitive markets. A substantial part of the income from oil and gas industries goes to developing the agricultural sector. Land-use change is, however, incompletely regulated. A more globalized lifestyle is adopted with consumption patterns mirroring those in other parts of the world. 


\section{Chapter 4}

\section{Exploring interactions between climate and land-use change effects on biodiversity}

This chapter is based on:

Nunez, S. and Alkemade, R. Exploring interaction effects between changes in climate and land use on biodiversity. (Submitted) 


\section{Abstract}

Changes in climate and land use are major drivers of biodiversity loss. These drivers likely interact and alter their mutual effects on biodiversity. The interaction mechanisms between these drivers are rarely considered in biodiversity assessments, as only the combined individual effects are reported. In this study, we explored interaction mechanisms that potentially affect species abundance and distribution shifts under climate change. These interactions arise if 1) species adapted to modified landscapes differ in their sensitivity to climate change from species adapted to natural landscapes and if 2) land-use composition restricts climate-change induced dispersal of species in fragmented landscapes. We verified the first condition by performing a meta-analysis of 42 bioclimatic studies on species distributions in landscapes with varying proportions of cropland. We used the Fraction of Remaining Species (FRS) as the effect-size metric in this meta-analysis. We reviewed studies on species' dispersal under climate change in fragmented landscapes to verified the second condition. We found no significant interaction effect for the first condition. This indicates that the influence of global mean temperature increase on the FRS did not change with different cropland levels. No quantitative studies were found to verify the second condition for climate-change induced dispersal of species. These findings emphasize the need to assess interactions between land-use and climatechange effects on biodiversity. Such assessments should also integrate other conditions, such as spatial location, adaptive capacity and time lags. Understanding these interaction mechanisms will help to better project future biodiversity trends and to develop coping strategies for biodiversity conservation. 


\subsection{Introduction}

Changes in land use and climate are major drivers of biodiversity loss in this century (Sala et al., 2000; Pereira et al., 2010; Tittensor et al., 2014). These drivers likely interact and potentially change their mutual effects on biodiversity (Opdam and Wascher, 2004; Oliver and Morecroft, 2014). Interaction mechanisms, however, are rarely considered by studies that assess both land-use and climate-change impacts on biodiversity (Alkemade et al., 2009; Visconti et al., 2015). Such studies commonly use scenario and model analysis that combine bioclimatic and land-use variables to evaluate species and habitat range changes (Jetz et al., 2007; Pompe et al., 2008; Asner et al., 2010; Beltran et al., 2014; Brown et al., 2015; Byrd et al., 2015; Garcia-Valdes et al., 2015; Jantz et al., 2015; Rondinini and Visconti, 2015; Visconti et al., 2015; Newbold, 2018) or models to spatially overlay the individual effects. They solely show combined or additive effects (e.g. Broennimann et al., 2006; Thuiller et al., 2006a; e.g. Mantyka-Pringle et al., 2012).

An interaction occurs when "two explanatory variables have an effect upon a response variable that is greater (synergism) or lesser (antagonism) than the effects expected from the explanatory variables acting independently, i.e. effects are 'multiplicative, ' rather than 'additive"'(Oliver and Morecroft, 2014). Land-use and climatechange effects will likely interact synergistically in several ways with respect to biodiversity. Oliver and Morecroft (2014) described possible interaction mechanisms between these drivers (Table 4.1). Interactions, for example, indicate that species in heavily modified landscapes may respond differently to climate change (i.e. they have higher sensitivity levels) than species in pristine landscapes. Modified landscapes suggest fragmented or converted areas that reduce available species' habitats and increase distances between remaining habitat patches (Fahrig, 2003). Interaction mechanisms (1) and (2) arise if species that are adapted to modified landscapes (e.g. cropland areas), differ in their sensitivity to climate change from species that are adapted to natural landscapes. Mechanism (3) occurs if modified landscapes (e.g. fragmented habitats) restrict climate induced dispersal of species. These interactions mechanisms, however, are poorly understood due to limited data availability and methodological constraints (Brook et al., 2008; de Chazal and Rounsevell, 2009).

These expected consequences can further elucidate on mechanisms to help validate the interaction effect on biodiversity (Table 4.1). The expected consequence for each mechanism can be verified using studies that assessed climate-change impacts, such as bioclimatic envelope modelling studies. These studies relate the geographical distribution of species to climatic variables so to enable projections of distributions under future climate-change scenarios (i.e. species distribution shifts; Heikkinen et al., 2006). Under climate change, the new climate envelope of a species may not only overlap with the old one. This depends on the time span and intensity of climate change, but also have multiple new land uses that influence the species' response to climate change. Such land-use change may include fragmented or converted land that will likely constitute a land barrier for dispersal. The interaction mechanisms (1) and (2) are expected to occur in this remaining, 
overlapping area with suitable climate, whereas mechanism (3) occurs in the new climate envelope. A thorough understanding of species' dispersal under projected land-use and climate changes is missing (Wiens et al., 2009). Regardless of species' dispersal being widely acknowledged in projecting geographic distribution of species (Thomas, 2000; Guisan and Thuiller, 2005; Midgley et al., 2006; Thuiller et al., 2008) how fragmented habitats hinder dispersal in response to climate change and how does the interaction mechanism on species dispersal actually function, remains unclear.

Table 4.1. Interaction mechanisms between the predictor variables 'land-use' and 'climate-change' effects.

Interaction mechanisms

(Oliver and Morecroft, 2014)

(1) Global mean temperature increase and the presence of conspecifics in modified habitats determine species' birth rates or extinction risk

(2) Global mean temperature increase and modified landscapes impose genetic variation on populations

(3) Modified landscapes affect species' dispersal in response to global mean temperature increase
Expected consequences

Potential test

(1) Declining species abundance in converted landscapes (e.g. a large proportion of cropland) is expected to affect species fecundity, which is highly dependent on temperature

(2) Genetic erosion resulting from converted landscapes is expected to reduce species' capacity to adapt to global mean temperature increase (3) Fragmented habitats restrict climate induced dispersal of species, making dispersal more difficult than in less fragmented, continuous landscapes
Fraction of Remaining

Species

Fraction of Remaining Species

Qualitative assessment

Our study aimed to explore interaction mechanisms between land-use and climate-change effects on biodiversity. For this purpose, we identified an expected consequence for each mechanism and validated the interactions with evidence from a literature review of studies that used bioclimatic models and climate-change scenarios in modified landscapes under different dispersal assumptions. We focused on intensively managed landscapes (i.e. croplands) where the occurrence of original species declines. We estimated the proportion of cropland area from these studies to indicate land use. We performed a meta-analysis of these studies and used the Fraction of Remaining Species (FRS) to indicate biodiversity decrease within the study region in the mechanisms (1) and (2). The interaction mechanisms occur if the FRS in large cropland areas is significantly different from the FRS in areas with small cropland. For mechanism (3), we qualitatively reviewed the body of literature to find scientific evidence on the impact of fragmentation on climate induced dispersal of species. By validating these expected consequences, we achieved a deeper understanding of drivers' interactions that can be used in future biodiversity assessments. 


\subsection{Methodology}

\subsubsection{Interaction mechanisms}

We identified expected consequences that elucidate interaction effects between land-use and climate-change effects in each mechanism. These expected consequences indicate that species' responses to climate change vary if the landscape changes (i.e. different proportions of cropland area). Expected consequences (1) and (2) (Table 4.1) indicate ecological processes that result in declining populations if land-use and climate-change effects interact synergistically upon species. Such processes are likely to occur in area with still suitable climates. Thus, declining populations can be evidenced with meta-analysis from bioclimatic modelling studies and the FRS indicator (Nunez et al., 2019). FRS measures the occurrence of a given number of species at a certain location before and after projected climate change. Expected consequence (3) indicates species' responses to climate change in fragmented landscapes and thus assumes that species have the ability to disperse. This mechanism occurs in the new climate envelope and can be evidenced with a review and analysis from the literature on the impact of fragmentation on climate induced dispersal.

\subsubsection{Literature review}

We conducted a literature review to find evidence on the interaction mechanism expected consequences. We queried the ISI Web-of-Science to identify bioclimatic model and scenario studies that (1) assessed the effects of global mean temperature increase on terrestrial species and (2) included cropland as one of the land-use types in their study area. We combined keywords into a search string to conduct the review: [(climat* SAME change*) OR (temperature SAME change*) OR (temperature SAME increase) OR (global SAME warming) OR (climat* SAME warming)] AND [(biodiversity) OR (diversity SAME species) OR (species SAME richness*) OR (species SAME distribution*) OR (species SAME abundance*) OR (species SAME occurrence*) OR (species SAME turnover) OR (species SAME loss*) OR (species SAME gain*) OR (species SAME composition) OR (species SAME assemblage*)]. We provide detailed information on the selection process in Nunez et al. (2019). We consolidated a database from all data extracted from the selected studies to perform meta-analysis on species distributions in landscapes with varying proportions of cropland. These data included study location, used global mean temperature increase, land use/land cover, number of species in the original and the projected climate situations, dispersal capacities, terrestrial biomes, taxonomic group, land extension and the spatial resolution. We also searched and qualitatively assessed studies on the impact of habitat fragmentation and climate change on species dispersal. 


\subsubsection{Projected land-use and climate changes}

Land use was indicated by the percentage of cropland in the original study areas. Croplands areas are intensively managed. We estimated cropland percentage using the land-cover maps from the European Space Agency (ESA) Climate Change Initiative (CCI) (Defourny et al., 2014) between 1992-2015 in ArcGIS 10.2.1. We also explored the land-use related assumptions made in the original studies to determine the applied level of change. Land-use change was classified as very low, low, moderate, high and very high, corresponding to $0-5 \%, 0-10 \%, 10-15 \%, 15-20 \%$ and $>20 \%$ of cropland (i.e. cropland level) respectively. Climate change in these studies was indicated by their scenario's global mean temperature increase.

\subsubsection{Meta-analysis}

We estimated the overall reduction in species abundance in converted landscapes with high cropland levels compared to low cropland levels with a mixed-effects meta-analysis. As an effect size, we calculated the FRS. We used the package 'Metafor' in the R-3.2.2 software (Viechtbauer, 2010) and the $r m a . m v()$ function assuming independence between the effect size and sampling variance. We built mixed-effects models with random-effects structures to examine variations in the relationship between the FRS and both cropland level and global mean temperature increase. We included firstorder interaction terms and second-order interaction terms to account for variation in the slope of the relationship between global mean temperature increases and cropland levels. We compared the models using the Bayesian Information Criterion (BIC).

\subsection{Results}

The systematic literature review yielded more than 100 studies that contained relevant titles and abstracts. Of these, 42 studies corresponded to the selected criteria for data extraction (Appendix 4.A.1). Some geographical bias was found since most of the studies were from either Western Europe (19) or Africa (10), while a few studies from the Western Hemisphere (7), Oceania (4) and China (2). We collated these studies, including 219 effect sizes (Table 4.A.1 in Appendix 4.A.2). These effect sizes corresponded to very low (53), low (54), moderate (31), high (12) and very high (69) cropland level. These studies covered a wide range of temperature increase up to $5^{\circ} \mathrm{C}$.

For the meta-analysis, we retained the random-effect structure $[1 \mid$ Study $+1 \mid$ Extent $]$ with the lowest Bayesian Information Criterion (BIC = -197.67) (Table 4.A.2 in Appendix 4.A.3). The second order interaction term (i.e. global mean temperature increase ${ }^{2}$.cropland level) did not improve the model fit and was therefore dismissed. The final model used was global mean temperature increase + cropland level + global mean temperature increase $\bullet$ cropland level. 
The results from the mixed random-effects model for mechanisms (1) and (2) indicated that global mean temperature increase is a good, significant model predictor for biodiversity decline (Table 4.2). However, the model results did not reveal significant interactions between cropland level and global mean temperature increase, indicating that the influence of all cropland levels on the FRS did not change with global mean temperature increase. A model using global mean temperature increase as the only predictor variable was significant (Table 4.3). This suggests that temperature had a strong influence on the FRS. Contrary, a model using cropland level as the only predictor variable was less significant, indicating that land use did not influence the FRS.

Our analysis of global mean temperature increase indicated a general decrease of FRS. Both estimates for temperature in Tables 4.2 and 4.3 resulted in FRS reduced by $14 \%$ (95\% Confidence Interval: $8-18 \%)$ and $12 \%$ (95\% Confidence Interval: 9-15\%), respectively.

Table 4.2. Results of the mixed-random effects model with FRS as response variable, global mean temperature increase, land use with the five levels (i.e. very low, low, moderate, high and very high) and interaction terms as predictor variables. The land-use level 'high' was used as intercept.

\begin{tabular}{|c|c|c|c|c|c|c|}
\hline Fixed effects & Estimate & SE & $p$-value & $z$-value & $\mathrm{CI}(\mathrm{lb})$ & $\mathrm{CI}(\mathrm{ub})$ \\
\hline Intercept & 0.0309 & 0.0591 & 0.6009 & 0.5230 & -0.0849 & 0.1467 \\
\hline Temperature $^{\mathrm{a}}$ & -0.0628 & 0.0129 & $<.0001$ & -4.8506 & -0.0881 & $-0.0374 * * *$ \\
\hline Land use $\mathrm{b}^{\mathrm{b}}$ & -0.0568 & 0.1026 & 0.5800 & -0.5533 & -0.2579 & 0.1443 \\
\hline Very low & -0.0342 & 0.0998 & 0.732 & -0.3424 & -0.2299 & 0.1615 \\
\hline Low & -0.0783 & 0.1137 & 0.4912 & -0.6885 & -0.3011 & 0.1446 \\
\hline Moderate & 0.0678 & 0.0676 & 0.3165 & 1.0017 & -0.0648 & 0.2003 \\
\hline Very high & -0.0019 & 0.0310 & 0.9510 & -0.0615 & -0.0627 & 0.0589 \\
\hline Temperature ${ }^{\mathrm{a}}$ : Land use very low & 0.0440 & 0.0293 & 0.1325 & 1.5043 & -0.0133 & 0.1014 \\
\hline Temperature $^{\mathrm{a}}$ : Land use low & 0.0548 & 0.0385 & 0.1548 & 1.4229 & -0.0207 & 0.1303 \\
\hline Temperature ${ }^{\mathrm{a}}$ : Land use moderate & 0.0071 & 0.0154 & 0.6461 & 0.4592 & -0.0231 & 0.0372 \\
\hline Temperature ${ }^{\text {a. }}$ Land use very high & 0.0309 & 0.0591 & 0.6009 & 0.5230 & -0.0849 & 0.1467 \\
\hline
\end{tabular}

${ }^{a}$ Global mean temperature increase

${ }^{\mathrm{b}}$ Cropland level

Significance codes: 0 (***) 0.001 ‘**) 0.01 ‘*’ 0.05 '? 0.1 ' ' 1 
Table 4.3. Results of the mixed-random effects model with FRS as response variable and global mean temperature increase and cropland level as predictor variables.

\begin{tabular}{|c|c|c|c|c|c|c|}
\hline Fixed effects & Estimate & SE & $p$-value & $z$-value & CI (lb) & $\mathrm{CI}(\mathrm{ub})$ \\
\hline \multicolumn{7}{|c|}{ Temperature $^{\mathrm{a}}$ (only predictor) } \\
\hline Intercept & 0.0670 & 0.0260 & 0.0090 & 2.6290 & 0.0170 & $0.1170 * *$ \\
\hline Temperature & -0.0560 & 0.0070 & $<.0001$ & -8.413 & -0.069 & $-0.0430 * * *$ \\
\hline \multicolumn{7}{|c|}{ Land $\mathrm{use}^{\mathrm{b}}$ (only predictor) } \\
\hline Intercept & -0.1524 & 0.0412 & 0.0002 & -3.7025 & -0.233 & -0.0717 \\
\hline Very low & -0.0377 & 0.0534 & 0.4798 & -0.7066 & -0.1424 & 0.0669 \\
\hline Low & 0.0989 & 0.0534 & 0.0637 & 1.8542 & -0.0056 & 0.2035 \\
\hline Moderate & 0.0908 & 0.0491 & 0.0641 & 1.8512 & -0.0053 & 0.1870 . \\
\hline Very high & 0.0831 & 0.0451 & 0.0655 & 1.8420 & -0.0053 & 0.1716 . \\
\hline
\end{tabular}

${ }^{a}$ Global mean temperature increase

${ }^{\mathrm{b}}$ Cropland level

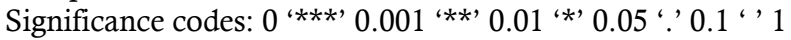

We did not find any study that quantified climate induced dispersal of species in fragmented landscapes to validate mechanism (3). Most studies we found focused on either single impacts of fragmentation (Thomas, 2000; Fahrig, 2003) or climate change (e.g. Araujo et al., 2004; McClean et al., 2005; Thuiller et al., 2005; Lawler et al., 2006; Malcolm et al., 2006; Thuiller et al., 2006a; Thuiller et al., 2006b; Alkemade et al., 2011; Walther and van Niekerk, 2015), assessed single species responses (Bennie et al., 2013) or assessed past dispersal trends (Schwartz, 1993).

\subsection{Discussion and conclusions}

Based on the expected consequences for the studied interaction mechanisms, we found no significant interaction effect between current levels of cropland and global mean temperature increases. This means that the FRS of areas with large proportion of cropland (i.e. intensively managed) did not significantly differ from those areas with a low cropland proportion (i.e. close to pristine, natural areas). This finding excluded interaction effects between global mean temperature increases and landscapes that are modified by other land uses than cropping. We, however, did not find any study that assessed interactions between land-use and climate-change effects. This makes assessing the interaction mechanisms in other modified landscapes unattainable.

The few studies for the mechanism that affected species' dispersal in response to global mean temperature increases indicated that species' dispersal ability is closely related to the landscape structure and level of fragmentation (e.g. Wiens et al., 2009; McGuire et al., 2016) and thus only species with unlimited dispersal capacities can establish remote populations in fragmented landscapes (Opdam and Wascher, 2004). However, the actual mechanisms could not be properly validated with the available evidence. Thus, the increasing landscape fragmentation will likely hinder dispersal species' distribution shifts in response to climate change. 
Previous studies that assessed additive land-use and climate change effects (Mantyka-Pringle et al., 2012; Newbold, 2018), indicated that changes in biodiversity are likely to vary spatially. For example, tropical forests are predicted to experience larger losses of biodiversity under projected climate change (Higgins, 2007; Asner et al., 2010) than temperate regions (Garcia-Valdes et al., 2015). Temperate regions have already undergone some of the largest biodiversity losses from land use over centuries and thus the climate effect is predicted to be small (Newbold, 2018). Our analysis, however, showed that man-made modified landscapes did not lead to different species responses to climate change. The species responses to climate change are likely most sensitive in deserts, temperate forests and shrublands, regardless of land use (Nunez et al., 2019). This spatial variation was not considered by the majority of studies that assessed combined effects of these drivers in multiple land-cover types simultaneously (e.g. Heubes et al., 2013; Jantz et al., 2015; Riordan et al., 2015). While most studies that assessed changes in climate and land use, found an increased combined effect (e.g. Jetz et al., 2007; Pompe et al., 2008), a few showed that the combined effect did not always have the strongest negative impact on biodiversity (Hoiss et al., 2013; Brown et al., 2015).

Our assessment approach of interaction mechanisms included factors which involve large uncertainties, such as species' dispersal capacities (Hellmann et al., 2016). Other inherent factors affecting interaction mechanisms include species adaptive capacity (Dawson et al., 2011) and the more gradual and long-term effects of climate change (Nunez et al., 2019) and changing atmospheric $\mathrm{CO}_{2}$ concentrations. Such factors also involve large uncertainties in projecting species distributions in response to climate change, and need to be included when assessing these mechanisms. Furthermore, future assessments should consider the physiological characteristics of species and the time lags resulting from the expected changes in both land use and climate. Although future projections of land-use and climate changes are challenging to create, our study serves as a starting point to introduce more elements to assess such changes and their interactions mechanisms.

The lack of integration of land-use and climate-change effects in mechanisms implies that the projected biodiversity responses may inadequately inform biodiversity managers and policy makers on possibilities to develop appropriate biodiversity-conservation measures (de Chazal and Rounsevell, 2009; Mantyka-Pringle et al., 2012; Heubes et al., 2013; Brown et al., 2015; MantykaPringle et al., 2015; Segan et al., 2016). This knowledge gap, however, can certainly be explored using the expected consequences to validate the interaction effects (c.f. Table 4.1). Our study supports the notion that the biodiversity-loss predictions for most species will approximate reality by acknowledging the interaction effects. This can become an important element in developing strategies for conservation of biodiversity. 


\subsection{Acknowledgements}

We acknowledge the "Impacts and Risks from High-End Scenarios: Strategies for Innovative Solutions (IMPRESSIONS)" project (Grant Agreement 603416) from the EU FP7 programme for providing financial support to conduct this research. 


\section{A Appendix}

\section{A.1 List of selected studies}

Study ID Study

RQ1-430 Araujo, M., Cabeza, M., Thuiller, W., Hannah, L., Williams, P. (2004). Would climate change drive species out of reserves? An assessment of existing reserveselection methods. Global Change Biology 10, 1618-1626

RQ1-623 Bakkenes, M., Eickhout, B., Alkemade, R. (2006). Impacts of different climate stabilisation scenarios on plant species in Europe. Global Environmental Change $16,19-28$

RQ1-291 Bakkenes, M., Alkemade, J., Ihle, F., Leemans, R., Latour, J. (2002). Assessing effects of forecasted climate change on the diversity and distribution of European higher plants for 2050. Global Change Biology 8, 390-407

RQ1-3751 Benito, B., Lorite, J., Perez-Perez, R., Gomez-Aparicio, L., Penas, J. (2014). Forecasting plant range collapse in a mediterranean hotspot: when dispersal uncertainties matter. Diversity and Distributions 20, 72-83

RQ1-172 Box, E., Crumpacker, D., Hardin, E. (1999). Predicted effects climatic change on distribution of ecologically important native tree and shrub species in Florida. Climatic Change 41, 213-248

RQ1-57 Brereton, R., Bennett, S., Mansergh, I. (1995). Enhanced greenhouse climatechange and its potential effect on selected fauna of South-Eastern Australia - a trend analysis. Biological Conservation 72, 339-354

RQ1-627 Broennimann, O., Thuiller, W., Hughes, G., Midgley, G.F., Alkemade, J., Guisan, A. (2006). Do geographic distribution, niche property and life form explain plants' vulnerability to global change? Global Change Biology 12, 1079-1093

RQ1-4627 Costion, C., Simpson, L., Pert, P., Carlsen, M., Kress, W.J., Crayn, D. (2015). Will tropical mountaintop plant species survive climate change? Identifying key knowledge gaps using species distribution modelling in Australia. Biological Conservation 191, 322-330

RQ1-2054 Engler, R. et al. (2011). 21st century climate change threatens mountain flora unequally across Europe. Global Change Biology 17, 2330-2341

RQ1-1279 Engler, R., Randin, C., Vittoz, P., Czaka, T., Beniston, M., Zimmermann, N., Guisan, A. (2009). Predicting future distributions of mountain plants under climate change: does dispersal capacity matter? Ecography 32, 34-45

RQ1-309 Erasmus, B.F.N., Van Jaarsveld, A.S., Chown, S.L., Kshatriya, M., Wessels, K.J. (2002). Vulnerability of South African animal taxa to climate change. Global Change Biology 8, 679-693

RQ1-1018 Fitzpatrick, M., Gove, A., Sanders, N., Dunn, R. (2008). Climate change, plant migration, and range collapse in a global biodiversity hotspot: the Banksia (Proteaceae) of Western Australia. Global Change Biology 14, 1337-1352

RQ1-3215 Goodenough, A., Hart, A. (2013). Correlates of vulnerability to climate-induced distribution changes in European avifauna: habitat, migration and endemism. Climatic Change 118, 659-669

RQ1-3254 Heubes, J. et al. (2013). The projected impact of climate and land use change on plant diversity: An example from West Africa. Journal of Arid Environments 96, $48-54$ 
RQ1-2639 Huntley, B., Barnard, P. (2012). Potential impacts of climatic change on southern African birds of fynbos and grassland biodiversity hotspots. Diversity and Distributions 18, 769-781

RQ1-65 Huntley, B., Berry, P.M., Cramer, W., McDonald, A.P. (1995). Modelling present and potential future ranges of some European higher plants using climate response surfaces. Journal of Biogeography 22, 967-1001

RQ1-1047 Huntley, B., Collingham, Y., Willis, S., Green, R. (2008). Potential Impacts of Climatic Change on European Breeding Birds. Plos One 3

RQ1-680 Lawler, J., White, D., Neilson, R., Blaustein, A. (2006). Predicting climate-induced range shifts: model differences and model reliability. Global Change Biology 12 , 1568-1584

RQ1-3345 Lemes, P., Loyola, R.D. (2013). Accommodating Species Climate-Forced Dispersal and Uncertainties in Spatial Conservation Planning. Plos One 8

RQ1-852 Levinsky, I., Skov, F., Svenning, J.-C., Rahbek, C. (2007). Potential impacts of climate change on the distributions and diversity patterns of European mammals. Biodiversity and Conservation 16, 3803-3816

RQ1-1729 Li, R., Tian, H., Li, X. (2010). Climate change induced range shifts of Galliformes in China. Integrative Zoology 5, 154-163

RQ1-1071 Loarie, S., Carter, B., Hayhoe, K., McMahon, S., Moe, R., Knight, C., Ackerly, D. (2008). Climate Change and the Future of California's Endemic Flora. Plos One 3

RQ1-1073 Luoto, M., Heikkinen, R. (2008). Disregarding topographical heterogeneity biases species turnover assessments based on bioclimatic models. Global Change Biology $14,483-494$

RQ1-2206 Maiorano, L. et al. (2011). The future of terrestrial mammals in the Mediterranean basin under climate change. Philosophical Transactions of the Royal Society BBiological Sciences 366, 2681-2692

RQ1-4980 Meller, L., Thuiller, W., Pironon, S., Barbet-Massin, M., Hof, A., Cabeza, M. (2015). Balance between climate change mitigation benefits and land use impacts of bioenergy: conservation implications for European birds. Global Change Biology Bioenergy 7, 741-751

RQ1-339 Midgley, G., Hannah, L., Millar, D., Rutherford, M., Powrie, L. (2002). Assessing the vulnerability of species richness to anthropogenic climate change in a biodiversity hotspot. Global Ecology and Biogeography 11, 445-451

RQ1-396 Midgley, G., Hannah, L., Millar, D., Thuiller, W., Booth, A. (2003). Developing regional and species-level assessments of climate change impacts on biodiversity in the Cape Floristic Region. Biological Conservation 112, 87-97

RQ1-702 Midgley, G., Hughes, G., Thuiller, W., Rebelo, A. (2006). Migration rate limitations on climate change-induced range shifts in Cape Proteaceae. Diversity and Distributions 12, 555-562

RQ1-480 Miles, L., Grainger, A., Phillips, O. (2004). The impact of global climate change on tropical forest biodiversity in Amazonia. Global Ecology and Biogeography 13, 553-565

RQ1-714 Ohlemuller, R., Gritti, E., Sykes, M., Thomas, C. (2006). Quantifying components of risk for European woody species under climate change. Global Change Biology 12, 1788-1799

RQ1-345 Peterson, A., Ortega-Huerta, M., Bartley, J., Sanchez-Cordero, V., Soberon, J., Buddemeier, R., Stockwell, D. (2002). Future projections for Mexican faunas under global climate change scenarios. Nature 416, 626-629

RQ1-1126 Pompe, S., Hanspach, J., Badeck, F., Klotz, S., Thuiller, W., Kuehn, I. (2008). Climate and land use change impacts on plant distributions in Germany. Biology Letters 4, 564-567

RQ1-414 Siqueira, M.F.d., Peterson, A.T. (2003). Consequences of global climate change for geographic distributions of cerrado tree species. Biota Neotropica 3, 1-14 
RQ1-496 Skov, F., Svenning, J. (2004). Potential impact of climatic change on the distribution of forest herbs in Europe. Ecography 27, 366-380

RQ1-601 Thuiller, W., Lavorel, S., Araujo, M.B., Sykes, M.T., Prentice, I.C. (2005). Climate change threats to plant diversity in Europe. Proceedings of the National Academy of Sciences of the United States of America 102, 8245-8250

RQ1-756 Thuiller, W., Midgley, G.F., Hughes, G.O., Bomhard, B., Drew, G., Rutherford, M.C., Woodward, F.I. (2006b). Endemic species and ecosystem sensitivity to climate change in Namibia. Global Change Biology 12, 759-776

RQ1-754 Thuiller, W., Broennimann, O., Hughes, G., Alkemade, J.R.M., Midgley, G.F., Corsi, F. (2006a). Vulnerability of African mammals to anthropogenic climate change under conservative land transformation assumptions. Global Change Biology 12, 424-440

RQ1-1174 Virkkala, R., Heikkinen, R., Leikola, N., Luoto, M. (2008). Projected large-scale range reductions of northern-boreal land bird species due to climate change. Biological Conservation 141, 1343-1353

RQ1-1889 Virkkala, R., Marmion, M., Heikkinen, R.K., Thuiller, W., Luoto, M. (2010). Predicting range shifts of northern bird species: Influence of modelling technique and topography. Acta Oecologica-International Journal of Ecology 36, 269-281

RQ1-5291 Walther, B., van Niekerk, A. (2015). Effects of climate change on species turnover and body mass frequency distributions of South African bird communities. African Journal of Ecology 53, 25-35

RQ1-1914 Yates, C., McNeill, A., Elith, J., Midgley, G. (2010). Assessing the impacts of climate change and land transformation on Banksia in the South West Australian Floristic Region. Diversity and Distributions 16, 187-201

RQ1-4465 Zhang, M.-G., Zhou, Z.-K., Chen, W.-Y., Cannon, C.H., Raes, N., Slik, J.W.F. (2014). Major declines of woody plant species ranges under climate change in Yunnan, China. Diversity and Distributions 20, 405-415 


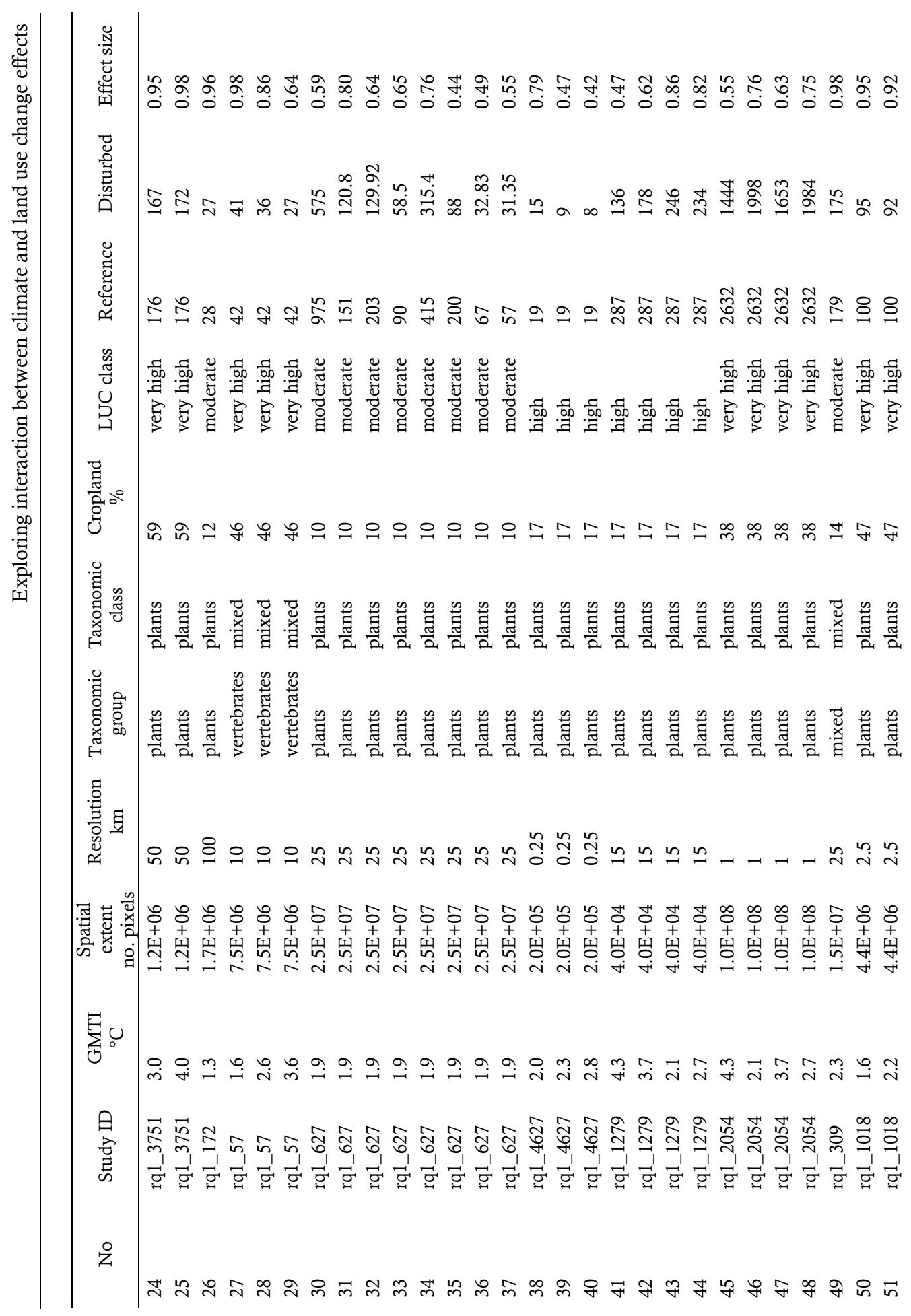




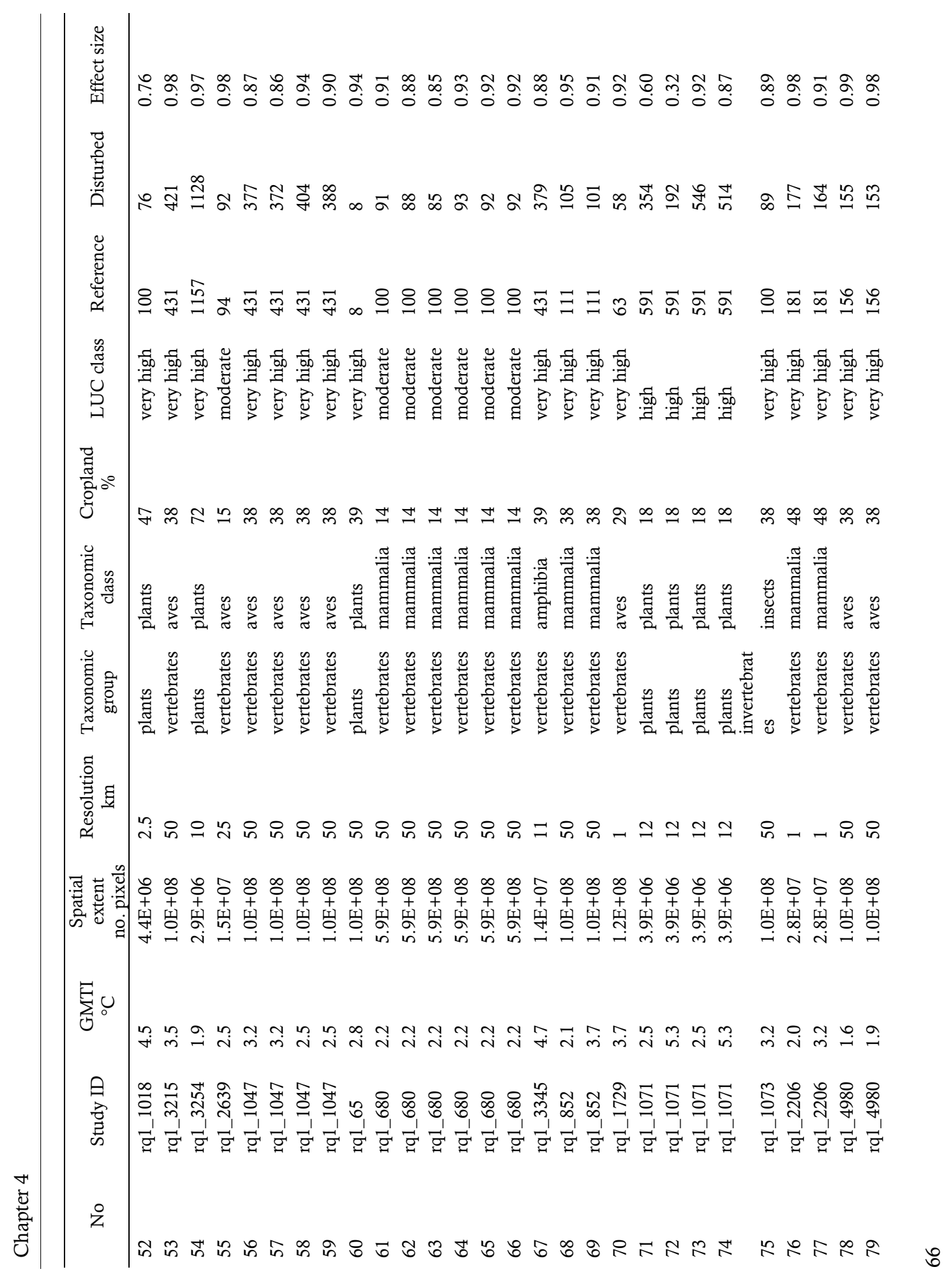




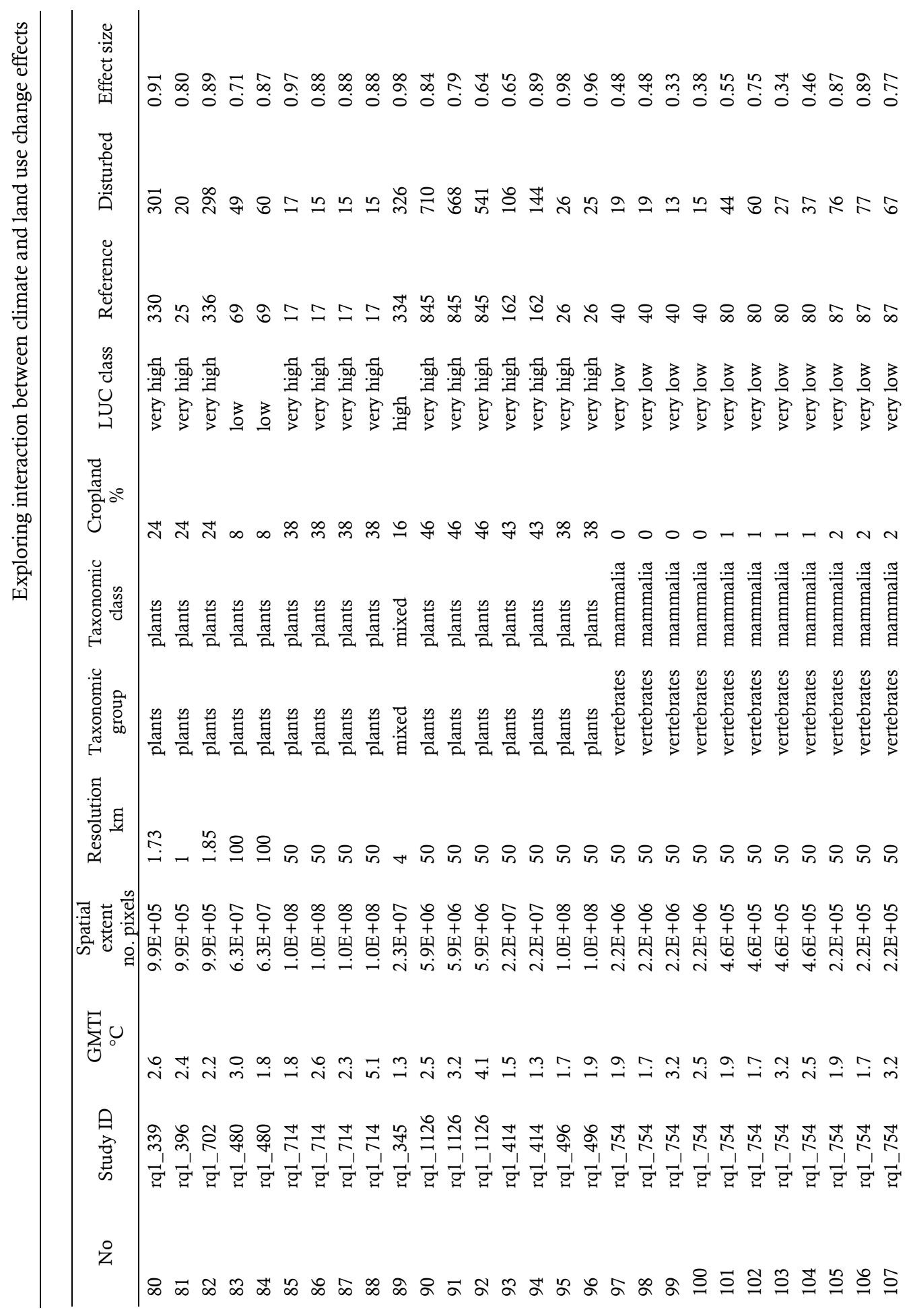




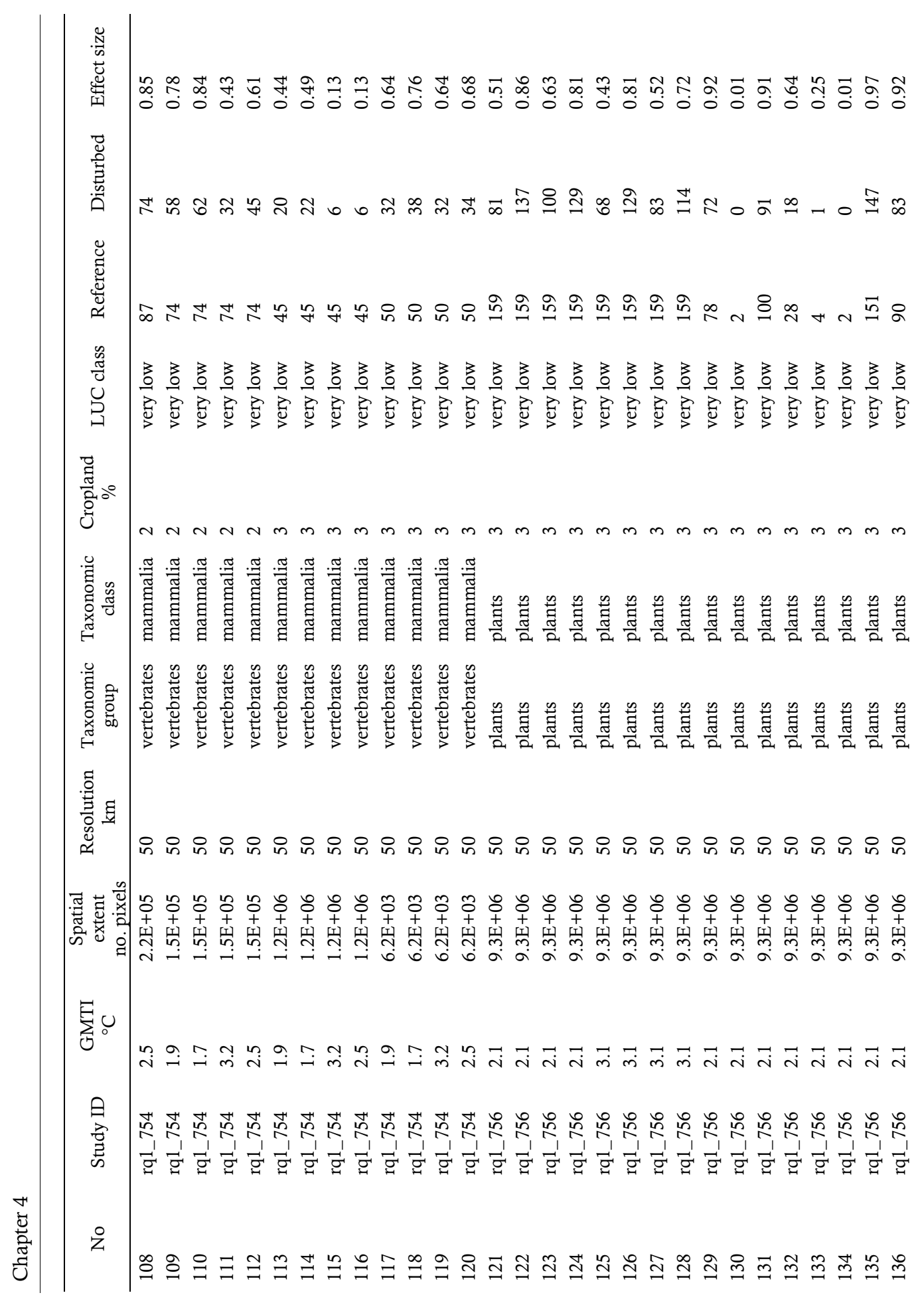




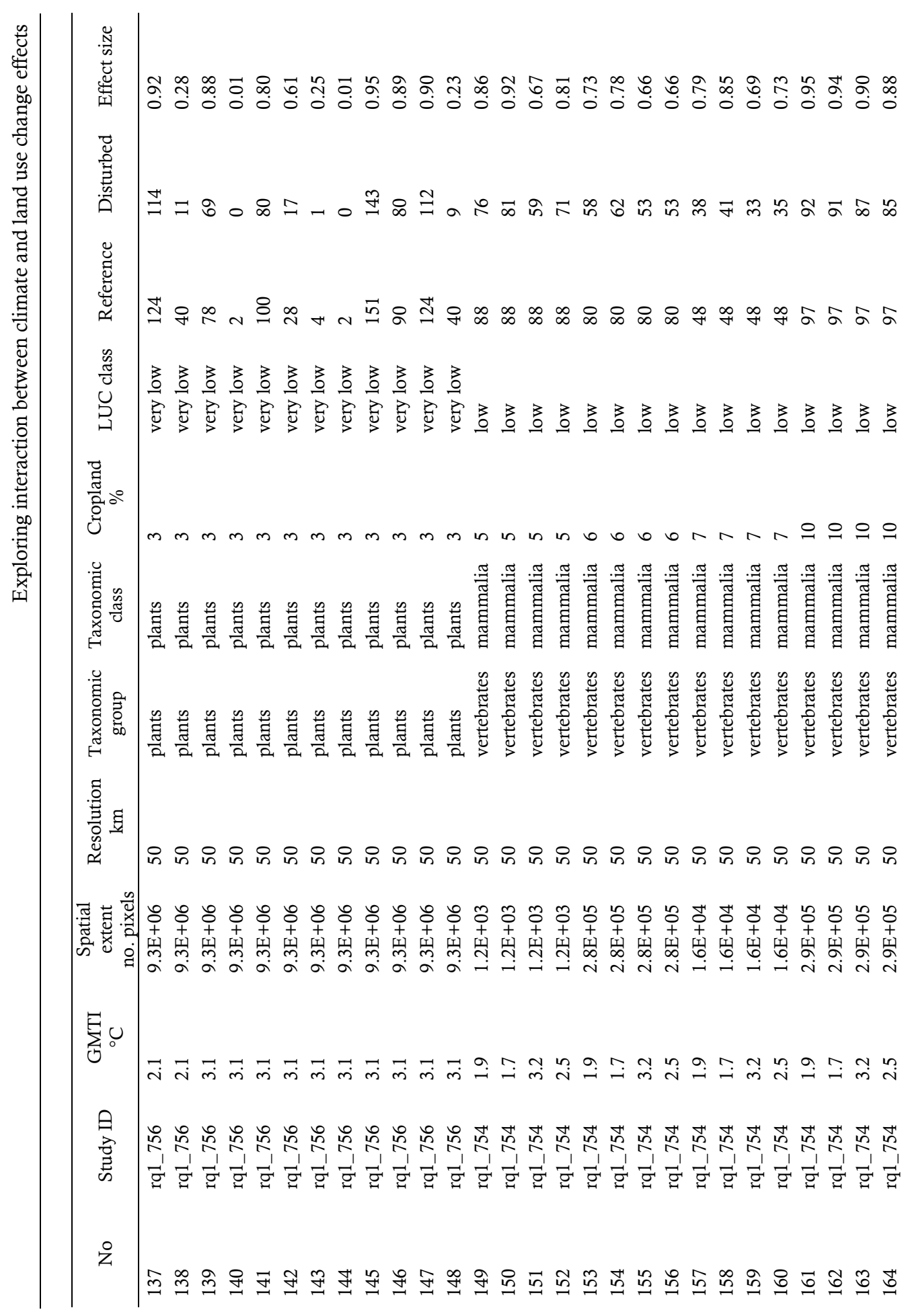




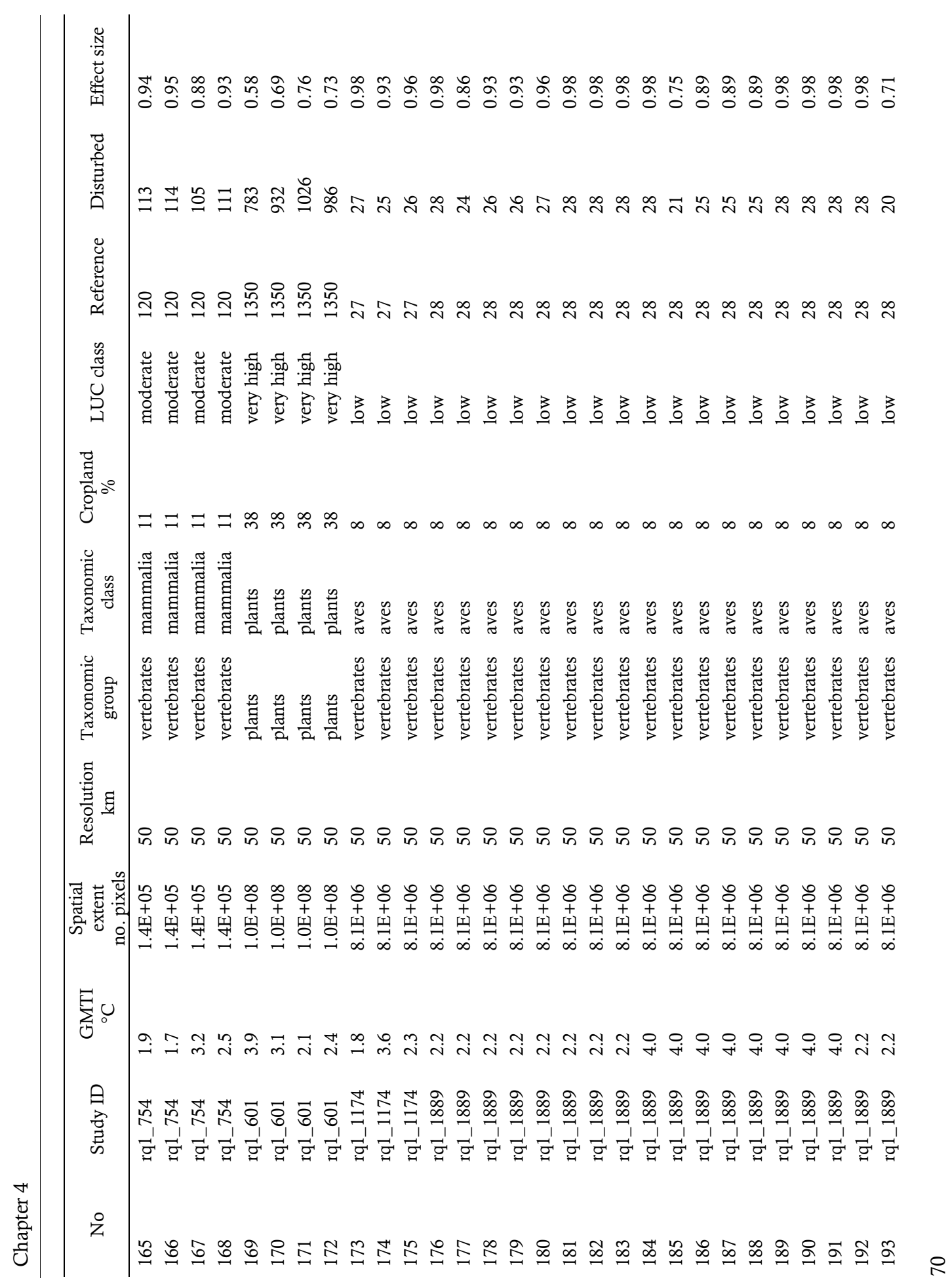




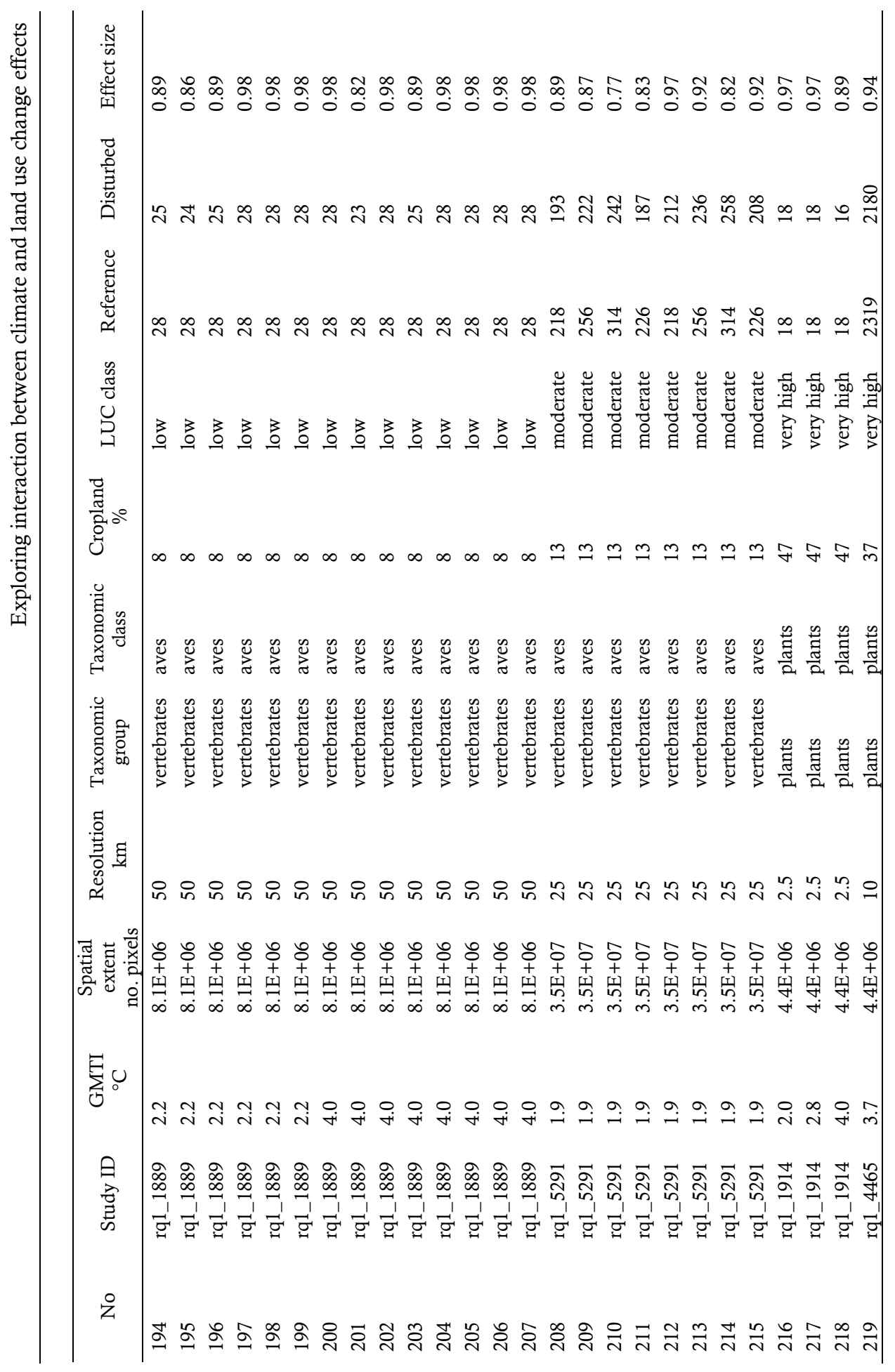




\section{A.3 Results of random effect models}

Table 4.A.2. Random-effect results for the used model.

\begin{tabular}{ll}
\hline Random-effect models & BIC \\
\hline 1 | 1 & -29.14 \\
1 | Study & -197.34 \\
1 | Resolution & -88.39 \\
1 | Extent & -132.87 \\
1 | Study + 1 | Resolution & -192.00 \\
1 | Study + 1 | Extent & -197.67 \\
1 | Resolution + 1 | Extent & -144.00 \\
1 | Study + 1 | Resolution +1 | Extent & -192.33 \\
\hline
\end{tabular}




\section{Chapter 5}

\section{Assessing implications of land-based mitigation on biodiversity}

This chapter is based on:

Nunez, S., Alkemade, R. and Verboom, J. Assessing implications of land-based mitigation on biodiversity. (Under review) 


\section{Abstract}

The Paris Agreement to keep global temperature increase to well-below $2^{\circ} \mathrm{C}$ and to pursue efforts to limit it to $1.5^{\circ} \mathrm{C}$ requires to formulate ambitious climate-change mitigation scenarios to reduce $\mathrm{CO}_{2}$ emissions and to enhance carbon sequestration. These scenarios likely require significant land-use change. Failing to mitigate climate change will result in an unprecedented warming with significant biodiversity loss. The mitigation potential on land is high. However, how land-based mitigation options potentially affect biodiversity is poorly understood. Some land-based mitigation options could also counter the biodiversity loss. Here we reviewed the recently scientific literature to assess twenty land-based mitigation options that are implemented in different mitigation pathways to comply with the Paris Agreement for their biodiversity impacts by using the Mean Species Abundance $\left(\mathrm{MSA}_{\mathrm{LU}}\right)$ indicator for land use. We showed the likely land-use transition and potential $\mathrm{MSA}_{\mathrm{LU}}$ changes for each option, compared their carbon sequestration opportunities ( $\mathrm{tC}$ per ha) and assessed the resulting biodiversity change in two case scenarios. Our results showed that most options benefit biodiversity. Reforestation of cultivated and managed areas together with restoration of wetlands deliver the largest $\mathrm{MSA}_{\mathrm{LU}}$ increases, if land is allowed to reach a mature state over time. A quarter of the assessed options, including intensification of agricultural areas and bioenergy with carbon capture and storage, decreased $\mathrm{MSA}_{\mathrm{LU}}$. Options, such as afforestation and reduced deforestation, either positively or negatively affected $\mathrm{MSA}_{\mathrm{LU}}$. This depends on their local implementation and adopted forest-conservation schemes. Comparing the different options showed that avoiding deforestation by implementing agroforestry at the expense of pastures delivered both the largest $\mathrm{MSA}_{\mathrm{LU}}$ increases and the highest carbon sequestration opportunities. However, agroforestry that leads to deforestation, enhanced carbon sequestration slightly but with a marginal $\mathrm{MSA}_{\mathrm{LU}}$ increase. This stresses the importance of avoiding forest conversion. Our study advances the understanding on current and future benefits and adverse effects of land-based mitigation options on biodiversity. This certainly helps biodiversity conservation and determines the regions with large land-based mitigation potential. 


\subsection{Introduction}

Changes in climate are projected to further adversely affect biodiversity this century (Thomas et al., 2004; Pereira et al., 2010; Urban, 2015), including changes in species composition, distribution and extinctions, and in ecosystem structure and functioning. These impacts increase in extent and magnitude in the worst-case climate-change scenarios (Bellard et al., 2012). Global efforts to combat climate change are thus required to limit these adverse effects on biodiversity. These efforts include a global policy response to keep global temperature increase well-below $2^{\circ} \mathrm{C}$ and to pursue efforts to limit it to $1.5^{\circ} \mathrm{C}$ (i.e. The Paris Agreement; UNFCCC, 2015). These ambitious targets require, among others, further stringent climate-change mitigation to reduce $\mathrm{CO}_{2}$ emissions in different sectors and regions. Without such additional efforts to reduce $\mathrm{CO}_{2}$ emissions beyond those in place today, global emissions growth is expected to persist and the global mean temperature increase will likely range from $3.7^{\circ} \mathrm{C}$ to $4.8^{\circ} \mathrm{C}$ above pre-industrial levels by the end of the century (IPCC, 2014b; IPCC, 2018). Such temperature increase will unprecedentedly affect biodiversity (IPCC, 2014b; IPCC, 2018), as already at moderate warming (i.e. $<2^{\circ} \mathrm{C}$ ) significant change in species and ecosystems are expected. These changes are shown in a recent meta-analysis of the climate-change effects on biodiversity, where $14 \%$ and $17 \%$ of the originally occurring species and habitats, respectively, could be locally lost between $1^{\circ} \mathrm{C}$ and $2^{\circ} \mathrm{C}$ increase (Nunez et al., 2019). Grave impacts on biodiversity could potentially occur with $3^{\circ} \mathrm{C}$ increase as over half of all ecosystem likely shift biome and a quarter (25\%) of the world's nature reserves consequently would not comply to their original conservation purposes any more (Leemans and Halpin, 1992).

The IPCC special report on Global Warming of $1.5^{\circ} \mathrm{C}$ (IPCC, 2018) and recent climate-change mitigation assessments (Griscom et al., 2017; Rogelj et al., 2018a; van Vuuren et al., 2018) reported mitigation pathways consistent with the Paris Agreement (i.e. to achieve $\mathrm{CO}_{2}$ emissions decline by about $45 \%$ from 2010 levels by 2030 for $1.5^{\circ} \mathrm{C}$ and $25 \%$ for warming to below $2^{\circ} \mathrm{C}$ ). These pathways require broad transformations in energy, industry, transport, building and land-use sectors and thus include a range of potential mitigation options, which largely rely on Carbon Dioxide Removal (CDR). The mitigation potential of the land-use sector is high with a likely contribution between $20 \%$ to $60 \%$ of total cumulative abatement to 2030 and $15 \%$ to $40 \%$ to 2100 (Smith et al., 2014). This contribution mainly comes from Bioenergy with Carbon Capture and Storage (BECCS) and removals in the Agriculture, Forestry and Other Land Use (AFOLU) sector (IPCC, 2018). AFOLU options are, for example, afforestation, reforestation, land restoration and soil carbon sequestration. Projecting changes in land use is central to understand the ways in which land-based mitigation options will counter or promote biodiversity conservation efforts (Rudel et al., 2005). How these land-based mitigation options will affect biodiversity is, however, poorly understood.

Priority areas to establish land-based mitigation will not always reflect biodiversity values (Miles and Kapos, 2008). Thus land-based mitigation options are unlikely to benefit all ecosystems equally and in some cases may be even harmful. For example, replacing degraded tropical forest by 
monoculture plantations can enhance terrestrial carbon storage in these ecosystems but the biodiversity value of monocultures is per definition low (Lal, 2008). Alternative options that promote degraded land to return to previous conditions, can be more beneficial to biodiversity. The challenge to identify and to select areas of high value for both climate change mitigation and biodiversity conservation urgently remains.

Our study aimed to assess the implications of land-based mitigation options on biodiversity. To this end, we identified mitigation options in the land-use sector that can substantially reduce and capture $\mathrm{CO}_{2}$ emissions. These are AFOLU-related CDR options implemented in different climate change mitigation scenarios (IPCC, 2018). These options could largely contribute to achieve the $1.5^{\circ} \mathrm{C}$ target from the Paris Agreement. We reviewed the scientific and policy literature on these different mitigation options and their land-use impacts to indicate whether they preserve, increase or deteriorate biodiversity. We used the Mean Species Abundance for land use (MSA; Alkemade et al., 2009) to quantify these impacts in a case scenario. As no single mitigation option sufficiently addresses climate change, we developed an approach to compare the carbon (C) storage ( $\mathrm{tC}$ per ha) on land and the resulting biodiversity change of different mitigation options. This approach can be used to asses local, regional or global impacts and it shows baseline scenarios with underlying assumptions that negatively affect biodiversity, and alternative mitigation scenarios that, on the contrary, will likely benefit biodiversity. Our results and findings can be used for current and future biodiversity conservation in regions with presumably large land-based mitigation potential.

\subsection{Methods}

\subsubsection{Selecting land-based mitigation options}

Our study focused on climate-change mitigation options in the land sector. We first searched climate-change mitigation options that are consistent with scenarios limiting global temperature increases to $1.5^{\circ} \mathrm{C}$. These options were reported in Chapter 2 of the IPCC's Special Report on Global Warming of $1.5^{\circ} \mathrm{C}$ (Rogelj et al., 2018b). Subsequently, we selected mitigation options that were implemented in agriculture and forestry and that endured changes in land management practices and technology. These are AFOLU-related CDR land-based mitigation options that will generally require greater land area under more stringent, ambitious mitigation pathways (Harper et al., 2018). We finally reviewed additional climate change mitigation studies in the context of the Paris Agreement to identify other potential land-based mitigation options (e.g. Harper et al., 2018; Rogelj et al., 2018a; van Vuuren et al., 2018). 


\subsubsection{Determining changes in land use}

We identified the potential land-use changes of each land-based mitigation option. To do this, we reviewed the scientific and policy literature of climate-change mitigation studies that assessed one or more selected options. These studies indicated the original land cover and/or use where the option is implemented. Land-based mitigation, which depends on the assumptions from the climatechange mitigation scenario in the original study, will likely result in land transition to achieve a substantial mitigation. In principle, this transition indicates land-cover and/or land-use change, but it can also indicate the same land cover and/or use with altered properties (e.g. land-use intensification). This land transition (or intensification) needed to achieve a substantial climatechange mitigation, was also indicated in the original study. We recorded the evidence on land changes from these studies to determine the initial and final land cover and/or use. This evidence helped to assess implications of these changes on biodiversity.

\subsubsection{Assessing potential biodiversity change}

To assess potential biodiversity change, we assigned $\mathrm{MSA}_{\mathrm{LU}}$ values (Table 5.A.1 in Appendix 5.A) to both the initial and final land cover and/or use for each mitigation option. The MSA $\mathrm{LU}_{\mathrm{LU}}$ is an indicator that expresses the mean abundance of original species in disturbed conditions relative to their abundance in undisturbed habitats, as an indicator of the degree to which an ecosystem is intact (Alkemade et al., 2009; Alkemade et al., 2013). This indicator ranges between 0 in areas where original biodiversity has completely disappeared (e.g. from land transition due to climate-change mitigation), to 1 in areas where species composition and abundance is fully original (i.e. pristine). Relationships between $\mathrm{MSA}_{\mathrm{LU}}$ and land use have been quantified in the GLOBIO model (Alkemade et al., 2009; Schipper et al., 2016). These relationships are based on studies and published datasets that reported species composition in a given type and intensity of land use and an undisturbed reference situation. Based on the $\mathrm{MSA}_{\mathrm{LU}}$ values, we determined whether biodiversity increases, decreases or remains unchanged under the assumption of each mitigation option.

We further quantified biodiversity changes in a specific case-scenario analysis by comparing alternative mitigation scenarios that implement one or more land-based mitigation options, with corresponding baseline scenarios that assumed no mitigation. We showed two cases. The first baseline scenario (BAU-1) assumed a continuation of current trends in underlying socio-economic drivers, such as population, technological and economic growth and consumption preferences. As a result, the demand for crop production (e.g. food and feed) increased (e.g. double) (Stehfest et al., 2019). This demand was realised by increasing cropland area onto forest areas. This resulted in deforestation. Alternative scenarios to BAU-1 offered the opportunity to assess avoid deforestation while fulfilling such crop demand. This was done by expanding cropland areas elsewhere (i.e. avoiding deforestation) in combination with other mitigation options. The second baseline scenario 
(BAU-2) also assumed that crop production doubles. This demand was realised by restoring degraded land into cropland. Alternative scenarios to BAU-2 assessed other possible restoration options.

Biodiversity changes that resulted from land-use transitions in each mitigation option were related to the carbon-storage ( $C S$; tC per ha) potential of the land cover and/or use where these options occur (Figure 5.1). We did this by calculating the total carbon storage $C S_{t}$ for all baseline and alternative scenarios (Equation 5.1).

$$
C S_{t, s}=\sum C S_{i} \cdot \mathrm{a}
$$

(Equation 5.1)

where $C S_{t, s,}$ is the total carbon stored in scenario $s, C S_{i}$ is the carbon storage capacity of land cover and/or land use $i$ and $a$ is the land cover and/or land use area (e.g. hectares). $a$ and $i$ vary depending on the mitigation option assumed in alternative scenarios. Subsequently, we calculated the absolute change between each alternative scenario and its corresponding baseline (Equation 5.2).

$$
\Delta \mathrm{CS}_{t}=C S_{t, s x}-C S_{t, s b}
$$

(Equation 5.2)

where $\Delta C S_{t}$ is the change in carbon stored between two scenarios, $C S_{t, s x}$ is the carbon stored in alternative scenario $x$ and $C S_{t, s b}$ is the carbon stored in baseline scenario $b$. These carbon-storage estimates were derived from scientific evidence in the reviewed studies (Table 5.A.2 in Appendix 5.A). We focused on the carbon storage of forests, croplands, pastures, peatlands and degraded lands.

Similarly, the MSA $\mathrm{LU}_{\mathrm{LU}}$ values for both the initial and final land cover and/or use for each scenario were compared (Equation 5.3).

$$
\Delta \mathrm{MSA}_{L U}=M S A_{L U, s x}-M S A_{L U, s b} \quad \text { Equation 5.3) }
$$

where $\triangle M S A_{L U}$ is the change in $\mathrm{MSA}_{L U}$ between two scenarios, $M S A_{L U s x}$ is the MSA $\mathrm{A}_{\mathrm{LU}}$ value alternative scenario $x$ and $C S_{t, s b}$ is the carbon stored in baseline scenario $b$. We assumed that degraded lands, which have not been assigned $\mathrm{MSA}_{L U}$ estimates yet, were in early stages of secondary vegetation. The MSA $A_{L U}$ of degraded land was estimated to be 0.4 . This was based on estimates for species richness in young secondary vegetation (Newbold et al., 2015). The $\mathrm{MSA}_{\mathrm{LU}}$ for agricultural land was also assigned 0.4 (Alkemade et al., 2009). Our comparison determined which option(s) obtained the largest carbon storage with the largest benefit to biodiversity. 


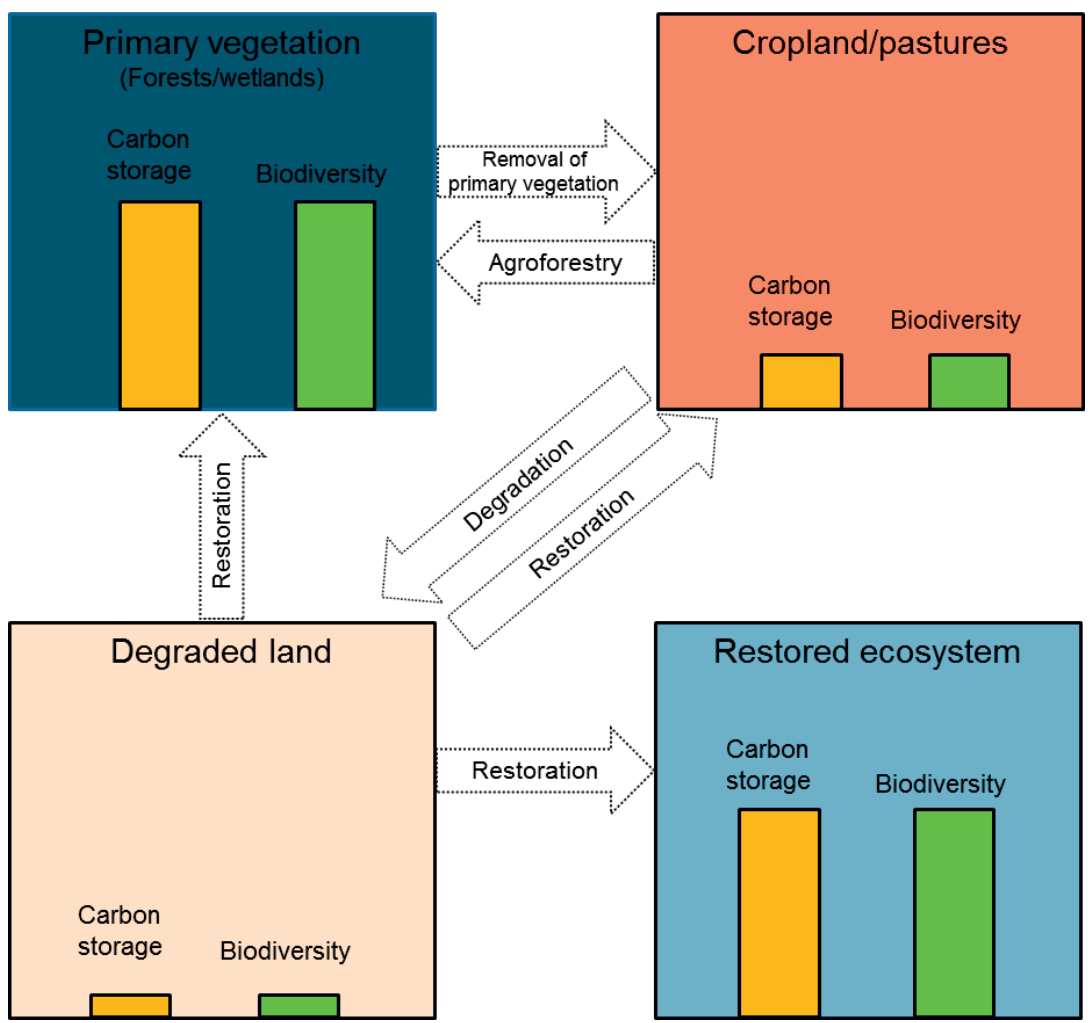

Figure 5.1. Examples of mitigation options in different land cover and/or use. Potential carbon storage CS (tC per ha) and $\mathrm{MSA}_{\mathrm{LU}}$ of land cover and/or use.

\subsection{Results}

We assessed twenty land-based mitigation options from AFOLU-related CDR. These options are presented in Table 5.1 together with their potential land cover and/or land use transitions. We found that more than half of these options could potentially benefit biodiversity by either maintaining (i.e. no change) or increasing the MSA value of the land cover and/or use where they occur. Mitigation options that increased its MSA included forest-related activities (i.e. forest restoration and afforestation), agriculture-related activities (i.e. agroforestry, urban and peri-urban agriculture and forestry and conservation agriculture) and degraded land-restoration options (i.e. reduced land degradation and restoration of wetlands). Restoration options included, for example, transitions from cleared or degraded land into primary vegetation. Land transitions into primary vegetation were indicated with MSA of 1 . This means that those areas could potentially reach an original (or possibly natural) state over time. Thus, restoration of wetlands offered a large potential to increase biodiversity. 
Land-based mitigation options in the livestock sector, such as grazing and manure management, did not require land-use change. Similarly, lands where silviculture, fire-management and pest-control options occurred did not transition into different land cover and/or use, and thus their MSA remained unchanged. These options helped to conserve forest structure and composition.

The mitigation options that reduced the MSA of land cover and/or use included changes in agricultural practices to enhance soil carbon, which increased agricultural productivity. Such BECCS options are one of the largest contributors to remove emissions from the atmosphere during this century (Harper et al., 2018). Reduced deforestation and avoided forest conversion benefited biodiversity through maintaining the forest-land cover. However, they can also be detrimental to biodiversity as these options could lead to large biodiversity declines through 'leakage' issues if forest conservation is not adequately implemented (e.g. leakage effects into non-forest ecosystems) (Aukland et al., 2003; Popp et al., 2014). 


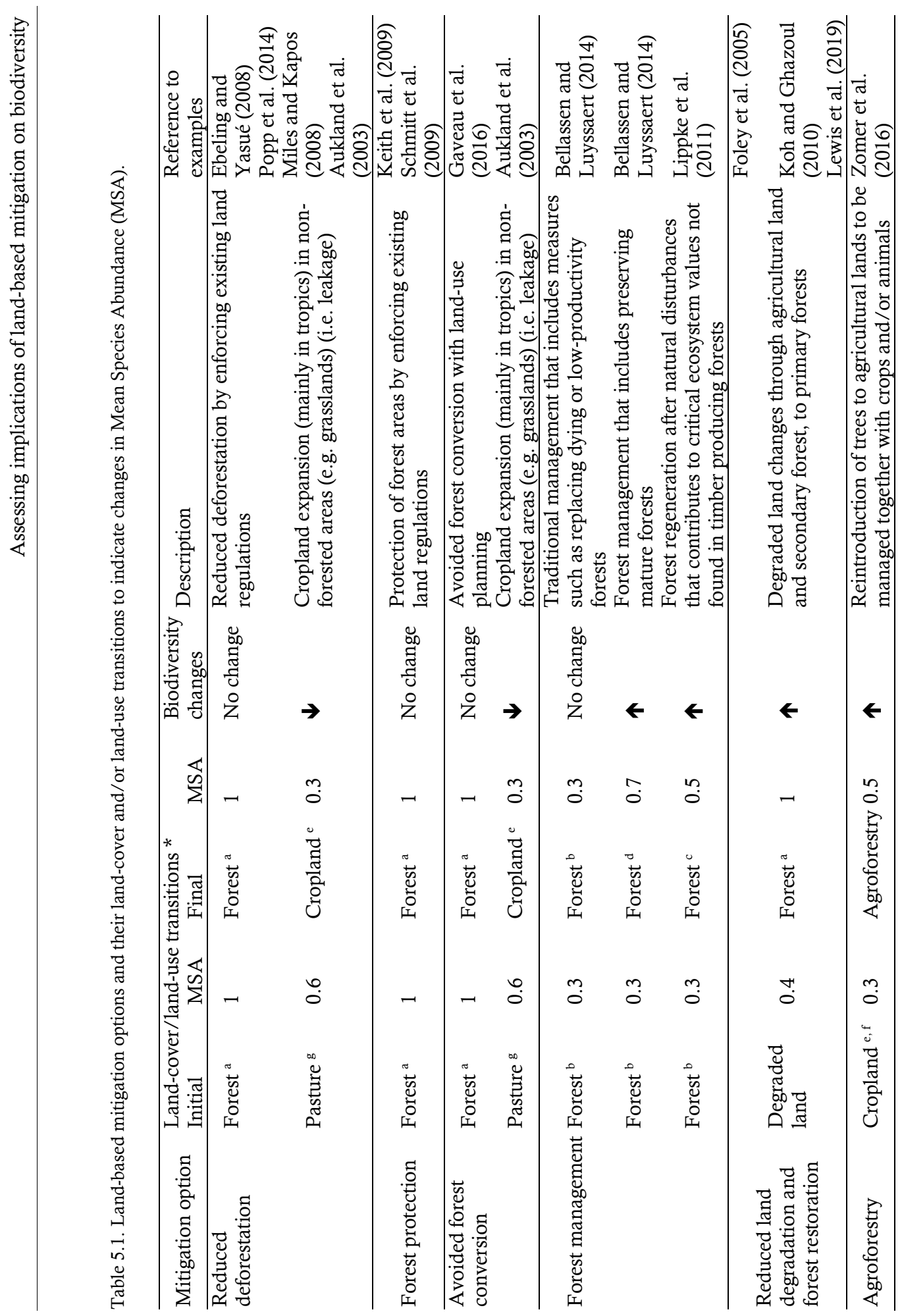




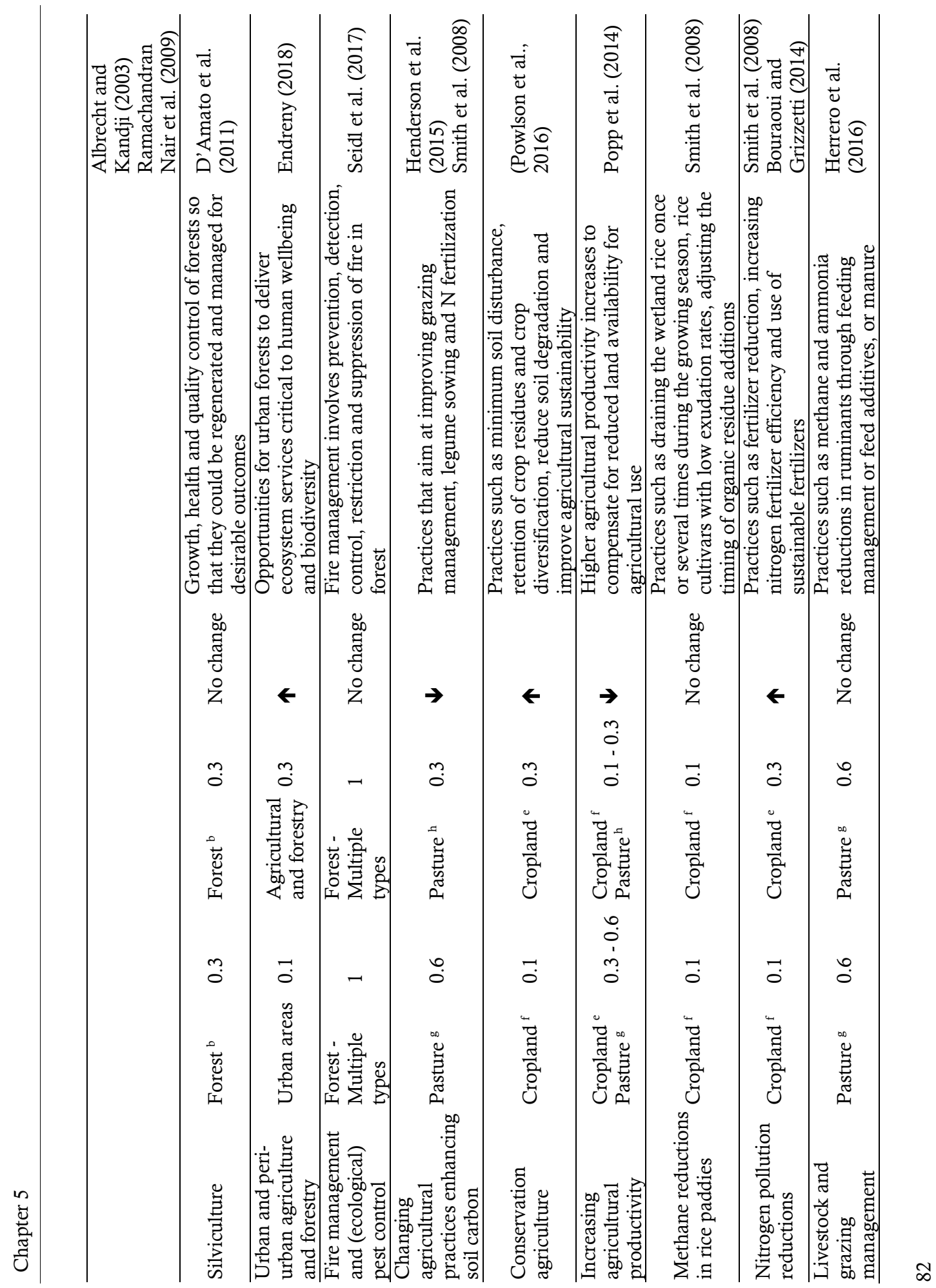




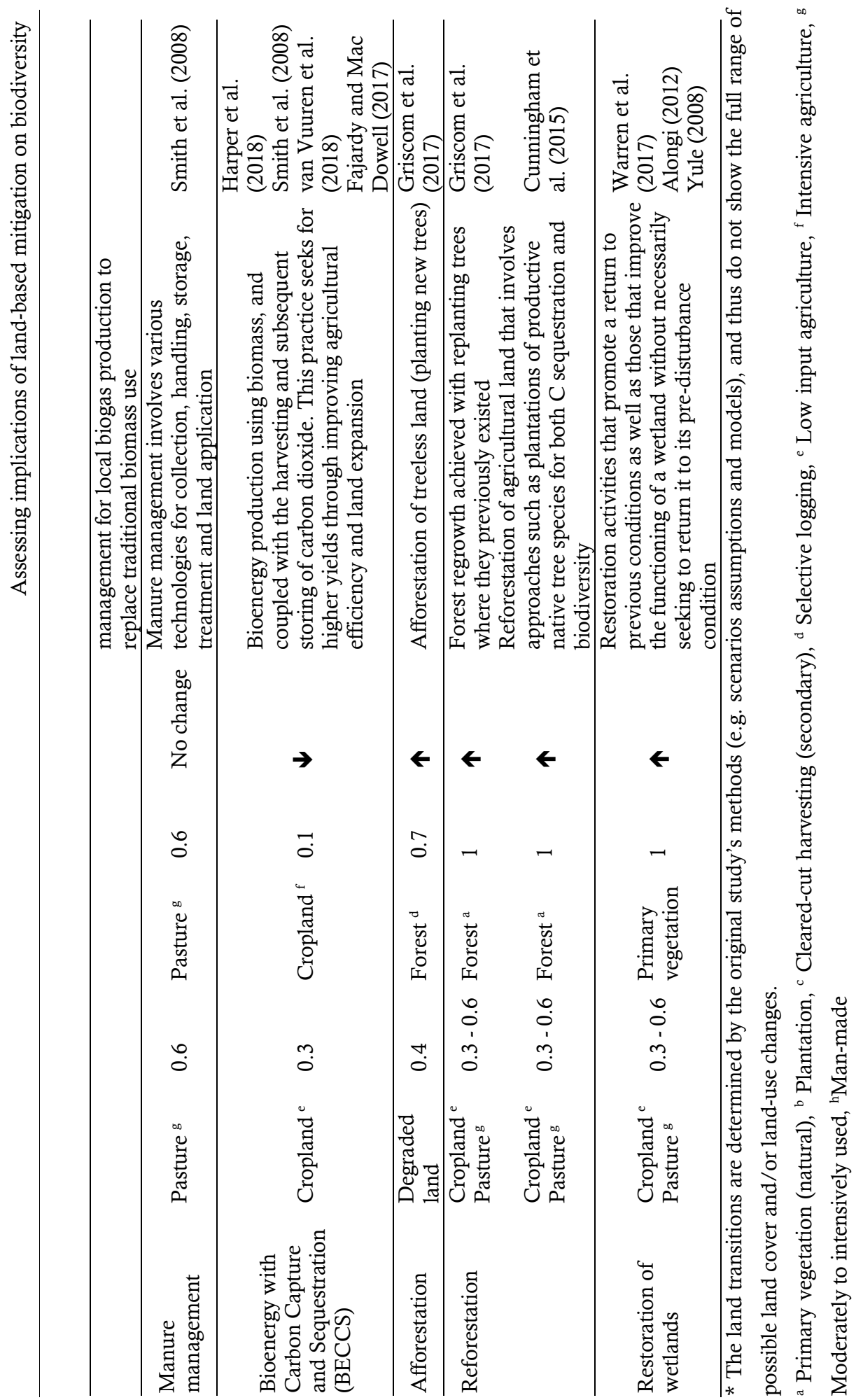


The scenario comparison showed the baseline and alternative mitigation scenarios for two cases: deforestation and restoration of degraded land into cropland (Table 5.2 and Tables 5.A.3 and 5.A.4 in Appendix 5.A). In the first case, we defined six alternative scenarios that contain options from Table 5.1, with the underlying assumption that food production doubles while avoiding deforestation (Table 5.2). These alternative scenarios showed different combinations of land-based mitigation in different land-cover/land-use types. We compared these scenarios with the baseline to determine which option derives both the highest carbon storage and MSA $\mathrm{LU}_{\mathrm{LU}}$ We found that agroforestry is by far the best option to avoid deforestation while maintaining, and even increasing, cropland production at the expense of pastures (Figure 5.2a). Both carbon storage and MSA $\mathrm{Lu}_{\mathrm{LU}}$ increased under this alternative option by $3185 \mathrm{MtC}$ and by $7 \%$, respectively. The least desired option to avoid deforestation was agroforestry at the expense of forest. The second case showed minimal benefits on biodiversity when land is restored into cropland (Figure 5.2b). We found that restoration of peatlands is the best alternative option for degraded land. 
Table 5.2. Alternative mitigation scenarios for i) BAU-1 'deforestation' and ii) BAU-2 'restoration of degraded land into cropland'. The main underlying assumption for these scenarios is that cropland area increases to achieve the desired food production.

\begin{tabular}{ll}
\hline Scenarios & Short description \\
\hline BAU 1 - deforestation & $\begin{array}{l}\text { BAU shows continuation of current socio-economic trends that } \\
\text { result in increasing food demand. Cropland area expands onto } \\
\text { forest (deforestation) }\end{array}$
\end{tabular}

Alternative 1 - cropland Food production increases by cultivating the established units of area increases at the expense of pastures ${ }^{\mathrm{a}}$ cropland and additional units of pasture (i.e. moderately used rangelands; Alkemade et al., 2013)

Alternative 2 - food Food production increases as technological change will result in production increases due to increasing crop productivity (yield/ha) (Stehfest et al., 2014), and agricultural productivity therefore no additional land is required increase per area Alternative 3 - agroforestry Reintroduction of trees to agricultural land will decrease land at the expense of forest productivity by $25 \%$. To compensate the productivity loss and to achieve the desired level of food production, cropland area increases at the expense of forest area

Alternative 4 - agroforestry Reintroduction of trees to agricultural land will decrease land at the expense of pastures ${ }^{\mathrm{a}}$ productivity by $25 \%$. To compensate the productivity loss and to achieve the desired level of food production, cropland area increases at the expense of pastures

Alternative 5 - agroforestry Reintroduction of trees to agricultural land will decrease land with agricultural productivity by $25 \%$. By means of technological change, productivity increase at the agricultural productivity increases in the agroforestry system. To expense of forest compensate the original productivity loss and to achieve the desired level of food production, cropland area increases at the expense of forest area

Alternative 6 - agroforestry Reintroduction of trees to agricultural land will decrease cropland with agricultural productivity by $25 \%$. By means of technological change, productivity increase at the agricultural productivity increases in the agroforestry system. To expense of pastures $^{\mathrm{a}} \quad$ compensate the original productivity loss and to achieve the desired level of food production, cropland area increases at the expense of pastures area

\section{BAU 1 - restoration of Degraded land is restored into cropland to fulfil food demand} degraded land 1- forest increase Degraded land is restored into forest

2- peatland increase Degraded land is restored into peatlands

3- pastures increase ${ }^{\text {a }} \quad$ Degraded land is restored into pastures

${ }^{a}$ This option assumes large changes in human diet (e.g. less meat) and consumption patterns that likely reduce the demand for livestock products. 


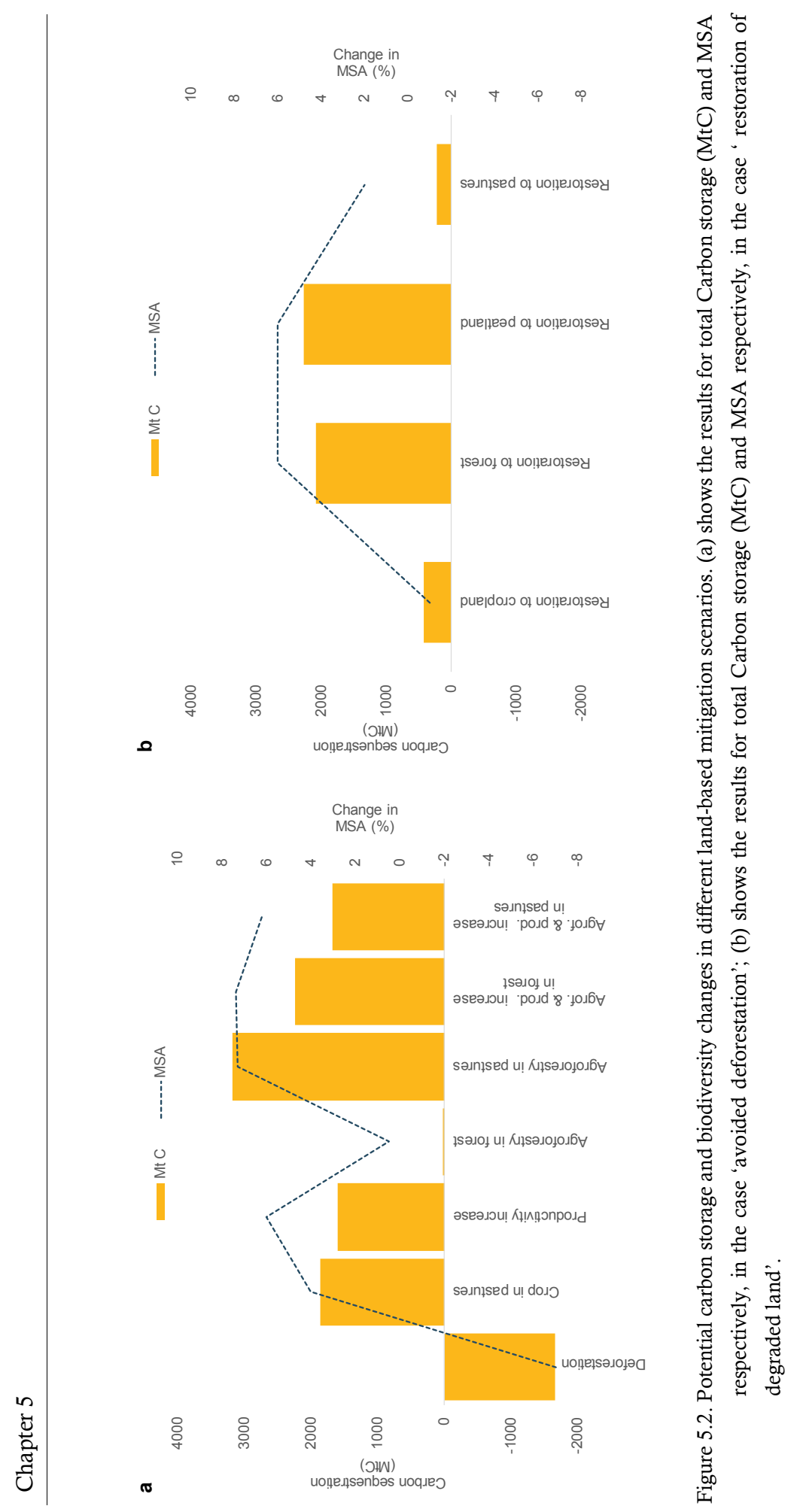




\subsection{Discussion and conclusions}

We assessed the implications of twenty land-based mitigation options on biodiversity. Our results showed that fifteen of the assessed options benefit biodiversity by either maintaining or increasing the MSA of the land use where they occur. Options that increased biodiversity included agroforestry, conservation agriculture, reforestation of croplands and pastures and restoration of degraded land (e.g. wetlands). Reforestation and restoration options could potentially allow land to reach a primary vegetation state (i.e. MSA of 1) over time, while improving the land carbon-storage capacity. Wetlands such as peatlands, which have some of the highest annual carbon sequestration rates (i.e. peat accumulates at rates of 0.5-1.0 mm yr-1; Ramsar, 2018), could return to important habitats and refuge for many rare and endangered species (Warren et al., 2017). This is particularly important to prevent wetlands from releasing methane, a potent greenhouse gas (Ramsar, 2018). We also found that avoided deforestation offered large benefits to biodiversity as it will preserve habitats for many species, especially in the tropics. However, avoided deforestation is contested as it creates a competing demand between climate-change mitigation and enhancing food security (i.e. demand for agricultural land) (Aukland et al., 2003; Miles and Kapos, 2008). This competing demand between agricultural land and more specifically croplands (e.g. SSP2; Popp et al., 2017; Stehfest et al., 2019), and forests was apparent in the baseline scenario for avoided deforestation. The expansion of cropland onto forest resulted in a 7\% MSA decrease and a loss of $1660 \mathrm{MtC}$, whereas implementing agroforestry with increasing agricultural productivity at the expense of pastures increased both carbon storage (i.e. with $2236 \mathrm{MtC}$ ) and MSA (i.e. with 7\% ). Similarly, afforestation either positively or negatively affects MSA. This depends on their spatial implementation and forestconservation schemes. All other mitigation options will negatively affect biodiversity due to intensification of cultivated and managed areas to increase soil carbon and to promote the deployment of BECCS.

Land-based mitigation potentially limit global temperature increase to $1.5^{\circ} \mathrm{C}$ above pre-industrial levels, with major contributions from BECCS and large-scale afforestation (Rogelj et al., 2018a; van Vuuren et al., 2018). The deployment of BECCS in the scenarios that are consistent with the Paris Agreement, is projected to range from 0-4.5 GtC per year in 2100. This assumes that BECCS occurs worldwide (IPCC, 2018) and it would require a large amount of land (i.e. up to 550 Mha by 2060 in the Shared Socio-economic Pathway 2, SSP2-RCP1.9) (Harper et al., 2018) to cultivate the biomass required for bioenergy, competing not only with producing food to support a growing population but also biodiversity conservation. This was previously shown in an assessment on the effects of changes in agricultural efficiency and consumption patterns on biodiversity loss (Powell and Lenton, 2013). This assessment showed a substantial biodiversity loss due to increasing intensity of biomass harvests. On the other hand, afforestation to mitigate climate change potentially increases biodiversity of degraded lands by growing new forests. Generally, these forests are plantations of non-native species that sequester carbon faster than native trees. However, afforestation could also 
be detrimental for biodiversity if implemented on non-degraded land. In such a case, reforestation by native trees on originally forested land is best for biodiversity (Cunningham et al., 2015).

While many studies assessed the climate-change mitigation potential of these options (e.g. Smith et al., 2008; Herrero et al., 2016; Zomer et al., 2016), only few addressed the likely impacts on biodiversity (Díaz et al., 2009; Powell and Lenton, 2013; Griscom et al., 2017; Smith et al., 2018). Yet, this limited number of studies focused mainly on impacts from individual land-based mitigation options or only qualitatively assessed biodiversity change. Our results advanced the findings of especially the recent study (Smith et al., 2018). We showed that cropland and agroforestry have a replacement effect if implemented in combination, whereas restoration of degraded land mostly increased biodiversity. However, restoration of severely degraded land is difficult and in some cases constrained by its short-term cost-effectiveness (Griscom et al., 2017).

We assessed land-based mitigation options implemented in scenarios that limit warming to $1.5^{\circ} \mathrm{C}$ (e.g. van Vuuren et al., 2017; Rogelj et al., 2018a; van Vuuren et al., 2018). These mitigation scenarios differ in the deployment level of land-based mitigation options into the energy system, on the assumed development of socio-economic drivers (e.g. population growth and economic development), implementation costs and uncertainties in future land projections due to differences in modelling approaches in current land-use models (Popp et al., 2014; IPCC, 2018). These differences affect the time before benefits to biodiversity become visible. This means that land-based mitigation options that deliver an early high mitigation potential (e.g. BECCS) do not necessarily benefit biodiversity by increasing the land-use's MSA. Considerable research still is needed to comprehensively analyse the best options that favour both climate change mitigation and biodiversity protection. This desired combination will contribute to achieve the climate target, while reducing detrimental biodiversity decline by unsuitable land-based mitigation options.

Overall, we showed that opportunities to mitigate climate change by land-use based options will largely benefit biodiversity. However, biodiversity protection strategies should also be considered. For example, implementation of forest-related efforts simultaneously reduce the pressures on biodiversity conservation and other ecosystem values (Miles and Kapos, 2008). A unique solution does not exist. With more claims on land, more pressure and higher potential biodiversity losses will occur. Yet, finding workable synergies requires solutions that are less effective for separate goals. The Paris Agreement call to limit global temperature increase can become a major risk to biodiversity conservation if the beneficial land-based mitigation options are not selected and implemented effectively. Thus addressing the impacts of different land-based mitigation with alternative mitigation options (e.g. van Vuuren et al., 2018), like we did in this study, on biodiversity and other co-benefits of nature, is essential. 


\subsection{Acknowledgements}

We acknowledge the "Impacts and Risks from High-End Scenarios: Strategies for Innovative Solutions (IMPRESSIONS)" project (Grant Agreement 603416) from the EU FP7 programme for providing financial support to conduct this research. 


\section{A Appendix}

Table 5.A.1. MSA $A_{L U}$ estimates for land cover/land use

\begin{tabular}{ll}
\hline GLOBIO land-use class & MSA $_{\mathrm{LU}}$ \\
\hline Forest - Natural & 1.00 \\
Forest - Plantation & 0.30 \\
Forest - Clear-cut harvesting & 0.50 \\
Forest - Selective logging & 0.70 \\
Forest - Reduced impact logging & 0.85 \\
Burnt forest & 1.00 \\
Natural grassland & 1.00 \\
Pasture - moderately to intensively used & 0.60 \\
Pasture - man-made & 0.30 \\
Extensive cropland & 0.30 \\
Intensive cropland & 0.10 \\
Irrigated cropland & 0.05 \\
Woody biofuels & 0.30 \\
Bare area & 1.00 \\
Snow and ice & 1.00 \\
Urban area & 0.05 \\
\hline
\end{tabular}


Table 5.A.2. Carbon storage estimates

\begin{tabular}{|c|c|c|}
\hline Land cover/land use/biome & tC per ha & Source \\
\hline Tropical forests & 243 & $\begin{array}{l}\text { IPCC Special Report Land Use, Land-use } \\
\text { change and forestry (2000) }\end{array}$ \\
\hline Temperate forests & 153 & $\begin{array}{l}\text { IPCC Special Report Land Use, Land-use } \\
\text { change and forestry (2000) }\end{array}$ \\
\hline Boreal forests & 408 & $\begin{array}{l}\text { IPCC Special Report Land Use, Land-use } \\
\text { change and forestry (2000) }\end{array}$ \\
\hline Tropical savannas & 147 & $\begin{array}{l}\text { IPCC Special Report Land Use, Land-use } \\
\text { change and forestry (2000) }\end{array}$ \\
\hline Temperate grasslands & 243 & $\begin{array}{l}\text { IPCC Special Report Land Use, Land-use } \\
\text { change and forestry (2000) }\end{array}$ \\
\hline Deserts and semideserts & 44 & $\begin{array}{l}\text { IPCC Special Report Land Use, Land-use } \\
\text { change and forestry (2000) }\end{array}$ \\
\hline Tundra & 134 & $\begin{array}{l}\text { IPCC Special Report Land Use, Land-use } \\
\text { change and forestry (2000) }\end{array}$ \\
\hline Wetlands & 686 & $\begin{array}{l}\text { IPCC Special Report Land Use, Land-use } \\
\text { change and forestry (2000) }\end{array}$ \\
\hline Croplands (extensive) & 82 & $\begin{array}{l}\text { IPCC Special Report Land Use, Land-use } \\
\text { change and forestry (2000) }\end{array}$ \\
\hline Grasslands & 62 & Griscom et al., (2017) \\
\hline Global peatlands & 267 & Griscom et al., (2017) \\
\hline Cropland soil (Available soil) ${ }^{\mathbf{a}}$ & 82 & Zomer (2017) \\
\hline Cropland soil (High SOC soils) ${ }^{a}$ & 252 & Zomer (2017) \\
\hline Mangroves & 937 & Alongi (2012) \\
\hline $\begin{array}{l}\text { Tropical and Subtropical Moist } \\
\text { Broadleaf Forests }\end{array}$ & 248 & Keith et al., (2009) \\
\hline $\begin{array}{l}\text { Tropical and Subtropical Dry } \\
\text { Broadleaf Forests }\end{array}$ & 111 & Keith et al., (2009) \\
\hline $\begin{array}{l}\text { Tropical and Subtropical } \\
\text { Coniferous Forests }\end{array}$ & 111 & Keith et al., (2009) \\
\hline $\begin{array}{l}\text { Temperate Broadleaf and Mixed } \\
\text { Forest }\end{array}$ & 642 & Keith et al., (2009) \\
\hline Temperate Conifer Forest & 278 & Keith et al., (2009) \\
\hline Boreal Forest/Taiga & 97 & Keith et al., (2009) \\
\hline Agroforestry $^{c}$ & 126 & Shi (2018) \\
\hline Cropland (intensive) & 77 & This study \\
\hline Degraded land & 40 & This study \\
\hline
\end{tabular}

a $30 \mathrm{cms}$ depth

${ }^{\mathrm{b}}$ Mean soil C Stocks $\mathrm{MgC} / \mathrm{ha}$

' For stock data 'No tillage' had significantly higher SOC stocks down to $30 \mathrm{~cm}$ than either 'High intensity' (4.61 Mg per ha) or 'Intermediate intensity' (3.85 Mg per ha). 


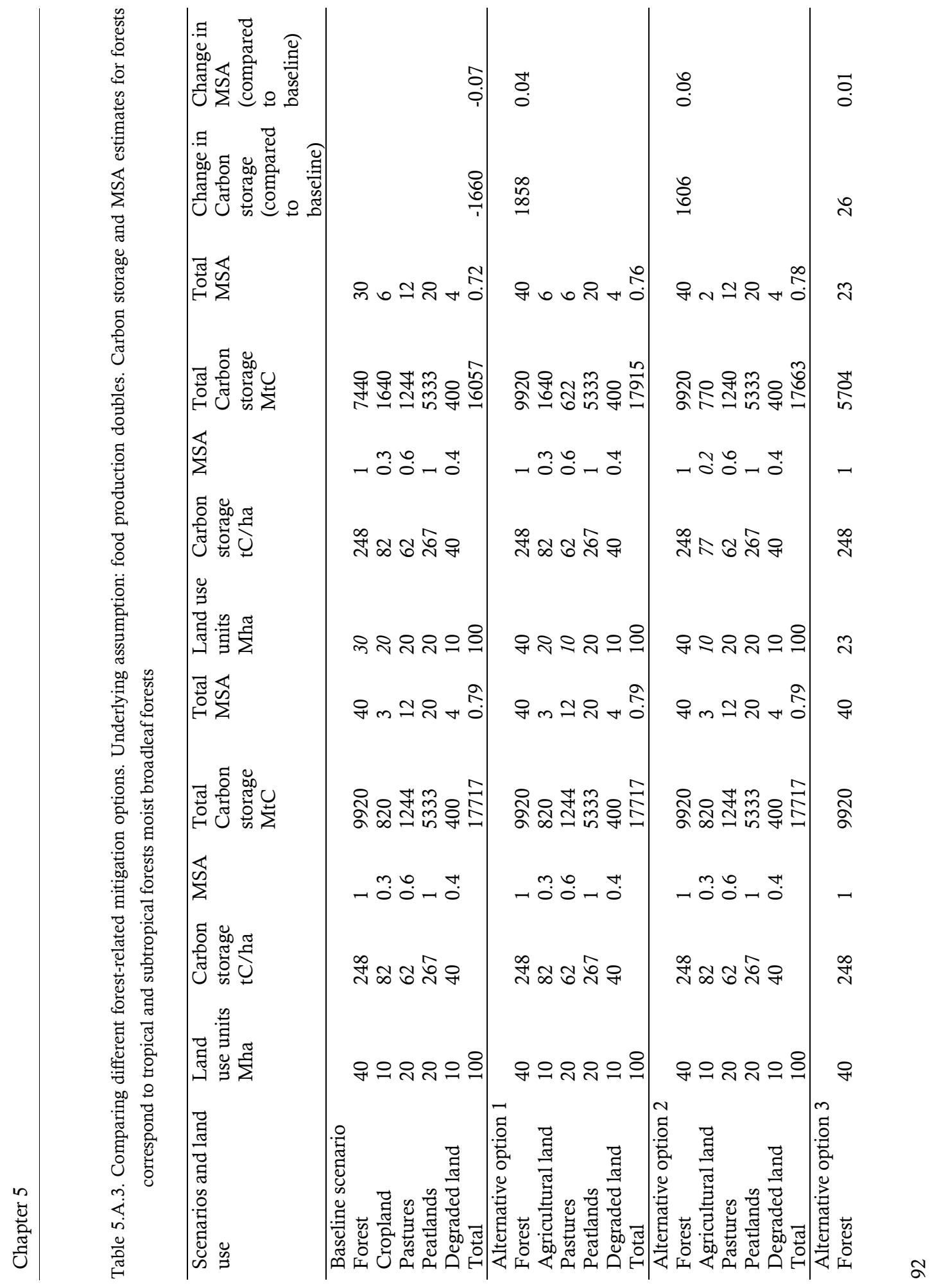




\begin{tabular}{|c|c|c|c|}
\hline & $\stackrel{5}{0}$ & $\stackrel{0}{0}$ & $\stackrel{1}{0}$ \\
\hline & $\stackrel{\infty}{\infty}$ & 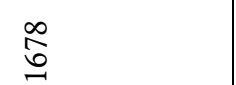 & $\stackrel{\sim}{\sim}$ \\
\hline 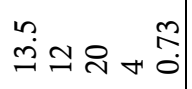 & 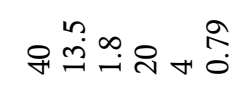 & ஸิ & 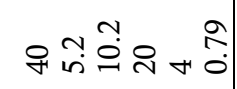 \\
\hline 䒬 & 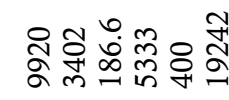 & 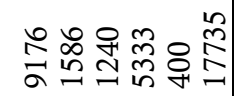 & 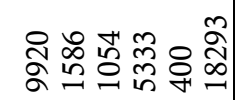 \\
\hline$\stackrel{0}{\circ}-\bar{c}$ & 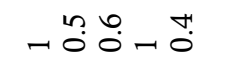 & - & ー \\
\hline 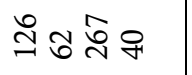 & 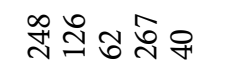 & 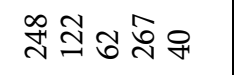 & 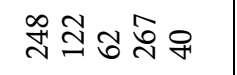 \\
\hline 규. & 위ำ요용 & ஸ் & 우듕ㅇㅇㅛ \\
\hline$\simeq \approx+\stackrel{2}{0}$ & Fn $\simeq$ กิ & 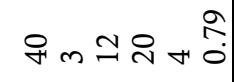 & 구 $\simeq$ ニ \\
\hline 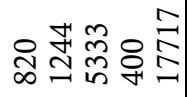 & 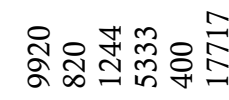 & 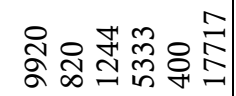 & ๙ুণ \\
\hline$\stackrel{0}{0}-\stackrel{t}{0}$ & - & $-\ddot{0}: \ddot{0}-\ddot{0}$ & $-\ddot{m}: \ddot{0}-\ddot{0}$ \\
\hline 저ㅇㅠㅠ & 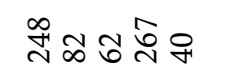 & $\stackrel{\infty}{\sim} \underset{\infty}{\infty}$ 기 : & $\stackrel{\infty}{N}$ 정 융요 \\
\hline 유유요 & 아으유유응 & 아으수유응 & 아으유옹ㅇ음 \\
\hline 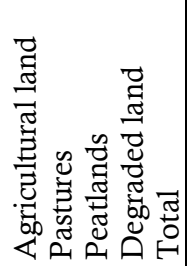 & 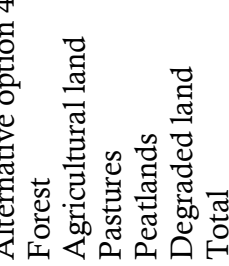 & 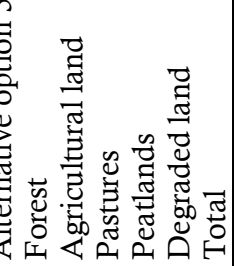 & 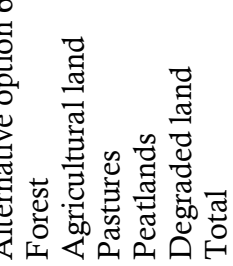 \\
\hline
\end{tabular}




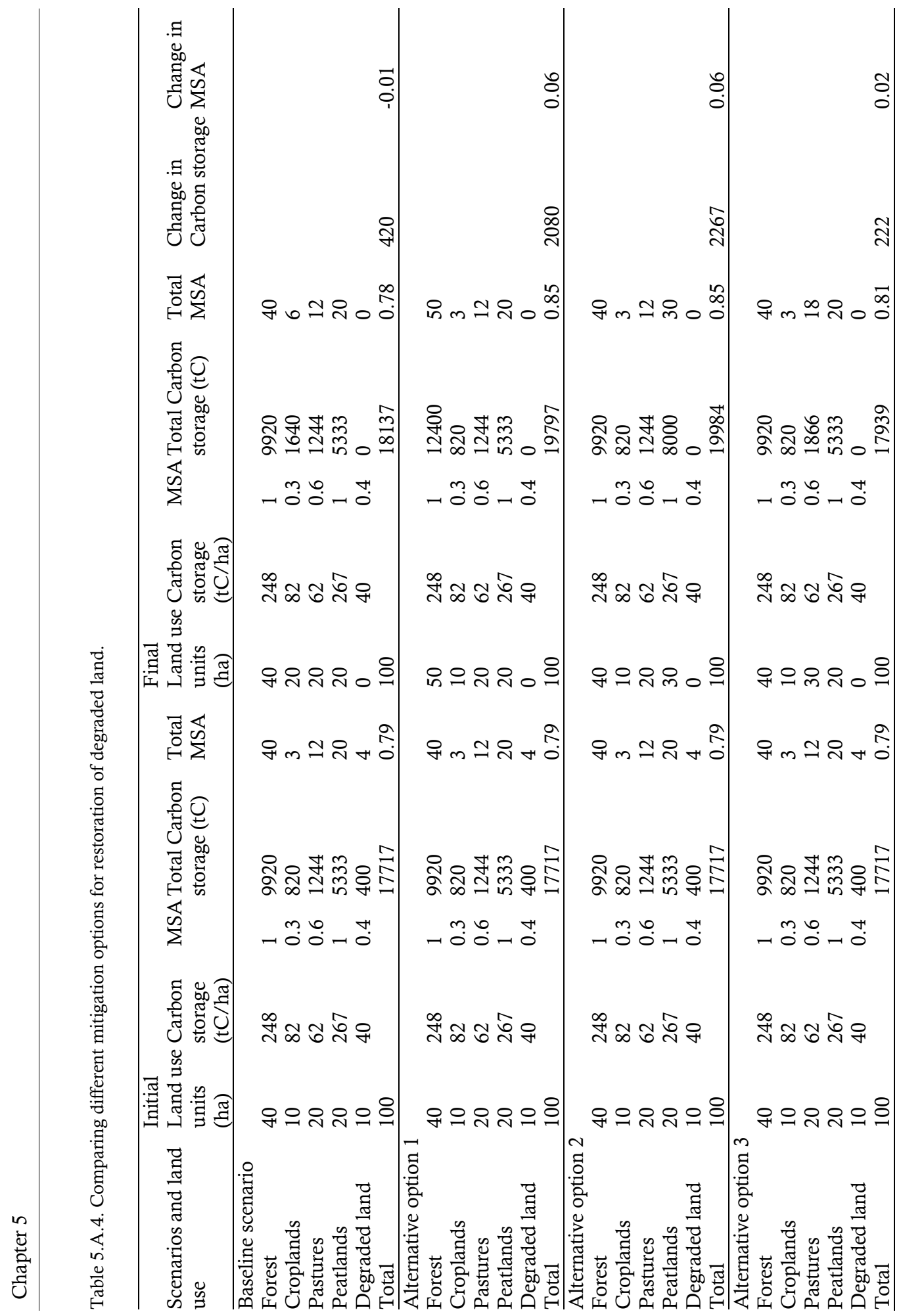


Chapter 6

Synthesis, discussion and conclusions 


\subsection{Introduction}

The overall objective of my thesis was to explore future biodiversity trends under projected direct and synergistic changes in climate and land use and to advance understanding of climate-change mitigation consequences for biodiversity. To achieve this objective I formulated four research questions:

RQ1 Is the well-below $2^{\circ} \mathrm{C}$ climate target adequate to protect biodiversity?

RQ2 How do projected changes in climate and land use affect biodiversity in a grassland ecosystem?

RQ3 How will interaction mechanisms between changes in climate and land use affect biodiversity?

RQ4 What are the implications on biodiversity of land-based mitigation?

These questions have been addressed in the previous chapters (Chapters 2 to 5). In Chapter 2, I addressed RQ1 by assessing the magnitude of expected changes of biodiversity by performing a meta-analysis of the responses of species distributions to climate change. In Chapter 3, I addressed RQ2 by developing climate and land-use scenarios based on the Shared Socio-economic Pathways and the Representative Concentration Pathways (i.e. SSP-RCP scenario framework) to explore biodiversity change in the Central Asian grasslands. In Chapter 4, I addressed RQ3 by exploring interaction effects between changes in climate and land use on biodiversity. In Chapter 5, I addressed RQ4 by assessing implications of land-based mitigation on biodiversity. In this synthesis chapter I first summarize the main findings for each research question, then I discuss the relevance of these findings in a wider research context and, finally, I present an outlook and recommendations for further research.

\subsection{Main findings of the thesis}

The general findings of my thesis provide a strong scientific advancement on understanding highend climate-change impacts (i.e. beyond the $2^{\circ} \mathrm{C}$ Paris target) and land-use change on biodiversity during the 21st century. These high-end conditions were derived from SSPs and RCPs scenarios, the latest Intergovernmental Panel on Climate Change (IPCC) scenarios, which are now becoming more popular in impact assessments. The findings of my thesis show that changes in climate and land use are major drivers of biodiversity decline, and that projected changes will place additional pressure on local biodiversity. In this section I answer each of the research questions formulated based on the findings from previous chapters. 


\subsubsection{Is the well-below $2^{\circ} \mathrm{C}$ climate target adequate to protect biodiversity?}

The main results from Chapter 2 and Chapter 3 did not demonstrate that a climate target of keeping global temperature increase well-below $2^{\circ} \mathrm{C}$ protects biodiversity. In Chapter 2, my meta-analysis revealed a gradual decrease in biodiversity with significant reductions in the fraction of remaining species (FRS) and the fraction of remaining area (FRA) with suitable climate for species of $14 \%$ and $35 \%$ between $1^{\circ} \mathrm{C}$ and $2{ }^{\circ} \mathrm{C}$ increases in global mean temperatures. This finding specifies that many species will go extinct locally and likely disappear from areas where they now occur. Mammals were projected to undergo the largest local species reduction. My results generically relate climate change and biodiversity loss. This relationship is useful to assess relative adverse effects of different climatechange scenarios and to stress the importance of holding climate change well-below $2^{\circ} \mathrm{C}$. The scenario analysis that was carried in Chapter 3, also showed large decreases in the biodiversity in the Central Asian grasslands, even in scenarios that depicted a moderate climate change (i.e. $<2^{\circ} \mathrm{C}$ ). Biodiversity declined strongly with higher temperature levels. These scenarios showed that about half of the currently pristine natural grasslands will likely convert into moderate or even high intensively used grasslands, and lose almost entirely their original occurring species. These findings indicated that already at moderate levels of warming many changes in species and ecosystems can be expected.

\subsubsection{How do projected changes in climate and land use affect biodiversity in}

\section{a grassland ecosystem?}

The main finding from Chapter 3 was that the extent of Central Asian pristine natural grasslands that contain the highest biodiversity (i.e. MSA of 1), will drastically decrease from changes in climate and land use already in 2040. In Chapter 3, I used scenario analysis based on the SSP-RCP scenario framework to estimate future biodiversity change in the Central Asian grasslands, which is the largest continuous grasslands region in the world but it is poorly studied and documented. The region has little information on current and future biodiversity trends. I developed land-use scenarios that describe the impact of socio-economic drivers (i.e. population increase, economic growth and technological development) on grasslands, under moderate (i.e. $\left.<2^{\circ} \mathrm{C}\right)$ and higher $\left(>4^{\circ} \mathrm{C}\right)$ warming. I found that biodiversity loss will be exacerbated in scenarios that project high temperatures and socio-economic developments (i.e. SSP3-RCP8.5 and SSP5-RCP8.5). Yet, in scenarios with moderate temperatures and socio-economic developments (i.e. SSP1-RCP4.5 and SSP4-RCP8.5) biodiversity will also undergo large decreases. These are major impacts for this grassland region. Critical levels of biodiversity loss were mainly found around population settlements, where land-use change is increasingly dynamic in response to population growth. These rapid changes relate mostly to a conversion from natural grassland to pastures and/or cropland. The results from my scenario analysis are consistent with the recent IPBES report that projects climate and land-use change 
impacts on biodiversity (IPBES, 2019). Changes to the grassland ecosystem as a result of changes in climate and land use, are likely to have substantial negative social, cultural and economic consequences for pastoralist communities in Central Asia.

\subsubsection{How will interaction mechanisms between changes in climate and land use affect biodiversity?}

The major finding from Chapter 4 was a no significant interaction effect for the mechanism 'climate change and the presence of conspecifics in modified habitats determines species' birth rates or extinction risk'. This unexpected finding was based on a meta-analysis of bioclimatic studies on species distributions under climate change in fragmented landscapes. A no significant interaction means that the FRS of areas with large proportion of cropland (i.e. intensively managed) did not significantly differ from those areas with a low cropland proportion (i.e. close to pristine, natural areas) under climate change. I found that global mean temperature increase is a significant model predictor for biodiversity decline. This suggest that temperature has a strong influence on FRS. The validation of interaction mechanisms between land-use and climate-change effects and other inherent factors that affect species' dispersal (e.g. adaptive capacity and time lags) will help to better project future biodiversity trends. However, the lack of integration between these drivers in the available literature limits the development of strategies for biodiversity conservation.

\subsubsection{What are the implications of land-based mitigation on biodiversity?}

The main finding from Chapter 5 was that climate-change mitigation by land-use based options will largely benefit biodiversity. This benefit arises from the possible positive synergies between land-use based options in certain climate-change mitigation scenarios. This was the case of agroforestry in combination with agricultural practices, which can deliver substantial benefits in terms of carbon sequestration and biodiversity conservation. I found that mitigation options such as reforestation of cultivated and managed areas and restoration of wetlands deliver the largest MSA increases, but only if land is allowed to reach a mature state over time. The Paris Agreement call to limit global temperature increase can become a major risk to biodiversity conservation if the beneficial landbased mitigation options are not selected and implemented effectively. This is the case of land-based mitigation options with large mitigation potential such as Bioenergy with Carbon Capture and Sequestration (BECCS) and intensification of agricultural areas. Both BECCS and the intensification of agricultural areas strongly rely on agricultural efficiency improvements and land expansion to achieve higher yields. These practices lead to land-use intensification (e.g. low-input agriculture to intensive agriculture) and eventually to land-use change (e.g. natural grasslands to pastures). Consequently, the originally occurring species in those agricultural areas will also change. In Chapter 3, I showed that grazing intensification, which increases the per hectare productivity of 
grassland areas, decreases the MSA in grasslands. Grazing will intensify in scenarios that feature high population and economic growth (e.g. SSP5) until the areas reach their potential grazing carrying capacity and then convert to another land use. These scenarios will likely require the largest mitigation efforts. Climate-change mitigation can thus be detrimental for biodiversity if the implementation of land-based mitigation options ignore the impacts of biodiversity.

\subsection{Addressing biodiversity change under species' adaptive capacity and unlimited dispersal cases}

The outcomes of my thesis were primarily based on an approach that uses species-distribution (i.e. species climate envelope) models to estimate biodiversity decline under climate change. These species-distribution models rely on statistical correlations between the observed species distributions and several climate variables to predict their distributions and hence their extinction risk under future climate scenarios (Pearson and Dawson, 2003; Guisan and Thuiller, 2005). My approach estimated the expected number of remaining species and areas with suitable climate for species. These likely conservative biodiversity estimates excluded the potential species gains (i.e. species turnover) as estimated in dynamic approaches. These approaches and the resulting increased biodiversity from a complementary meta-analysis to Chapter 2 that uses data for unlimited dispersal cases, are discussed in this section.

More dynamic approaches that assess the vulnerability of species to climate change, showed that observed climate-change induced responses are influenced by species' biological traits (Dawson et al., 2011). Vulnerability, in such dynamic context, refers to the extent to which a species or population is threatened with decline, reduced fitness, genetic loss or extinction owing to climate change. These dynamic approaches require consideration of all aspects of vulnerability: exposure, sensitivity and adaptive capacity (Williams et al., 2008), and probably reflect future trends of increased biodiversity. These positive trends have been shown in previous studies that assessed distributions of vertebrate (e.g. reptile and amphibian) and plant species under climate change (Araujo et al., 2006; Fordham et al., 2012).

Adaptive capacity is the ability of a species (or a system) to cope with climatic change by persisting in situ, by shifting to more suitable local microhabitats or by migrating to more suitable regions (Lindner et al., 2010; Dawson et al., 2011; Beever et al., 2016). Adaptive capacity largely depends on species' dispersal ability. This is shown on the left and right parts of Figure 6.1 (i.e. potential adaptation of species in the original area with suitable climate and potential dispersal of species in the projected area with suitable climate). Previous studies that assessed potential adaptation in situ (e.g. Hamann and Aitken, 2013) found that biodiversity could be maintained under moderate climate change until the end of the century. These results are useful for conservation planning only 
when they indicate that threats to biodiversity have been considered in such scenario assessments (e.g. Foden et al., 2013; Pacifici et al., 2015).

Dispersal refers to the ability of species to disperse within and across habitats, to track the preferred climate space and to expand rapidly following disturbance (Solomon and Leemans, 1990; Williams et al., 2008). Most climate and land-use change impact assessments on biodiversity report changes in species distributions and habitats based on two extreme cases: no dispersal and unlimited dispersal (e.g. Thomas et al., 2004; Rondinini and Visconti, 2015; Visconti et al., 2015; Newbold, 2018). No dispersal restricts future predictions of suitable habitat to the extent of the current distributions, whereas unlimited dispersal assumes that a species could instantaneously reach all geographical areas with projected suitable habitat, overcoming different land-use barriers (Bateman et al., 2013). The analyses that were conducted in my thesis, particularly in Chapters 2, 3 and 4 were based on the no-dispersal case. No dispersal has been shown to be closer to species specific dispersal data (Hellmann et al., 2016). Hellmann et al. (2016) estimated climate change sensitivity scores for vertebrate and plant species and found that both assumptions (i.e. no dispersal and unlimited dispersal) are unrealistic. However, unlimited dispersal largely overestimates the extent of future species distributions, while no dispersal probably only slightly underestimates projected distribution extents. Thus, the FRS, FRA and MSA that I used in my research, reflected changes in biodiversity that are likely much closer to species specific dispersal estimates than estimates for unlimited dispersal.

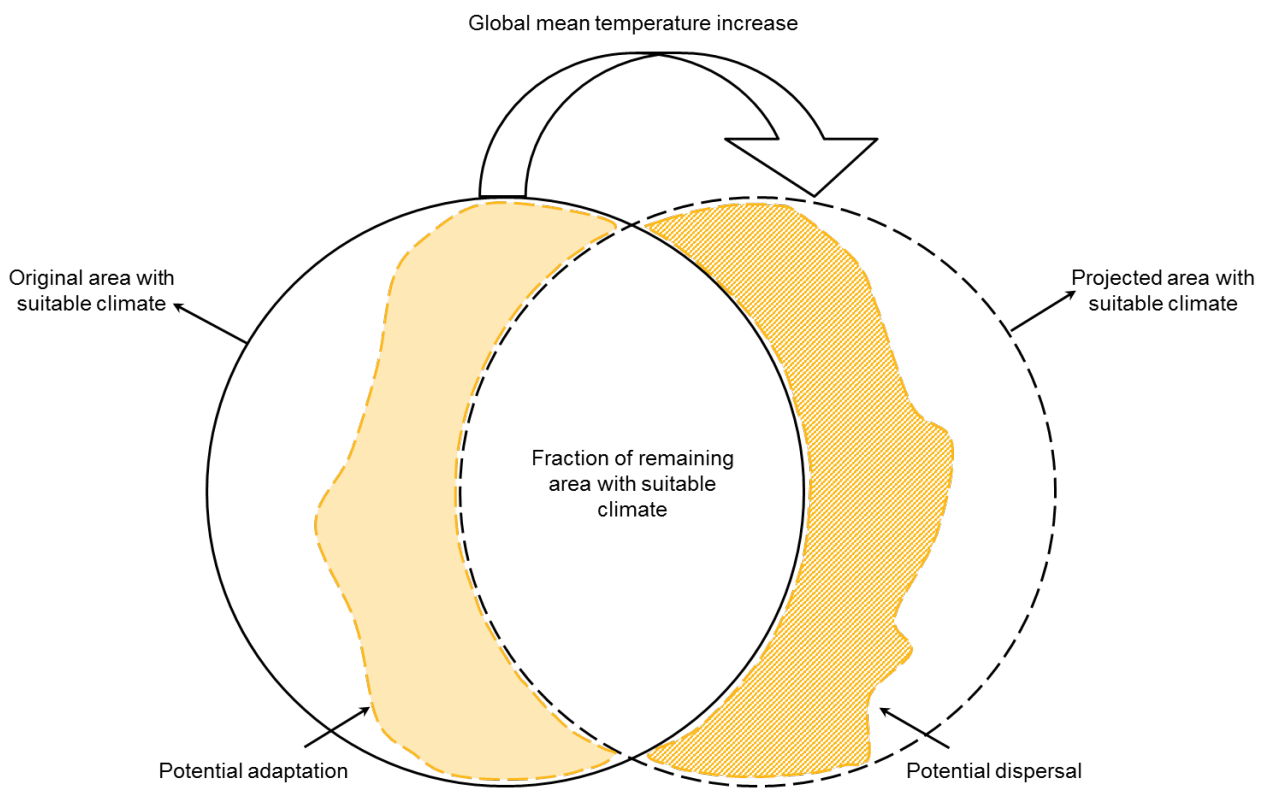

Figure 6.1. Schematic illustration to indicate potential species adaptation, FRA and species potential dispersal under projected global mean temperature increase. 
The unlimited dispersal assessment (Figures $6.2 \mathrm{~b}$ and $6.2 \mathrm{~d}$ ), as expected, showed that current biodiversity levels likely remain intact whereas the no-dispersal situation projected a gradual decrease in both FRS and FRA (Figures 6.2a and 6.2c). Such decrease was significantly larger for FRA (i.e. $21 \%$ at $95 \%$ confidence interval: $15-26 \%$ ) (Table 6.1 ) than for FRS. In the unlimited dispersal case, the originally occurring species were perfectly able to track areas with suitable climate and thus remained constant (Figure 6.2b). The area with suitable climate was projected to slightly increase (Figure 6.2d). However, some previous studies that assessed unlimited dispersal concluded that despite this being an optimistic situation, the species response is strongly linked to the local climatic conditions (and the stochastic extreme weather events) of the original study area and thus should not be generalized too much (Engler et al., 2009).

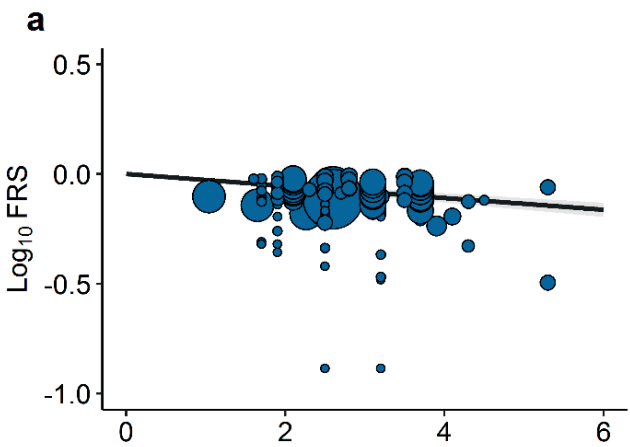

\section{b}
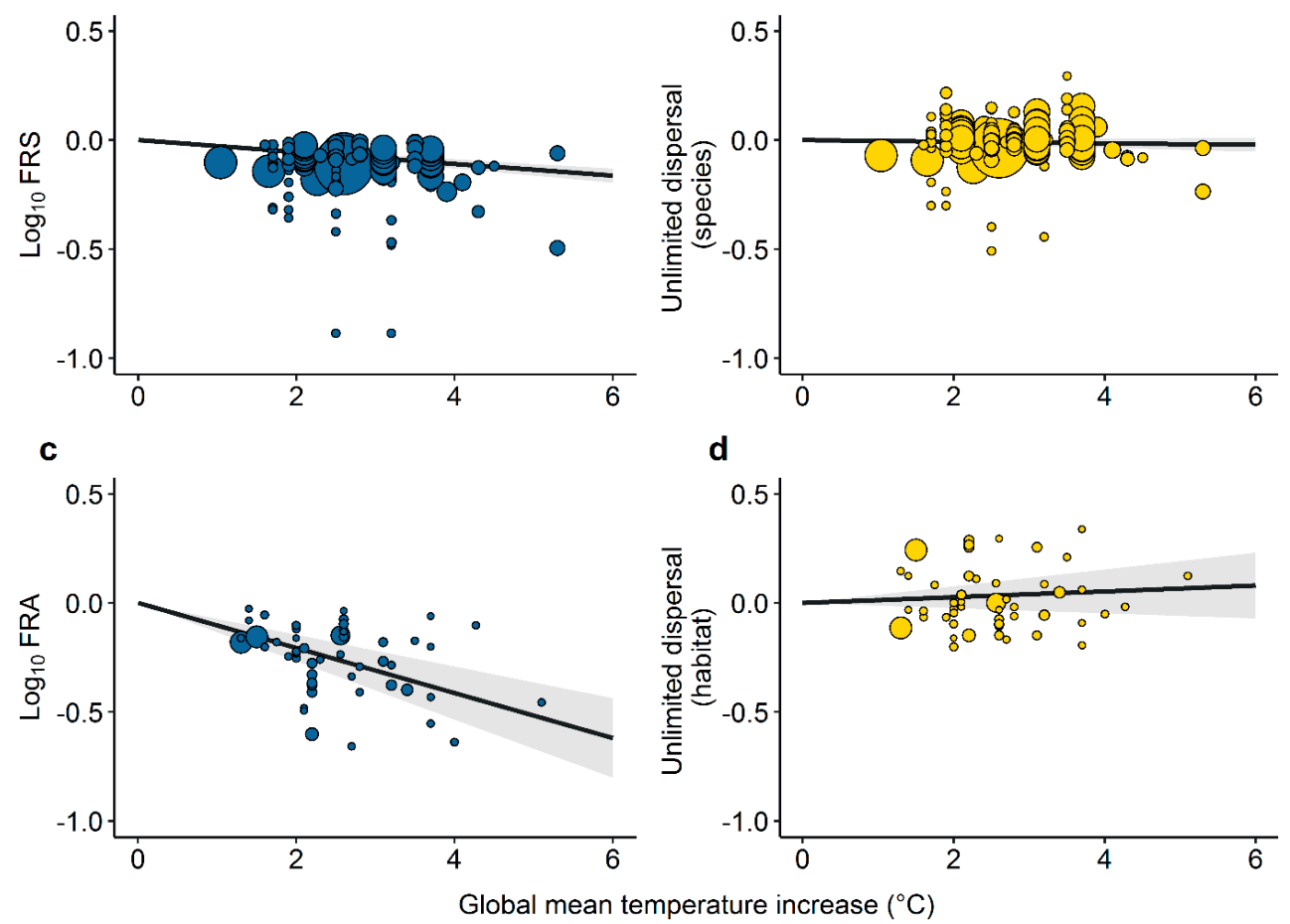

Figure 6.2. Meta-regressions on global mean temperature increase for $\log _{10}$ effect sizes (a) Fraction of Remaining Species, (b) Unlimited dispersal for local original occurring species, (c) Fraction of Remaining Area with suitable climate and (d) Unlimited dispersal for projected area with suitable climate. Confidence intervals (CI 95\%) are shown by the shadowed line. Each effect size is represented by a circle, and the size of the circle indicates the number of species in the original study. 
The relative rates of environmental and evolutionary change that will likely affect biodiversity, need to be further addressed (c.f. Bradshaw and Holzapfel, 2006). Although accounting for either modelling approaches that attempt to simulate species' dynamics under future climate scenarios provides optimistic future biodiversity trends, my conservative assumption shown to be more promising in the projection of biodiversity responses. This is because assuming no dispersal only differs slightly from climate sensitivity scores calculated with species specific dispersal data. Remaining uncertainty will then likely relate most to the magnitude of climate change (c.f. Engler et al., 2009) and land-use change as it was shown in Chapter 3.

\subsection{Biodiversity sensitivity to changes in climate and land} use

In Chapter 4, I showed that the interaction effect between current levels of cropland and global mean temperature increases on biodiversity is not significant. This outcome counteracts the intuitive assumption that climate and land-use change effects will synergistically interact upon species. In practice, this synergy likely happens. Theoretically, the many factors that influence this synergistic effect (e.g. time lags, species dispersal ability and species adaptive capacity) are difficult to integrate in biodiversity assessments. Moreover, integrated assessments that focus on crop productivity and shifts in potential production areas neglect the wide range of human adaptive responses to climate change in land-use systems. For example, spatial displacement of activities can pose a significant threat to biodiversity (Titeux et al., 2016). This neglect also limits a holistic integration of all relevant factors to address the interaction mechanisms (including feedbacks, trade-offs and synergies). The generally addressed synergy assumption therefore has most often been reported as an accumulated individual effect rather than the actual interaction (e.g. Mantyka-Pringle et al., 2012; Brown et al., 2015; Garcia-Valdes et al., 2015). A more thorough theoretical understanding and methodological approach to assess interaction effects is still needed. This can be achieved, for instance, by moving away from the relatively linear relationships between all relevant drivers, and focus on the more complex dynamic interactions (Pereira et al., 2010). Such complexity could help to explain the unanticipated outcome from Chapter 4.

This section is thus devoted to explore and test the sensitivity of biodiversity to changes in cropland extent (\%) and global mean temperature $\left({ }^{\circ} \mathrm{C}\right)$ (i.e. mixed-effect model in Section 4.2 .4 of this thesis) across Europe, using a sensitivity analysis. A sensitivity analysis is a tool to determine how much of the variability and uncertainty in model output variables can be attributed to different inputs variables (Leemans, 1991). I used a model protocol designed in the IMPRESSIONS project (Fronzek et al., 2019) to perform additional model runs with GLOBIO3, which is a model to assess the impact of different environmental drivers on terrestrial biodiversity (Alkemade et al., 2009). 


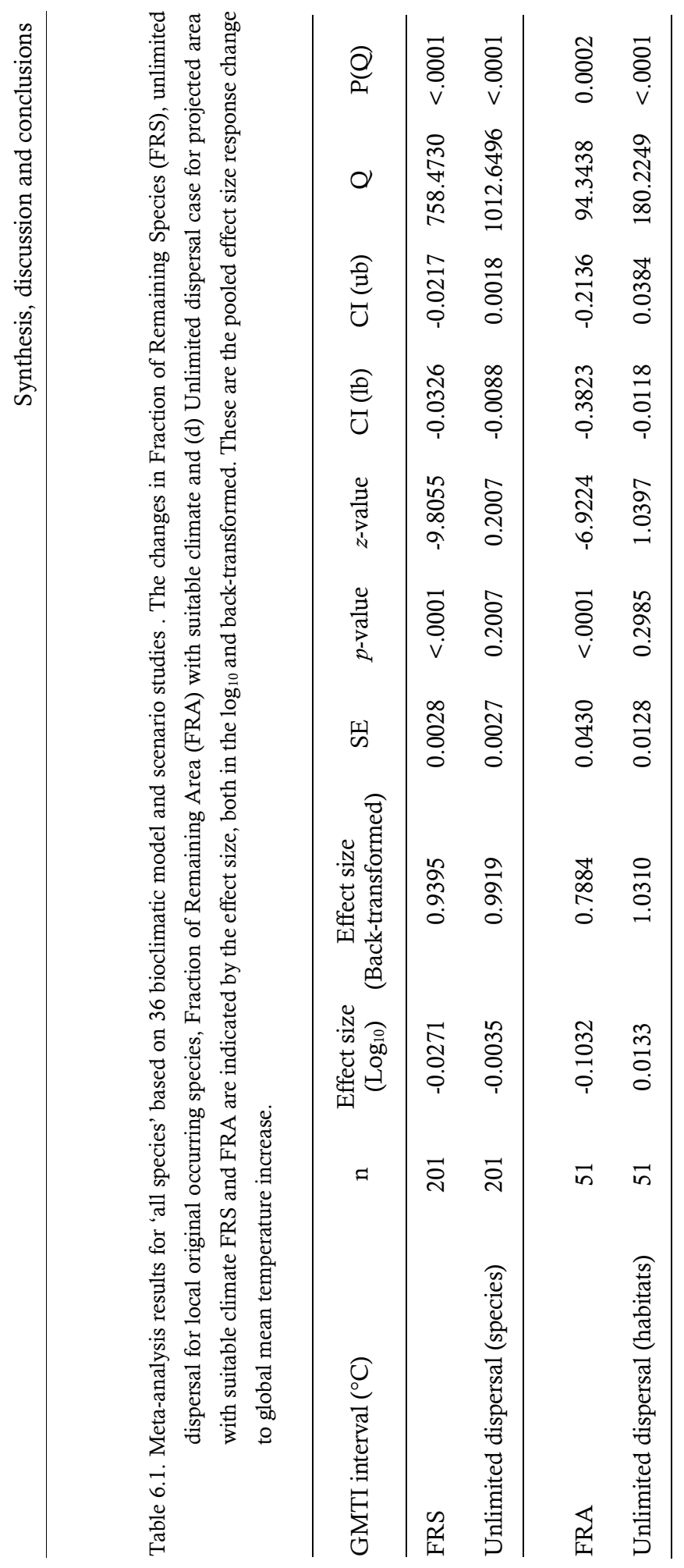


The results of the sensitivity analysis showed that biodiversity decreases with both warming and expansion of cropland (Figure 6.3), but the model is most sensitive to changes in temperature. The effect of a moderate increased in temperature (e.g. $2^{\circ} \mathrm{C}$ ), that was determined at no cropland change, decreased the relative species abundance (i.e. MSA) on average from 38\% to $36 \%$ across Europe. With no temperature change, the MSA only decreased when cropland extent increased beyond $10 \%$, with the strongest decrease (i.e. from $38 \%$ to $33 \%$ ) occurring when cropland expands by $30 \%$. Climate-change effects were quantified per biome. This means that the degree of biodiversity loss is strongly linked to the biomes of this region. Thus, the dramatic biodiversity decrease projected for the Mediterranean region (i.e. MSA from $38 \%$ to $23 \%$ ) at a more extreme climate change (i.e. $>4^{\circ} \mathrm{C}$ ) is in agreement with findings from Chapter 2. In Chapter 2, I also found that shrublands are among the most sensitive biomes projected to experience the largest reductions in local species abundance. The effect of cropland expansion is, however, largely determined by the allocation algorithm in GLOBIO3. Based on this algorithm, cropland expansion is first allocated to non-forest natural vegetation classes, followed by forest classes. Thus, regions such as Eastern Europe and France, which are characterized by large agricultural land extents, are likely to experience large effects from increasing cropland area when determined at no temperature change. On the contrary, regions such as the Alps, British Isles and Northern Europe, which are characterized by natural vegetation classes (e.g. forests), are less likely to be affected by increases in cropland. Further results of this sensitivity analysis have been published in Fronzek et al. (2019).

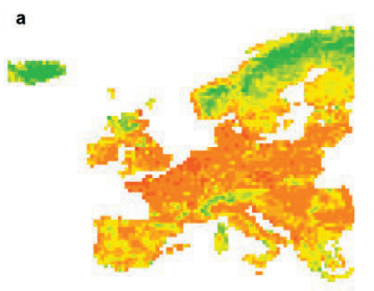

\section{b}

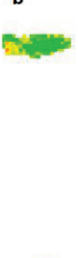

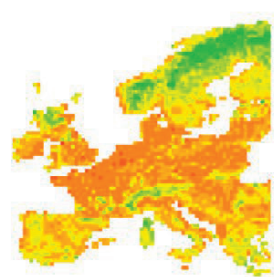

c

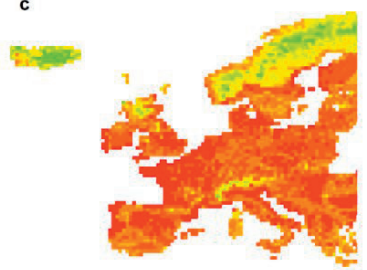

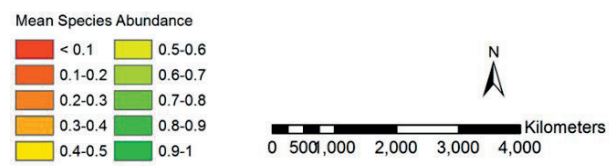

Figure 6.3. Maps of biodiversity change in Europe (all regions) under three combinations of temperature change and cropland extent. (a) Baseline conditions (i.e. no change), (b) Conservative conditions (i.e. $-1{ }^{\circ} \mathrm{C}$ and $10 \%$ decrease in cropland area) and (c) Extreme conditions (i.e. $+11^{\circ} \mathrm{C}$ and $30 \%$ increase in cropland area). 
The different combinations of temperature change and cropland extent that were used in my analysis, projected plausible futures with varying effects on biodiversity. However, extreme climate conditions, such as temperature increases beyond $7^{\circ} \mathrm{C}$ or allocation of large cropland areas, are far beyond the reach of the GLOBIO3 model and thus the results for such scenarios need to be contemplated carefully. The biodiversity response was fairly linear to changes in climate and land use (Figure 6.4). This can be attributed to the lack of complex drivers interactions within GLOBIO3. The model's linearity helped to verify consistency and robustness of GLOBIO3's simulated biodiversity patterns and changes therein. More specifically, the model results indicated that interactions among environmental drivers were mostly absent. In general terms, this means that uncertainties related to the parameterisation of complex cause-effect relationships, the considered drivers, the scenario inputs to specify trends in drivers, the underlying data and the used indicators need to be further assessed. This could likely improve GLOBIO3 and modelling approaches such as the one used in my research, in a direction that more robust and maybe more realistic and precise results will become available to the impact assessment community.
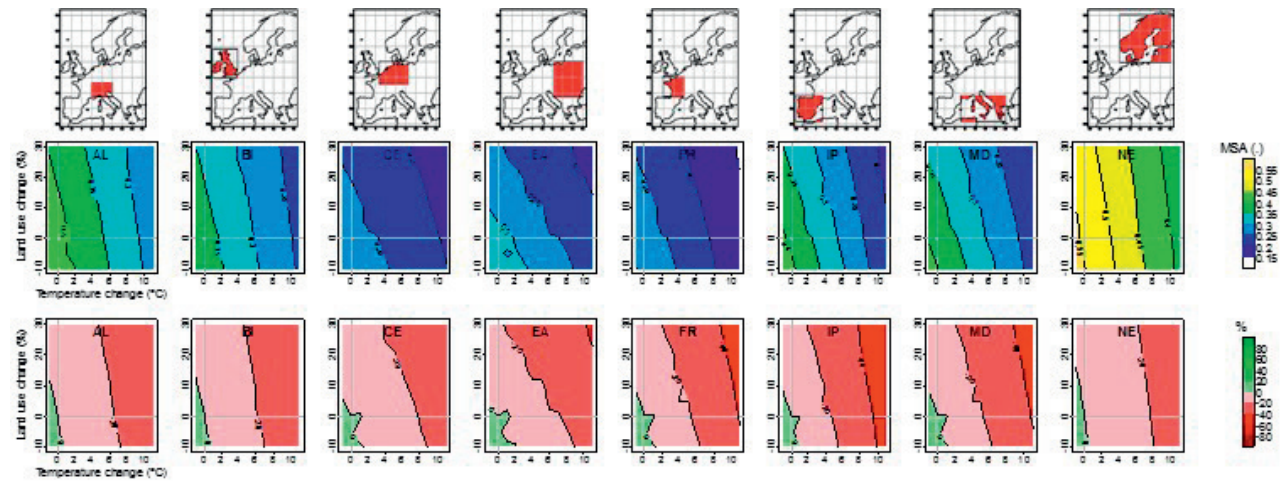

Figure 6.4. Simulation results over European regions for mean species abundance (MSA) plotted as contoured Impact Response Surfaces (IRSs) with respect to temperature change $\left({ }^{\circ} \mathrm{C}\right)$ and land-use change (\%) (adapted from Fronzek et al., 2019). Top row shows absolute changes between the simulated baseline (unperturbed- at the intersection of the zero change lines) and perturbed responses of MSA. Bottom row shows relative changes between the simulated baseline (unperturbed- at the intersection of the zero change lines) and perturbed responses of MSA. 


\subsection{Future outlook: prioritising efforts to protect biodiversity}

The $2^{\circ} \mathrm{C}$ and the stricter $1.5^{\circ} \mathrm{C}$ climate targets from the Paris Agreement strongly differ in their negative consequences for biodiversity, both locally and globally (Leemans and Vellinga, 2017; Smith et al., 2018; Warren et al., 2018). The stricter target has substantially lesser impacts (IPCC, 2018). A recent study that assessed different consequences (including biodiversity) of various climate-change scenarios in Europe across different sectors (Harrison et al., 2019a), also found that impacts are considerably larger under the high-end (i.e. $>4{ }^{\circ} \mathrm{C}$ ) than low-end (i.e. $<2{ }^{\circ} \mathrm{C}$ ) climate change. Since the average global temperature reached approximately $1^{\circ} \mathrm{C}$ above pre-industrial levels in 2017 (IPCC, 2018), limiting climate change to the $2^{\circ} \mathrm{C}$ target and more desirably to $1.5^{\circ} \mathrm{C}$ would require large mitigation efforts, including those from the land sector. Such efforts probably threaten species and habitats and jeopardize biodiversity conservation as a whole (c.f. Chapter 5). To prioritize efforts, projecting plausible biodiversity trends that minimize uncertainty to the climate and land-use change effects, will be necessary (Newbold et al., 2019). Such trends have been shown in Chapters 2 to 5 of my thesis. Nevertheless, urgent advances remain needed to estimate trends under projected changes in climate and land use, that can help prioritizing biodiversity protection efforts. These advances are discussed below.

A consistent approach to estimate biodiversity trends under low-end and high-end climate change.

Higher levels of warming are expected in the coming decades. Thus, future advancements in projecting biodiversity trends require an agreed approach to estimate biodiversity losses under different climate-change ends. In Chapters 2 and 3 of my thesis, I also assessed biodiversity responses to global mean temperature increases beyond $2^{\circ} \mathrm{C}$. In Chapter 2, I used intervals of temperature increase that cover up to $7^{\circ} \mathrm{C}$ increase as reported in previous studies (e.g. Shoo et al., 2005; Loarie et al., 2008; Sekercioglu et al., 2008). In Chapter 3, I used the reported global mean temperature increase from high climate-change scenarios (i.e. $3.7^{\circ} \mathrm{C}$ relative to the $1986-2005$ period in RCP8.5; IPCC, 2013b). I found that biodiversity declines more strongly with higher temperature-increase levels. I proposed methods to estimate such consequences (i.e. future biodiversity trends). These methods and their resulting trends are based on a conservative approach. This approach focuses on assessing the proportion of local remaining species and their habitats after projected changes in climate and land use. Similar approaches to the one that I used in my thesis, can provide the robust and needed results to adequately inform efforts on biodiversity conservation.

Assessments of the interaction mechanisms between climate and land-use change effects that integrate other conditions (e.g. spatial location, adaptive capacity and time lags).

The understanding of the interactions between climate and land-use change effects is improving but scientific progress is still urgently needed (Oliver and Morecroft, 2014). For example, estimates of the interaction effects for different ecosystems at both $2^{\circ} \mathrm{C}$ and $1.5 \mathrm{C}^{\circ} \mathrm{C}$ would provide more robust 
arguments for the stricter target, allow to better project future biodiversity trends and help develop coping strategies for biodiversity conservation. The lack of integration of climate and land-use change effects in the current climate-change negotiations implies that the projected biodiversity responses probably also inadequately inform biodiversity managers and policy makers on possibilities to develop synergistic biodiversity-conservation measures consistent with limiting climate change to well-below $2^{\circ} \mathrm{C}$ and preferably lower (Chapters 2 and 3). Efforts on advancing the understanding of drivers interactions should certainly be among priorities to project future biodiversity trends. Although clear evidence to verify some of these mechanisms is lacking, Chapter 4 explored different mechanisms to estimate the potential interaction effect of these drivers.

Translate estimates of biodiversity loss in grassland ecosystems.

A major challenge highlighted in my thesis, is the urgent need to translate findings of Chapter 3 into better management strategies for especially the Central Asia's grasslands. Such findings resulted from contrasting scenario combinations from the SSP-RCP scenario framework, and showed that grasslands' biodiversity will decline under each scenario. This is particularly important when assessing mitigation pathways that rely heavily on untested mitigation approaches such as BECCS (Chapter 5). Although these biodiversity estimates stress the potential vulnerability of this region to increasing land-use intensity and climate change, they are the result of a static model and scenario approach which should be further advance to deliver dynamic projections of land-use changes.

The way forward of the Post-2020 Global Biodiversity Framework.

The Post-2020 Global Biodiversity Framework comprises actions towards the development of an ambitious post-2020 strategy that would contribute to the achievement of the Sustainable Development Goals (SDGs), and support the Rio Conventions as well as other biodiversity-related conventions (IUCN, 2019b). This framework, which will likely follow up the Strategic Plan for Biodiversity 2011-2020 and its 20 Aichi Biodiversity Targets, will become the core for several advances for which this thesis provides strong scientific advancement. For example, the findings of my thesis can contribute to identifying ways and means by which the CBD and the Post-2020 Global Biodiversity Framework can achieve the transformational change of pathways towards a sustainable, plausible future, as established in the 2050 Vision for Biodiversity.

\subsection{Conclusions}

The loss of biodiversity is an environmental problem that society at large has been facing during the last decades. This thesis generated state-of-the-art knowledge for the scientific community and policy-makers on impacts from high-end scenarios on biodiversity and the effectiveness of different mitigation strategies to cope with extreme climate change. This was achieved by applying existing and novel approaches to fill four major knowledge gaps: 1) a consolidated body of knowledge to assess the response of biodiversity to a global mean temperature increase well-below $2^{\circ} \mathrm{C}, 2$ ) an 
integrated assessment of climate and land-use change impacts on biodiversity in grasslands, 3) a better understanding of interaction mechanisms between climate and land-use change effects on biodiversity and 4) a thorough understanding of implications of climate-change mitigation on biodiversity. From this generated knowledge, I can conclude the following:

- The magnitude of expected changes of biodiversity differs considerably across different intervals of temperature increase and land use. These changes, however, indicate gradual continuous decreases of species abundance and habitats that exacerbate under projected high-end climate change (i.e. beyond the $2^{\circ} \mathrm{C}$ target) and large societal developments. Translating the relevant information on socioeconomic and climate-change drivers in the SSP-RCP scenario framework and determining the consequences of these drivers on biodiversity urgently requires better approaches. Only then, can the obtained future trends of biodiversity adequately inform biodiversityconservation planning;

- There is no evidence that the well-below $2^{\circ} \mathrm{C}$ climate target protects biodiversity. My results position climate change as a major driver of biodiversity loss and thus support findings from the latest Global Assessment Report on Biodiversity and Ecosystem Services (IPBES, 2019). Although my findings do not demonstrate that the well-below $2{ }^{\circ} \mathrm{C}$ climate target protects biodiversity, they surely support the pledge to limit global temperature increases to $1.5^{\circ} \mathrm{C}$ and preferably lower;

- Approaches that focus on assessing the proportion of local remaining species and their habitats after projected environmental changes are preferred over 'optimistic approaches' that incorporate dispersal and adaptive capacities of species. These more optimistic approaches likely overestimate future species distributions. My results can be used to develop ambitious strategies to monitor biodiversity impacts and to minimize global extinctions; and

- Climate change and land-use change are major drivers of biodiversity loss in grasslands and thus should be given equal importance. My thesis contributed to the IMPRESSIONS project in providing results to support EU policy initiatives and to understand high-end climate change based on a set of integrated climate and socio-economic scenarios developed during the duration of the project between 2014-2018. These integrated scenarios were used to assess climate and land-use change impacts on the Central Asian grassland region, which has been previously neglected in global biodiversity assessments and still has large information gaps of past and current biodiversity trends.

Overall, my thesis provided knowledge that is quickly becoming an important element to develop strategies for regional and global biodiversity conservation, and can thus feed into the current UN Conventions on Biological Diversity and Climate Change agendas (e.g. the processes for developing the post-2020 global biodiversity framework and ongoing efforts from the Paris Agreement to combat climate change and its impacts). 


\section{References}

Albrecht, A., Kandji, S.T. (2003). Carbon sequestration in tropical agroforestry systems. Agriculture, Ecosystems \& Environment 99, 15-27.

Alkemade, R., Bakkenes, M., Eickhout, B. (2011). Towards a general relationship between climate change and biodiversity: An example for plant species in Europe. Regional Environmental Change 11, 143-150.

Alkemade, R., Reid, R.S., van den Berg, M., de Leeuw, J., Jeuken, M. (2013). Assessing the impacts of livestock production on biodiversity in rangeland ecosystems. Proceedings of the National Academy of Sciences 110, 20900-20905.

Alkemade, R., van Oorschot, M., Miles, L., Nellemann, C., Bakkenes, M., ten Brink, B. (2009). GLOBIO3: A Framework to Investigate Options for Reducing Global Terrestrial Biodiversity Loss. Ecosystems 12, 374-390.

Alongi, D.M. (2012). Carbon sequestration in mangrove forests. Carbon Management 3, 313 322.

Araujo, M., Cabeza, M., Thuiller, W., Hannah, L., Williams, P. (2004). Would climate change drive species out of reserves? An assessment of existing reserve-selection methods. Global Change Biology 10, 1618-1626.

Araujo, M.B., Thuiller, W., Pearson, R.G. (2006). Climate warming and the decline of amphibians and reptiles in Europe. Journal of Biogeography 33, 1712-1728.

Asner, G.P., Loarie, S.R., Heyder, U. (2010). Combined effects of climate and land-use change on the future of humid tropical forests. Conservation Letters 3, 395-403.

Aukland, L., Costa, P.M., Brown, S. (2003). A conceptual framework and its application for addressing leakage: the case of avoided deforestation. Climate Policy 3, 123-136.

Balmford, A., Bennun, L., ten Brink, B., Cooper, D., Côté, I.M., Crane, P., Dobson, A., Dudley, N., Dutton, I., Green, R.E., Gregory, R.D., Harrison, J., Kennedy, E.T., Kremen, C., Leader-Williams, N., Lovejoy, T.E., Mace, G., May, R., Mayaux, P., Morling, P., Phillips, J., Redford, K., Ricketts, T.H., Rodríguez, J.P., Sanjayan, M., Schei, P.J., van Jaarsveld, A.S., Walther, B.A. (2005). The Convention on Biological Diversity's 2010 Target. Science 307, 212-213.

Bartholomé, E., Belward, A.S. (2005). GLC2000: a new approach to global land cover mapping from Earth observation data. International Journal of Remote Sensing 26, 1959-1977.

Bateman, B.L., Murphy, H.T., Reside, A.E., Mokany, K., VanDerWal, J. (2013). Appropriateness of full-, partial- and no-dispersal scenarios in climate change impact modelling. Diversity and Distributions 19, 1224-1234.

Beever, E.A., O'Leary, J., Mengelt, C., West, J.M., Julius, S., Green, N., Magness, D., Petes, L., Stein, B., Nicotra, A.B., Hellmann, J.J., Robertson, A.L., Staudinger, M.D., Rosenberg, A.A., Babij, E., Brennan, J., Schuurman, G.W., Hofmann, G.E. (2016). Improving Conservation Outcomes with a New Paradigm for Understanding Species' Fundamental and Realized Adaptive Capacity. Conservation Letters 9, 131-137.

Bellard, C., Bertelsmeier, C., Leadley, P., Thuiller, W., Courchamp, F. (2012). Impacts of climate change on the future of biodiversity. Ecology Letters 15, 365-377.

Bellassen, V., Luyssaert, S. (2014). Carbon sequestration: Managing forests in uncertain times. Nature 506, 153-155. 
Beltran, B.J., Franklin, J., Syphard, A.D., Regan, H.M., Flint, L.E., Flint, A.L. (2014). Effects of climate change and urban development on the distribution and conservation of vegetation in a Mediterranean type ecosystem. International Journal of Geographical Information Science 28, 1561-1589.

Benítez-López, A., Alkemade, R., Schipper, A.M., Ingram, D.J., Verweij, P.A., Eikelboom, J.A.J., Huijbregts, M.A.J. (2017). The impact of hunting on tropical mammal and bird populations. Science $356,180-183$.

Bennie, J., Hodgson, J.A., Lawson, C.R., Holloway, C.T.R., Roy, D.B., Brereton, T., Thomas, C.D., Wilson, R.J. (2013). Range expansion through fragmented landscapes under a variable climate. Ecology Letters 16, 921-929.

Berry, P., Ogawa-Onishi, Y., McVey, A. (2013). The vulnerability of threatened species: adaptive capability and adaptation opportunity. Biology 2, 872-893.

Bertrand, R., Lenoir, J., Piedallu, C., Riofrio-Dillon, G., de Ruffray, P., Vidal, C., Pierrat, J.-C., Gegout, J.-C. (2011). Changes in plant community composition lag behind climate warming in lowland forests. Nature 479, 517-520.

Blake, J.G., Karr, J.R. (1987). Breeding Birds of Isolated Woodlots: Area and Habitat Relationships. Ecology 68, 1724-1734.

Borenstein, M., Hedges, L.V., Higgins, J.P.T., Rothstein, H.R. (2009). Introduction to MetaAnalysis. John Wiley \& Sons, New York.

Bouraoui, F., Grizzetti, B. (2014). Modelling mitigation options to reduce diffuse nitrogen water pollution from agriculture. Science of the Total Environment 468-469, 1267-1277.

Box, E.O. (1981). Macroclimate and Plant Forms: An Introduction to Predictive Modeling in Phytogeography. Dr. W. Junk Publishers, The Hague.

Bradshaw, W.E., Holzapfel, C.M. (2006). Evolutionary Response to Rapid Climate Change. Science 312, 1477-1478.

Broennimann, O., Thuiller, W., Hughes, G., Midgley, G.F., Alkemade, J., Guisan, A. (2006). Do geographic distribution, niche property and life form explain plants' vulnerability to global change? Global Change Biology 12, 1079-1093.

Brook, B.W., Sodhi, N.S., Bradshaw, C.J.A. (2008). Synergies among extinction drivers under global change. Trends in Ecology \& Evolution 23, 453-460.

Brown, K.A., Parks, K.E., Bethell, C.A., Johnson, S.E., Mulligan, M. (2015). Predicting Plant Diversity Patterns in Madagascar: Understanding the Effects of Climate and Land Cover Change in a Biodiversity Hotspot. PLoS ONE 10, e0122721.

Butchart, S., Walpole, M., Collen, B., van Strien, A., Scharlemann, J., Almond, R., Baillie, J., Bomhard, B., Brown, C., Bruno, J. (2010). Global biodiversity: indicators of recent declines. Science 328, 1164-1168.

Bütof, A., von Riedmatten, L.R., Dormann, C.F., Scherer-Lorenzen, M., Welk, E., Bruelheide, H. (2012). The responses of grassland plants to experimentally simulated climate change depend on land use and region. Global Change Biology 18, 127-137.

Byrd, K.B., Flint, L.E., Alvarez, P., Casey, C.F., Sleeter, B.M., Soulard, C.E., Flint, A.L., Sohl, T.L. (2015). Integrated climate and land use change scenarios for California rangeland ecosystem services: wildlife habitat, soil carbon, and water supply. Landscape Ecology 30, 729-750.

Cardinale, B., Duffy, J.E., Gonzalez, A., Hooper, D., Perrings, C., Venail, P., Narwani, A., Mace, G., Tilman, D., Wardle, D., Kinzig, A., Daily, G., Loreau, M., Grace, J.B., Larigauderie, A., Srivastava, D., Naeem, S. (2012). Biodiversity loss and its impact on humanity. Nature 486, 59.

CBD (1992). Convention on Biological Diversity. United Nations, Montreal, Canada. 
CBD (2014). Global Biodiversity Outlook 4. Secretariat of the Convention on Biological Diversity, Montreal, Canada.

CBD (2016). Indicators for the Strategic Plan for Biodiversity 2011-2020 and the Aichi Biodiversity Targets (XIII/28.) Decision adopted by the Conference of the Parties to the Convention on Biological Diversity. Secretariat of the Convention on Biological Diversity, Montreal, Canada.

CBD (2019). Biodiversity and the 2030 Agenda for Sustainable Development. Technical Note. Secretariat of the Convention on Biological Diversity, Montreal, Canada.

CEE (2013). Guidelines for Systematic Review and Evidence Synthesis in Environmental Management. Version 4.2. Centre for Evidence-Based Conservation, Bangor University, UK.

Chen, F., Wang, J., Jin, L., Zhang, Q., Li, J., Chen, J. (2009). Rapid warming in mid-latitude central Asia for the past 100 years. Frontiers of Earth Science in China 3, 42.

Chen, T., Bao, A., Jiapaer, G., Guo, H., Zheng, G., Jiang, L., Chang, C., Tuerhanjiang, L. (2019). Disentangling the relative impacts of climate change and human activities on arid and semiarid grasslands in Central Asia during 1982-2015. Science of the Total Environment 653, 1311-1325.

Christensen, L., Coughenour, M.B., Ellis, J.E., Chen, Z.Z. (2004). Vulnerability of the Asian typical steppe to grazing and climate change. Climatic Change 63, 351-368.

Cook, B.I., Wolkovich, E.M., Davies, T.J., Ault, T.R., Betancourt, J.L., Allen, J.M., Bolmgren, K., Cleland, E.E., Crimmins, T.M., Kraft, N.J.B., Lancaster, L.T., Mazer, S.J., McCabe, G.J., McGill, B.J., Parmesan, C., Pau, S., Regetz, J., Salamin, N., Schwartz, M.D., Travers, S.E. (2012). Sensitivity of Spring Phenology to Warming Across Temporal and Spatial Climate Gradients in Two Independent Databases. Ecosystems 15, 1283-1294.

Cramer, W.P., Leemans, R. (1993). Assessing impacts of climate change on vegetation using climate classification systems. In Vegetation dynamics modelling and global change. Chapman-Hall, New York, 190-217.

Cunningham, S.C., Mac Nally, R., Baker, P.J., Cavagnaro, T.R., Beringer, J., Thomson, J.R., Thompson, R.M. (2015). Balancing the environmental benefits of reforestation in agricultural regions. Perspectives in Plant Ecology, Evolution and Systematics 17, 301317.

D’Amato, A.W., Bradford, J.B., Fraver, S., Palik, B.J. (2011). Forest management for mitigation and adaptation to climate change: Insights from long-term silviculture experiments. Forest Ecology and Management 262, 803-816.

Dangal, S.R.S., Tian, H., Lu, C., Pan, S., Pederson, N., Hessl, A. (2016). Synergistic effects of climate change and grazing on net primary production of Mongolian grasslands. Ecosphere 7, e01274-n/a.

Dawson, T.P., Jackson, S.T., House, J.I., Prentice, I.C., Mace, G.M. (2011). Beyond Predictions: Biodiversity Conservation in a Changing Climate. Science 332, 53-58.

de Beurs, K.M., Henebry, G.M., Owsley, B.C., Sokolik, I. (2015). Using multiple remote sensing perspectives to identify and attribute land surface dynamics in Central Asia 2001-2013. Remote Sensing of Environment 170, 48-61.

de Chazal, J., Rounsevell, M.D.A. (2009). Land-use and climate change within assessments of biodiversity change: A review. Global Environmental Change-Human and Policy Dimensions 19, 306-315.

Defourny, P., Boettcher, M., Bontemps, S., Kirches, G., Krueger, O., Lamarche, C., Lembrée, C., Radoux, J., Verheggen, A. (2014). Algorithm theoretical basis document for land cover climate change initiative. European Space Agency, 191. 
Díaz, S., Demissew, S., Carabias, J., Joly, C., Lonsdale, M., Ash, N., Larigauderie, A., Adhikari, J.R., Arico, S., Báldi, A., Bartuska, A., Baste, I.A., Bilgin, A., Brondizio, E., Chan, K.M.A., Figueroa, V.E., Duraiappah, A., Fischer, M., Hill, R., Koetz, T., Leadley, P., Lyver, P., Mace, G.M., Martin-Lopez, B., Okumura, M., Pacheco, D., Pascual, U., Pérez, E.S., Reyers, B., Roth, E., Saito, O., Scholes, R.J., Sharma, N., Tallis, H., Thaman, R., Watson, R., Yahara, T., Hamid, Z.A., Akosim, C., Al-Hafedh, Y., Allahverdiyev, R., Amankwah, E., Asah, T.S., Asfaw, Z., Bartus, G., Brooks, A.L., Caillaux, J., Dalle, G., Darnaedi, D., Driver, A., Erpul, G., Escobar-Eyzaguirre, P., Failler, P., Fouda, A.M.M., Fu, B., Gundimeda, H., Hashimoto, S., Homer, F., Lavorel, S., Lichtenstein, G., Mala, W.A., Mandivenyi, W., Matczak, P., Mbizvo, C., Mehrdadi, M., Metzger, J.P., Mikissa, J.B., Moller, H., Mooney, H.A., Mumby, P., Nagendra, H., Nesshover, C., OtengYeboah, A.A., Pataki, G., Roué, M., Rubis, J., Schultz, M., Smith, P., Sumaila, R., Takeuchi, K., Thomas, S., Verma, M., Yeo-Chang, Y., Zlatanova, D. (2015). The IPBES Conceptual Framework - connecting nature and people. Current Opinion in Environmental Sustainability 14, 1-16.

Díaz, S., Fargione, J., Chapin, F.S., Tilman, D. (2006). Biodiversity Loss Threatens Human Well-Being. PLoS Biology 4, e277.

Díaz, S., Hector, A., Wardle, D.A. (2009). Biodiversity in forest carbon sequestration initiatives: not just a side benefit. Current Opinion in Environmental Sustainability 1, 55-60.

Doelman, J.C., Stehfest, E., Tabeau, A., van Meijl, H., Lassaletta, L., Gernaat, D.E.H.J., Hermans, K., Harmsen, M., Daioglou, V., Biemans, H., van der Sluis, S., van Vuuren, D.P. (2018). Exploring SSP land-use dynamics using the IMAGE model: Regional and gridded scenarios of land-use change and land-based climate change mitigation. Global Environmental Change 48, 119-135.

Dornelas, M., Gotelli, N.J., McGill, B., Shimadzu, H., Moyes, F., Sievers, C., Magurran, A.E. (2014). Assemblage Time Series Reveal Biodiversity Change but Not Systematic Loss. Science 344, 296-299.

Ebeling, J., Yasué, M. (2008). Generating carbon finance through avoided deforestation and its potential to create climatic, conservation and human development benefits. Philosophical transactions of the Royal Society of London. Series B, Biological sciences 363, 1917 1924.

Endreny, T.A. (2018). Strategically growing the urban forest will improve our world. Nature Communications 9, 1160-1160.

Engler, R., Randin, C., Vittoz, P., Czaka, T., Beniston, M., Zimmermann, N., Guisan, A. (2009). Predicting future distributions of mountain plants under climate change: does dispersal capacity matter? Ecography $32,34-45$.

Fahrig, L. (2003). Effects of Habitat Fragmentation on Biodiversity. Annual Review of Ecology, Evolution and Systematics 34, 487-515.

Fajardy, M., Mac Dowell, N. (2017). Can BECCS deliver sustainable and resource efficient negative emissions? Energy \& Environmental Science 10, 1389-1426.

FAO (2007). Subregional report on animal genetic resources: Central Asia. Annex to The State of the World's Animal Genetic Resources for Food and Agriculture Food and Agriculture Organization of the United Nations, Rome.

Foden, W.B., Butchart, S.H.M., Stuart, S.N., Vie, J.-C., Akcakaya, H.R., Angulo, A., DeVantier, L.M., Gutsche, A., Turak, E., Cao, L., Donner, S.D., Katariya, V., Bernard, R., Holland, R.A., Hughes, A.F., O'Hanlon, S.E., Garnett, S.T., Sekercioglu, C.H., Mace, G.M. (2013). Identifying the World's Most Climate Change Vulnerable Species: A Systematic Trait-Based Assessment of all Birds, Amphibians and Corals. PLoS ONE 8, e65427. 
Foley, J.A., DeFries, R., Asner, G.P., Barford, C., Bonan, G., Carpenter, S.R., Chapin, F.S., Coe, M.T., Daily, G.C., Gibbs, H.K., Helkowski, J.H., Holloway, T., Howard, E.A., Kucharik, C.J., Monfreda, C., Patz, J.A., Prentice, I.C., Ramankutty, N., Snyder, P.K. (2005). Global Consequences of Land Use. Science 309, 570-574.

Fordham, D.A., Akcakaya, H.R., Araujo, M.B., Elith, J., Keith, D.A., Pearson, R., Auld, T.D., Mellin, C., Morgan, J.W., Regan, T.J., Tozer, M., Watts, M.J., White, M., Wintle, B.A., Yates, C., Brook, B.W. (2012). Plant extinction risk under climate change: are forecast range shifts alone a good indicator of species vulnerability to global warming? Global Change Biology 18, 1357-1371.

Fronzek, S., Carter, T.R., Pirttioja, N., Alkemade, R., Audsley, E., Bugmann, H., Flörke, M., Holman, I., Honda, Y., Ito, A., Janes-Bassett, V., Lafond, V., Leemans, R., Mokrech, M., Nunez, S., Sandars, D., Snell, R., Takahashi, K., Tanaka, A., Wimmer, F., Yoshikawa, M. (2019). Determining sectoral and regional sensitivity to climate and socio-economic change in Europe using impact response surfaces. Regional Environmental Change 19, 679-693.

Garcia-Valdes, R., Svenning, J.-C., Zavala, M.A., Purves, D.W., Araujo, M.B. (2015). Evaluating the combined effects of climate and land-use change on tree species distributions. Journal of Applied Ecology 52, 902-912.

Gärdenfors, U. (2001). Classifying threatened species at national versus global levels. Trends in Ecology \& Evolution 16, 511-516.

Gaveau, D.L.A., Sheil, D., Husnayaen, Salim, M.A., Arjasakusuma, S., Ancrenaz, M., Pacheco, P., Meijaard, E. (2016). Rapid conversions and avoided deforestation: examining four decades of industrial plantation expansion in Borneo. Scientific Reports 6, 32017.

Gintzburger, G., Le Houérou, H.N., Toderich, K.N. (2005). The Steppes of Middle Asia: Post1991 Agricultural and Rangeland Adjustment. Arid Land Research and Management 19, 215-239.

Griscom, B.W., Adams, J., Ellis, P.W., Houghton, R.A., Lomax, G., Miteva, D.A., Schlesinger, W.H., Shoch, D., Siikamäki, J.V., Smith, P., Woodbury, P., Zganjar, C., Blackman, A., Campari, J., Conant, R.T., Delgado, C., Elias, P., Gopalakrishna, T., Hamsik, M.R., Herrero, M., Kiesecker, J., Landis, E., Laestadius, L., Leavitt, S.M., Minnemeyer, S., Polasky, S., Potapov, P., Putz, F.E., Sanderman, J., Silvius, M., Wollenberg, E., Fargione, J. (2017). Natural climate solutions. Proceedings of the National Academy of Sciences $114,11645-11650$.

Guisan, A., Thuiller, W. (2005). Predicting species distribution: offering more than simple habitat models. Ecology Letters 8, 993-1009.

Guisan, A., Zimmermann, N.E. (2000). Predictive habitat distribution models in ecology. Ecological Modelling 135, 147-186.

Hamann, A., Aitken, S.N. (2013). Conservation planning under climate change: accounting for adaptive potential and migration capacity in species distribution models. Diversity and Distributions 19, 268-280.

Hamidov, A., Helming, K., Balla, D. (2016). Impact of agricultural land use in Central Asia: a review. Agronomy for Sustainable Development 36, 6.

Harper, A.B., Powell, T., Cox, P.M., House, J., Huntingford, C., Lenton, T.M., Sitch, S., Burke, E., Chadburn, S.E., Collins, W.J., Comyn-Platt, E., Daioglou, V., Doelman, J.C., Hayman, G., Robertson, E., van Vuuren, D., Wiltshire, A., Webber, C.P., Bastos, A., Boysen, L., Ciais, P., Devaraju, N., Jain, A.K., Krause, A., Poulter, B., Shu, S. (2018). Land-use emissions play a critical role in land-based mitigation for Paris climate targets. Nature Communications 9, 2938. 
Harrison, P.A., Dunford, R.W., Holman, I.P., Cojocaru, G., Madsen, M.S., Chen, P.-Y., Pedde, S., Sandars, D. (2019a). Differences between low-end and high-end climate change impacts in Europe across multiple sectors. Regional Environmental Change 19, 695-709.

Harrison, P.A., Jäger, J., Frantzeskaki, N., Berry, P. (2019b). Understanding high-end climate change: from impacts to co-creating integrated and transformative solutions. Regional Environmental Change 19, 621-627.

Heikkinen, R.K., Luoto, M., Araujo, M.B., Virkkala, R., Thuiller, W., Sykes, M.T. (2006). Methods and uncertainties in bioclimatic envelope modelling under climate change. Progress in Physical Geography 30, 751-777.

Heink, U., Kowarik, I. (2010). What criteria should be used to select biodiversity indicators? Biodiversity and Conservation 19, 3769-3797.

Hellmann, F., Alkemade, R., Knol, O.M. (2016). Dispersal based climate change sensitivity scores for European species. Ecological Indicators 71, 41-46.

Henderson, B.B., Gerber, P.J., Hilinski, T.E., Falcucci, A., Ojima, D.S., Salvatore, M., Conant, R.T. (2015). Greenhouse gas mitigation potential of the world's grazing lands: Modeling soil carbon and nitrogen fluxes of mitigation practices. Agriculture, Ecosystems \& Environment 207, 91-100.

Herrero, M., Henderson, B., Havlík, P., Thornton, P.K., Conant, R.T., Smith, P., Wirsenius, S., Hristov, A.N., Gerber, P., Gill, M., Butterbach-Bahl, K., Valin, H., Garnett, T., Stehfest, E. (2016). Greenhouse gas mitigation potentials in the livestock sector. Nature Climate Change 6, 452.

Herrero, M., Thornton, P.K., Gerber, P., Reid, R.S. (2009). Livestock, livelihoods and the environment: understanding the trade-offs. Current Opinion in Environmental Sustainability 1, 111-120.

Heubes, J., Schmidt, M., Stuch, B., Marquez, J.R.G., Wittig, R., Zizka, G., Thiombiano, A., Sinsin, B., Schaldach, R., Hahn, K. (2013). The projected impact of climate and land use change on plant diversity: An example from West Africa. Journal of Arid Environments 96, 48-54.

Heywood, V.H., Watson, R.T. (1995). Global biodiversity assessment. Cambridge University Press Cambridge.

Higgins, P.A.T. (2007). Biodiversity loss under existing land use and climate change: an illustration using northern South America. Global Ecology and Biogeography 16, 197204.

Hoegh-Guldberg, O., Jacob, D., Taylor, M., Bindi, M., Brown, S., Camilloni, I., Diedhiou, A., Djalante, R., Ebi, K.L., Engelbrecht, F., Guiot, J., Hijioka, Y., Mehrotra, S., Payne, A., Seneviratne, S.I., Thomas, A., Warren, R., Zhou, G. (2018). Impacts of $1.5^{\circ} \mathrm{C}$ Global Warming on Natural and Human Systems. In: Global Warming of $1.5^{\circ} \mathrm{C}$. An IPCC Special Report on the impacts of global warming of $1.5^{\circ} \mathrm{C}$ above pre-industrial levels and related global greenhouse gas emission pathways, in the context of strengthening the global response to the threat of climate change, sustainable development, and efforts to eradicate poverty Intergovernmental Panel on Climate Change, In Press.

Hoffmann, A., Sgrò, C. (2011). Climate change and evolutionary adaptation. Nature 470, 479.

Hoiss, B., Gaviria, J., Leingartner, A., Krauss, J., Steffan-Dewenter, I. (2013). Combined effects of climate and management on plant diversity and pollination type in alpine grasslands. Diversity and Distributions 19, 386-395.

Hu, Z., Zhang, C., Hu, Q., Tian, H. (2014). Temperature Changes in Central Asia from 1979 to 2011 Based on Multiple Datasets. Journal of Climate 27, 1143-1167. 
IMPRESSIONS (2014). Impacts and Risks from High-End Scenarios: Strategies for Innovative Solutions. Proposal for a Collaborative Project. PART B. IMPRESSIONS project, Environmental Change Institute, Oxford.

IPBES (2016). Summary for policymakers of the methodological assessment report on scenarios and models of biodiversity and ecosystem services of the Intergovernmental SciencePolicy Platform on Biodiversity and Ecosystem Services. Secretariat of the Intergovernmental Science-Policy Platform on Biodiversity and Ecosystem Services, Bonn.

IPBES (2018a). The IPBES regional assessment report on biodiversity and ecosystem services for Africa. Secretariat of the Intergovernmental Science-Policy Platform on Biodiversity and Ecosystem Services, Bonn.

IPBES (2018b). The IPBES regional assessment report on biodiversity and ecosystem services for Asia and the Pacific. Secretariat of the Intergovernmental Science-Policy Platform on Biodiversity and Ecosystem Services, Bonn.

IPBES (2018c). The IPBES regional assessment report on biodiversity and ecosystem services for Europe and Central Asia. Secretariat of the Intergovernmental Science-Policy Platform on Biodiversity and Ecosystem Services, Bonn.

IPBES (2018d). The IPBES regional assessment report on biodiversity and ecosystem services for the Americas. Secretariat of the Intergovernmental Science-Policy Platform on Biodiversity and Ecosystem Services, Bonn.

IPBES (2019). Summary for Policymakers of the Global Assessment Report on Biodiversity and Ecosystem Services of the Intergovernmental Science - Policy Platform on Biodiversity and Ecosystem Services. Bonn.

IPCC (2013a). Annex II: Climate System Scenario Tables. In: Stocker, T.F., D. Qin, G.-K. Plattner, M. Tignor, S.K. Allen, J. Boschung, A. Nauels, Y. Xia, V. Bex and P.M. Midgley (eds.). Climate Change 2013: The Physical Science Basis. Contribution of Working Group I to the Fifth Assessment Report of the Intergovernmental Panel on Climate Change. IPCC, Cambridge University Press, Cambridge.

IPCC (2013b). Climate Change 2013: The Physical Science Basis. Contribution of Working Group I to the Fifth Assessment Report of the Intergovernmental Panel on Climate Change. Cambridge University Press Cambridge.

IPCC (2014a). Annex II: Glossary. Mach, K.J., S. Planton and C. von Stechow (eds.). In: Core Writing Team, R.K. Pachauri and L.A. Meyer (eds.). Climate Change 2014: Synthesis Report. Contribution of Working Groups I, II and III to the Fifth Assessment Report of the Intergovernmental Panel on Climate Change. IPCC, Geneva, Switzerland. pp. 117130.

IPCC (2014b). Climate Change 2014: Synthesis Report. Contribution of Working Groups I, II and III to the Fifth Assessment Report of the Intergovernmental Panel on Climate Change. IPCC, Geneva, Switzerland.

IPCC (2018). Summary for Policymakers. In: Global Warming of $1.5^{\circ}$ C. An IPCC Special Report on the impacts of global warming of $1.5^{\circ} \mathrm{C}$ above pre-industrial levels and related global greenhouse gas emission pathways, in the context of strengthening the global response to the threat of climate change, sustainable development, and efforts to eradicate poverty. Integovernmental Panel on Climate Change, In Press. pp. 1-32

IUCN (2019a). The IUCN Red List of Threatened Species. Version 2018-2.

IUCN (2019b). Post-2020 Global Biodiversity Framework. International Union for Conservation of Nature.

Jantz, S.M., Barker, B., Brooks, T.M., Chini, L.P., Huang, Q., Moore, R.M., Noel, J., Hurtt, G.C. (2015). Future habitat loss and extinctions driven by land-use change in biodiversity 
hotspots under four scenarios of climate-change mitigation. Conservation Biology 29, $1122-1131$.

Jetz, W., Wilcove, D., Dobson, A. (2007). Projected impacts of climate and land-use change on the global diversity of birds. PLoS Biology 5, e157.

Johnson, C.N., Balmford, A., Brook, B.W., Buettel, J.C., Galetti, M., Guangchun, L., Wilmshurst, J.M. (2017). Biodiversity losses and conservation responses in the Anthropocene. Science 356, 270-275.

Joint Research Centre (2003). The Global Land Cover Map for the Year 2000.

Jones, B., O'Neill, B. (2013). Historically grounded spatial population projections for the continental United States. Environmental Research Letters 8, 044021.

Kalwij, J.M., Robertson, M.P., van Rensburg, B.J. (2015). Annual monitoring reveals rapid upward movement of exotic plants in a montane ecosystem. Biological Invasions 17, 3517-3529.

Kamp, J., Koshkin, M.A., Bragina, T.M., Katzner, T.E., Milner-Gulland, E.J., Schreiber, D., Sheldon, R., Shmalenko, A., Smelansky, I., Terraube, J., Urazaliev, R. (2016). Persistent and novel threats to the biodiversity of Kazakhstan's steppes and semi-deserts. Biodiversity and Conservation 25, 2521-2541.

Kamp, J., Urazaliev, R., Donald, P.F., Hölzel, N. (2011). Post-Soviet agricultural change predicts future declines after recent recovery in Eurasian steppe bird populations. Biological Conservation 144, 2607-2614.

Keith, H., Mackey, B.G., Lindenmayer, D.B. (2009). Re-evaluation of forest biomass carbon stocks and lessons from the world's most carbon-dense forests. Proceedings of the National Academy of Sciences 106, 11635-11640.

Kintisch, E. (2009). Projections of climate change go from bad to worse. Science 323, 15461547.

Koh, L.P., Ghazoul, J. (2010). Spatially explicit scenario analysis for reconciling agricultural expansion, forest protection, and carbon conservation in Indonesia. Proceedings of the National Academy of Sciences 107, 11140-11144.

Kok, K., Pedde, S. (2016). IMPRESSIONS socio-economic scenarios. IMPRESSIONS project, Environmental Change Institute, Oxford.

Kok, K., Pedde, S., Gramberger, M., Harrison, P.A., Holman, I.P. (2019). New European socioeconomic scenarios for climate change research: operationalising concepts to extend the shared socio-economic pathways. Regional Environmental Change 19, 643-654.

Kok, M.T.J., Alkemade, R., Bakkenes, M., van Eerdt, M., Janse, J., Mandryk, M., Kram, T., Lazarova, T., Meijer, J., van Oorschot, M., Westhoek, H., van der Zagt, R., van der Berg, M., van der Esch, S., Prins, A.-G., van Vuuren, D.P. (2018). Pathways for agriculture and forestry to contribute to terrestrial biodiversity conservation: A global scenario-study. Biological Conservation 221, 137-150.

Kuiper, J., Janse, J., Teurlincx, S., Verhoeven, J., Alkemade, R. (2014). The impact of river regulation on the biodiversity intactness of floodplain wetlands. Wetlands Ecology and Management 22, 647-658.

Lal, R. (2008). Carbon sequestration. Philosophical Transactions of the Royal Society B: Biological Sciences 363, 815-830.

Lawler, J., White, D., Neilson, R., Blaustein, A. (2006). Predicting climate-induced range shifts: model differences and model reliability. Global Change Biology 12, 1568-1584.

Leadley, P., Krug, C., Alkemade, R., Pereira, H., U., S., Walpole, M., Marques, A., Newbold, T., Teh, L., van Kolck, J., Bellard, C., Januchowski-Hartley, S., Mumby, P. (2014). Progress towards the Aichi Biodiversity Targets: An Assessment of Biodiversity Trends, 
Policy Scenarios and Key Actions. Technical Series 78. Secretariat of the Convention on Biological Diversity, Montreal, Canada.

Leemans, R. (1991). Sensitivity analysis of a forest succession model. Ecological Modelling 53, 247-262.

Leemans, R., Halpin, P.N. (1992). Biodiversity and Global Climate Change. In: Groombridge, B. (Ed.) Global Biodiversity. Springer, Dordrecht, Pages 254-255

Leemans, R., Vellinga, P. (2017). The scientific motivation of the internationally agreed 'well below $2{ }^{\circ} \mathrm{C}^{\prime}$ climate protection target: a historical perspective. Current Opinion in Environmental Sustainability 26-27, 134-142.

Lewis, S.L., Wheeler, C.E., Mitchard, E.T.A., Koch, A. (2019). Restoring natural forests is the best way to remove atmospheric carbon. Nature 568, 25-28.

Lindner, M., Maroschek, M., Netherer, S., Kremer, A., Barbati, A., Garcia-Gonzalo, J., Seidl, R., Delzon, S., Corona, P., Kolström, M., Lexer, M.J., Marchetti, M. (2010). Climate change impacts, adaptive capacity, and vulnerability of European forest ecosystems. Forest Ecology and Management 259, 698-709.

Lioubimtseva, E., Henebry, G.M. (2009). Climate and environmental change in arid Central Asia: Impacts, vulnerability, and adaptations. Journal of Arid Environments 73, 963-977.

Lippke, B., Oneil, E., Harrison, R., Skog, K., Gustavsson, L., Sathre, R. (2011). Life cycle impacts of forest management and wood utilization on carbon mitigation: knowns and unknowns. Carbon Management 2, 303-333.

Loarie, S., Carter, B., Hayhoe, K., McMahon, S., Moe, R., Knight, C., Ackerly, D. (2008). Climate Change and the Future of California's Endemic Flora. PLoS ONE 3,

MA (2005). Ecosystems and Human Well-being. Millenium Ecosystem Assessment, Washington, DC.

Mace, G.M., Baillie, J.E.M. (2007). The 2010 Biodiversity Indicators: Challenges for Science and Policy. Conservation Biology 21, 1406-1413.

Malcolm, J., Liu, C., Neilson, R., Hansen, L., Hannah, L. (2006). Global warming and extinctions of endemic species from biodiversity hotspots. Conservation Biology 20, 538-548.

Mallon, D.P., Zhigang, J. (2009). Grazers on the plains: challenges and prospects for large herbivores in Central Asia. Journal of Applied Ecology 46, 516-519.

Mantyka-Pringle, C.S., Martin, T.G., Rhodes, J.R. (2012). Interactions between climate and habitat loss effects on biodiversity: a systematic review and meta-analysis. Global Change Biology 18, 1239-1252.

Mantyka-Pringle, C.S., Visconti, P., Di Marco, M., Martin, T.G., Rondinini, C., Rhodes, J.R. (2015). Climate change modifies risk of global biodiversity loss due to land-cover change. Biological Conservation 187, 103-111.

McClean, C., Lovett, J., Kuper, W., Hannah, L., Sommer, J., Barthlott, W., Termansen, M., Smith, G., Tokamine, S., Taplin, J. (2005). African plant diversity and climate change. Annals of the Missouri Botanical Garden 92, 139-152.

McGuire, J.L., Lawler, J.J., McRae, B.H., Nuñez, T.A., Theobald, D.M. (2016). Achieving climate connectivity in a fragmented landscape. Proceedings of the National Academy of Sciences, USA 113, 7195-7200.

Meyer, S.E., Leger, E.A., Eldon, D.R., Coleman, C.E. (2016). Strong genetic differentiation in the invasive annual grass Bromus tectorum across the Mojave-Great Basin ecological transition zone. Biological Invasions 18, 1611-1628.

Midgley, G., Hughes, G., Thuiller, W., Rebelo, A. (2006). Migration rate limitations on climate change-induced range shifts in Cape Proteaceae. Diversity and Distributions 12, 555 562 . 
Miles, L., Kapos, V. (2008). Reducing Greenhouse Gas Emissions from Deforestation and Forest Degradation: Global Land-Use Implications. Science 320, 1454-1455.

Mirzabaev, A. (2013). Impacts of Weather Variability and Climate Change on Agricultural Revenues in Central Asia. Quarterly Journal of International Agriculture 25, 237-252.

Mirzabaev, A., Ahmed, M., Werner, J., Pender, J., Louhaichi, M. (2015). Rangelands of Central Asia: challenges and opportunities. Journal of Arid Land 8, 93-108.

Moss, R., Edmonds, J., Hibbard, K., Manning, M., Rose, S., van Vuuren, D., Carter, T., Emori, S., Kainuma, M., Kram, T., Meehl, G., Mitchell, J., Nakicenovic, N., Riahi, K., Smith, S., Stouffer, R., Thomson, A., Weyant, J., Wilbanks, T. (2010). The next generation of scenarios for climate change research and assessment. Nature 463, 747-756.

NASA (2019). Effects of Changing the Carbon Cycle.

Newbold, T. (2018). Future effects of climate and land-use change on terrestrial vertebrate community diversity under different scenarios. Proceedings of the Royal Society of London, Series B: Biological Sciences 285, 20180792.

Newbold, T., Adams, G.L., Albaladejo Robles, G., Boakes, E.H., Braga Ferreira, G., Chapman, A.S.A., Etard, A., Gibb, R., Millard, J., Outhwaite, C.L., Williams, J.J. (2019). Climate and land-use change homogenise terrestrial biodiversity, with consequences for ecosystem functioning and human well-being. Emerging Topics in Life Sciences 3, $207-$ 219.

Newbold, T., Hudson, L.N., Arnell, A.P., Contu, S., De Palma, A., Ferrier, S., Hill, S.L.L., Hoskins, A.J., Lysenko, I., Phillips, H.R.P., Burton, V.J., Chng, C.W.T., Emerson, S., Gao, D., Pask-Hale, G., Hutton, J., Jung, M., Sanchez-Ortiz, K., Simmons, B.I., Whitmee, S., Zhang, H., Scharlemann, J.P.W., Purvis, A. (2016). Has land use pushed terrestrial biodiversity beyond the planetary boundary? A global assessment. Science $353,288-291$.

Newbold, T., Hudson, L.N., Hill, S.L.L., Contu, S., Lysenko, I., Senior, R.A., Borger, L., Bennett, D.J., Choimes, A., Collen, B., Day, J., De Palma, A., Diaz, S., EcheverriaLondono, S., Edgar, M.J., Feldman, A., Garon, M., Harrison, M.L.K., Alhusseini, T., Ingram, D.J., Itescu, Y., Kattge, J., Kemp, V., Kirkpatrick, L., Kleyer, M., Correia, D.L.P., Martin, C.D., Meiri, S., Novosolov, M., Pan, Y., Phillips, H.R.P., Purves, D.W., Robinson, A., Simpson, J., Tuck, S.L., Weiher, E., White, H.J., Ewers, R.M., Mace, G.M., Scharlemann, J.P.W., Purvis, A. (2015). Global effects of land use on local terrestrial biodiversity. Nature 520, 45-50.

Newbold, T., Hudson, L.N., Phillips, H.R., Hill, S.L., Contu, S., Lysenko, I., Blandon, A., Butchart, S.H., Booth, H.L., Day, J. (2014). A global model of the response of tropical and sub-tropical forest biodiversity to anthropogenic pressures. Proceedings of the Royal Society B: Biological Sciences 281, 20141371.

Nunez, S., Arets, E., Alkemade, R., Verwer, C., Leemans, R. (2019). Assessing the impacts of climate change on biodiversity: is below $2{ }^{\circ} \mathrm{C}$ enough? Climatic Change 154, 351-365.

O’Neill, B.C., Kriegler, E., Riahi, K., Ebi, K.L., Hallegatte, S., Carter, T.R., Mathur, R., van Vuuren, D.P. (2014). A new scenario framework for climate change research: the concept of shared socioeconomic pathways. Climatic Change 122, 387-400.

Oliver, T.H., Morecroft, M.D. (2014). Interactions between climate change and land use change on biodiversity: attribution problems, risks, and opportunities. Wiley Interdisciplinary Reviews-Climate Change 5, 317-335.

Olson, D., Dinerstein, E., Wikramanayake, E., Burgess, N., Powell, G., Underwood, E., D'Amico, J., Itoua, I., Strand, H., Morrison, J., Loucks, C., Allnutt, T., Ricketts, T., Kura, Y., Lamoreux, J., Wettengel, W., Hedao, P., Kassem, K. (2001). Terrestrial ecoregions of the worlds: A new map of life on Earth. Bioscience 51, 933-938. 
Opdam, P., Wascher, D. (2004). Climate change meets habitat fragmentation: linking landscape and biogeographical scale levels in research and conservation. Biological Conservation 117, 285-297.

Pacifici, M., Foden, W.B., Visconti, P., Watson, J.E.M., Butchart, S.H.M., Kovacs, K.M., Scheffers, B.R., Hole, D.G., Martin, T.G., Akçakaya, H.R., Corlett, R.T., Huntley, B., Bickford, D., Carr, J.A., Hoffmann, A.A., Midgley, G.F., Pearce-Kelly, P., Pearson, R.G., Williams, S.E., Willis, S.G., Young, B., Rondinini, C. (2015). Assessing species vulnerability to climate change. Nature Climate Change 5, 215-225.

Pacifici, M., Visconti, P., Butchart, S.H.M., Watson, J.E.M., Cassola, F.M., Rondinini, C. (2017). Species' traits influenced their response to recent climate change. Nature Climate Change 7, 205-208.

Parmesan, C. (2006). Ecological and Evolutionary Responses to Recent Climate Change. Annual Review of Ecology, Evolution, and Systematics 37, 637-669.

Parmesan, C., Burrows, M.T., Duarte, C.M., Poloczanska, E.S., Richardson, A.J., Schoeman, D.S., Singer, M.C. (2013). Beyond climate change attribution in conservation and ecological research. Ecology Letters 16, 58-71.

Parmesan, C., Yohe, G. (2003). A globally coherent fingerprint of climate change impacts across natural systems. Nature 421, 37-42.

PBL (2012). Roads from Rio+20. Pathways to achieve global sustainability goals by 2050 . Netherlands Environmental Assessment Agency, The Hague. 286.

Pearson, R.G., Dawson, T.P. (2003). Predicting the impacts of climate change on the distribution of species: are bioclimate envelope models useful? Global Ecology and Biogeography $12,361-371$.

Pearson, R.G., Thuiller, W., Araujo, M.B., Martinez-Meyer, E., Brotons, L., McClean, C., Miles, L., Segurado, P., Dawson, T.P., Lees, D.C. (2006). Model-based uncertainty in species range prediction. Journal of Biogeography 33, 1704-1711.

Pecl, G., Araújo, M., Bell, J., Blanchard, J., Bonebrake, T., Chen, I.-C., Clark, T., Colwell, R., Danielsen, F., Evengård, B., Falconi, L., Ferrier, S., Frusher, S., Garcia, R., Griffis, R., Hobday, A., Janion-Scheepers, C., Jarzyna, M., Jennings, S., Lenoir, J., Linnetved, H., Martin, V., McCormack, P., McDonald, J., Mitchell, N., Mustonen, T., Pandolfi, J., Pettorelli, N., Popova, E., Robinson, S., Scheffers, B., Shaw, J., Sorte, C., Strugnell, J., Sunday, J., Tuanmu, M.-N., Vergés, A., Villanueva, C., Wernberg, T., Wapstra, E., Williams, S. (2017). Biodiversity redistribution under climate change: Impacts on ecosystems and human well-being. Science 355, eaai9214.

Pedde, S., Kok, K., Onigkeit, J., Brown, C., Holman, I., Harrison, P.A. (2019). Bridging uncertainty concepts across narratives and simulations in environmental scenarios. Regional Environmental Change 19, 655-666.

Peñuelas, J., Sardans, J., Estiarte, M., Ogaya, R., Carnicer, J., Coll, M., Barbeta, A., RivasUbach, A., Llusià, J., Garbulsky, M., Filella, I., Jump, A.S. (2013). Evidence of current impact of climate change on life: a walk from genes to the biosphere. Global Change Biology 19, 2303-2338.

Pereira, H.M., Leadley, P.W., Proença, V., Alkemade, R., Scharlemann, J.P.W., FernandezManjarrés, J.F., Araújo, M.B., Balvanera, P., Biggs, R., Cheung, W.W.L., Chini, L., Cooper, H.D., Gilman, E.L., Guénette, S., Hurtt, G.C., Huntington, H.P., Mace, G.M., Oberdorff, T., Revenga, C., Rodrigues, P., Scholes, R.J., Sumaila, U.R., Walpole, M. (2010). Scenarios for global biodiversity in the 21st century. Science 330, 1496-1501.

Petz, K., Alkemade, R., Bakkenes, M., Schulp, C.J.E., van der Velde, M., Leemans, R. (2014). Mapping and modelling trade-offs and synergies between grazing intensity and 
ecosystem services in rangelands using global-scale datasets and models. Global Environmental Change 29, 223-234.

Pompe, S., Hanspach, J., Badeck, F., Klotz, S., Thuiller, W., Kuehn, I. (2008). Climate and land use change impacts on plant distributions in Germany. Biology Letters 4, 564-567.

Popp, A., Calvin, K., Fujimori, S., Havlik, P., Humpenöder, F., Stehfest, E., Bodirsky, B.L., Dietrich, J.P., Doelmann, J.C., Gusti, M., Hasegawa, T., Kyle, P., Obersteiner, M., Tabeau, A., Takahashi, K., Valin, H., Waldhoff, S., Weindl, I., Wise, M., Kriegler, E., Lotze-Campen, H., Fricko, O., Riahi, K., Vuuren, D.P.v. (2017). Land-use futures in the shared socio-economic pathways. Global Environmental Change 42, 331-345.

Popp, A., Humpenöder, F., Weindl, I., Bodirsky, B.L., Bonsch, M., Lotze-Campen, H., Müller, C., Biewald, A., Rolinski, S., Stevanovic, M., Dietrich, J.P. (2014). Land-use protection for climate change mitigation. Nature Climate Change 4, 1095.

Powell, T.W.R., Lenton, T.M. (2013). Scenarios for future biodiversity loss due to multiple drivers reveal conflict between mitigating climate change and preserving biodiversity. Environmental Research Letters 8, 025024.

Powlson, D.S., Stirling, C.M., Thierfelder, C., White, R.P., Jat, M.L. (2016). Does conservation agriculture deliver climate change mitigation through soil carbon sequestration in tropical agro-ecosystems? Agriculture, Ecosystems \& Environment 220, 164-174.

Ramachandran Nair, P.K., Mohan Kumar, B., Nair, V.D. (2009). Agroforestry as a strategy for carbon sequestration. Journal of Plant Nutrition and Soil Science 172, 10-23.

Ramsar (2018). Global Wetland Outlook: State of the World's Wetlands and their Services to People. Ramsar Convention Secretariat, Gland, Switzerland.

Riahi, K., Rao, S., Krey, V., Cho, C., Chirkov, V., Fischer, G., Kindermann, G., Nakicenovic, N., Rafaj, P. (2011). RCP 8.5-A scenario of comparatively high greenhouse gas emissions. Climatic Change 109, 33.

Riahi, K., van Vuuren, D.P., Kriegler, E., Edmonds, J., O’Neill, B.C., Fujimori, S., Bauer, N., Calvin, K., Dellink, R., Fricko, O., Lutz, W., Popp, A., Cuaresma, J.C., Kc, S., Leimbach, M., Jiang, L., Kram, T., Rao, S., Emmerling, J., Ebi, K., Hasegawa, T., Havlik, P., Humpenöder, F., Da Silva, L.A., Smith, S., Stehfest, E., Bosetti, V., Eom, J., Gernaat, D., Masui, T., Rogelj, J., Strefler, J., Drouet, L., Krey, V., Luderer, G., Harmsen, M., Takahashi, K., Baumstark, L., Doelman, J.C., Kainuma, M., Klimont, Z., Marangoni, G., Lotze-Campen, H., Obersteiner, M., Tabeau, A., Tavoni, M. (2017). The Shared Socioeconomic Pathways and their energy, land use, and greenhouse gas emissions implications: An overview. Global Environmental Change 42, 153-168.

Riordan, E.C., Gillespie, T.W., Pitcher, L., Pincetl, S.S., Jenerette, G.D., Pataki, D.E. (2015). Threats of future climate change and land use to vulnerable tree species native to Southern California. Environmental Conservation 42, 127-138.

Ripple, W.J., Wolf, C., Newsome, T.M., Hoffmann, M., Wirsing, A.J., McCauley, D.J. (2017). Extinction risk is most acute for the world's largest and smallest vertebrates. Proceedings of the National Academy of Sciences 114, 10678-10683.

Rogelj, J., Popp, A., Calvin, K.V., Luderer, G., Emmerling, J., Gernaat, D., Fujimori, S., Strefler, J., Hasegawa, T., Marangoni, G., Krey, V., Kriegler, E., Riahi, K., van Vuuren, D.P., Doelman, J., Drouet, L., Edmonds, J., Fricko, O., Harmsen, M., Havlík, P., Humpenöder, F., Stehfest, E., Tavoni, M. (2018a). Scenarios towards limiting global mean temperature increase below $1.5^{\circ} \mathrm{C}$. Nature Climate Change 8, 325-332.

Rogelj, J., Shindell, D., Jiang, K., Fifita, S., Forster, P., Ginzburg, V., Handa, C., Kheshgi, H., Kobayashi, S., Kriegler, E., Mundaca, L., Séférian, R., Vilariño, M.V. (2018b). Mitigation Pathways Compatible with $1.5^{\circ} \mathrm{C}$ in the Context of Sustainable Development. In: Global Warming of $1.5^{\circ} \mathrm{C}$. An IPCC Special Report on the impacts of global warming 
of $1.5^{\circ} \mathrm{C}$ above pre-industrial levels and related global greenhouse gas emission pathways, in the context of strengthening the global response to the threat of climate change, sustainable development, and efforts to eradicate poverty. Intergovernmental Panel on Climate Change, In Press.

Rondinini, C., Visconti, P. (2015). Scenarios of large mammal loss in Europe for the 21(st) century. Conservation Biology 29, 1028-1036.

Rudel, T.K., Coomes, O.T., Moran, E., Achard, F., Angelsen, A., Xu, J., Lambin, E. (2005). Forest transitions: towards a global understanding of land use change. Global Environmental Change 15, 23-31.

Rydin, H., Borgegard, S.-O. (1988). Plant Species Richness on Islands Over a Century of Primary Succession: Lake Hjalmaren. Ecology 69, 916-927.

Sala, O.E., Chapin, F.S., Armesto, J.J., Berlow, E., Bloomfield, J., Dirzo, R., Huber-Sanwald, E., Huenneke, L.F., Jackson, R.B., Kinzig, A. (2000). Global biodiversity scenarios for the year 2100. Science 287, 1770-1774.

Schipper, A., Bakkenes, M., Meijer, J., Alkemade, R., Huijbregts, M. (2016). The GLOBIO model. A technical description of version 3.5. PBL REPORT. The Netherlands Environmental Assessment Agency, The Hague. pp. 1-34.

Schmitt, C.B., Burgess, N.D., Coad, L., Belokurov, A., Besançon, C., Boisrobert, L., Campbell, A., Fish, L., Gliddon, D., Humphries, K., Kapos, V., Loucks, C., Lysenko, I., Miles, L., Mills, C., Minnemeyer, S., Pistorius, T., Ravilious, C., Steininger, M., Winkel, G. (2009). Global analysis of the protection status of the world's forests. Biological Conservation 142, 2122-2130.

Schnitzler, A., Hale, B.W., Alsum, E.M. (2007). Examining native and exotic species diversity in European riparian forests. Biological Conservation 138, 146-156.

Scholes, R.J., Biggs, R. (2005). A biodiversity intactness index. Nature 434, 45-49.

Schwartz, M.W. (1993). Modelling effects of habitat fragmentation on the ability of trees to respond to climatic warming. Biodiversity and Conservation 2, 51-61.

Segan, D.B., Murray, K.A., Watson, J.E.M. (2016). A global assessment of current and future biodiversity vulnerability to habitat loss-climate change interactions. Global Ecology and Conservation 5, 12-21.

Seidl, R., Thom, D., Kautz, M., Martin-Benito, D., Peltoniemi, M., Vacchiano, G., Wild, J., Ascoli, D., Petr, M., Honkaniemi, J., Lexer, M.J., Trotsiuk, V., Mairota, P., Svoboda, M., Fabrika, M., Nagel, T.A., Reyer, C.P.O. (2017). Forest disturbances under climate change. Nature Climate Change 7, 395.

Sekercioglu, C., Schneider, S., Fay, J., Loarie, S. (2008). Climate change, elevational range shifts, and bird extinctions. Conservation Biology 22, 140-150.

Settele, J., Scholes, R., Betts, R., Bunn, S., Leadley, P., Nepstad, D., Overpeck, J.T., Taboada, M.A. (2014). Terrestrial and inland water systems. In Climate Change 2014: Impacts, Adaptation, and Vulnerability. Part A: Global and Sectoral Aspects. Contribution of Working Group II to the Fifth Assessment Report of the Intergovernmental Panel on Climate Change. Intergovernmental Panel on Climate Change, Cambridge University Press, Cambridge, United Kingdom and New York, NY, USA, 271-359

Shoo, L., Williams, S., Hero, J. (2005). Climate warming and the rainforest birds of the Australian Wet Tropics: Using abundance data as a sensitive predictor of change in total population size. Biological Conservation 125, 335-343.

Singh, N.J., Grachev, I.A., Bekenov, A.B., Milner-Gulland, E.J. (2010). Tracking greenery across a latitudinal gradient in central Asia - the migration of the saiga antelope. Diversity and Distributions 16, 663-675. 
Smith, P., Bustamante, M., Ahammad, H., Clark, H., Dong, H., Elsiddig, E.A., Haberl, H., Harper, R., House, J., Jafari, M., Masera, O., Mbow, C., Ravindranath, N.H., Rice, C.W., Robledo Abad, C., Romanovskaya, A., Sperling, F., Tubiello, F. (2014). Agriculture, Forestry and Other Land Use (AFOLU). In: Climate Change 2014: Mitigation of Climate Change. Contribution of Working Group III to the Fifth Assessment Report of the Intergovernmental Panel on Climate Change Cambridge University Press, Cambridge, United Kingdom and New York, NY, USA.

Smith, P., Martino, D., Cai, Z., Gwary, D., Janzen, H., Kumar, P., McCarl, B., Ogle, S., O'Mara, F., Rice, C., Scholes, B., Sirotenko, O., Howden, M., McAllister, T., Pan, G., Romanenkov, V., Schneider, U., Towprayoon, S., Wattenbach, M., Smith, J. (2008). Greenhouse gas mitigation in agriculture. Philosophical Transactions of the Royal Society B: Biological Sciences 363, 789-813.

Smith, P., Price, J., Molotoks, A., Warren, R., Malhi, Y. (2018). Impacts on terrestrial biodiversity of moving from a $2^{\circ} \mathrm{C}$ to a $1.5^{\circ} \mathrm{C}$ target. Philosophical Transactions of the Royal Society A: Mathematical, Physical and Engineering Sciences 376, 20160456.

Solomon, A., Leemans, R. (1990). Climatic change and landscape-ecological response: issues and analysis. In: Boer, M.M., de Groot, R.S. (Eds.), Landscape Ecological Impact of Climatic Change. IOS Press, Amsterdam, pp. 293-317.

Stehfest, E., van Vuuren, D., Kram, T., Bouwman, L., Alkemade, R., Bakkenes, M., Biemans, H., Bouwman, A., den Elzen, M., Janse, J., Lucas, P., van Minnen, J., Müller, C., Gerdien Prins, A. (2014). Integrated Assessment of Global Environmental Change with IMAGE 3.0. Model Description and Policy Applications. PBL Netherlands Environmental Assessment Agency, The Hague.

Stehfest, E., van Zeist, W.-J., Valin, H., Havlik, P., Popp, A., Kyle, P., Tabeau, A., MasonD’Croz, D., Hasegawa, T., Bodirsky, B.L., Calvin, K., Doelman, J.C., Fujimori, S., Humpenöder, F., Lotze-Campen, H., van Meijl, H., Wiebe, K. (2019). Key determinants of global land-use projections. Nature Communications 10, 2166.

Suleimenov, M. (2014). Trends in the Agriculture of Central Asia and Implications for Rangelands and Croplands. In Novel Measurement and Assessment Tools for Monitoring and Management of Land and Water Resources in Agricultural Landscapes of Central Asia. Springer International Publishing, Cham, 91-105.

Thomas, C., Cameron, A., Green, R.E., Bakkenes, M., Beaumont, L.J., Collingham, Y.C., Erasmus, B.F.N., de Siqueira, M.F., Grainger, A., Hannah, L., Hughes, L., Huntley, B., van Jaarsveld, A.S., Midgley, G.F., Miles, L., Ortega-Huerta, M.A., Townsend Peterson, A., Phillips, O.L., Williams, S.E. (2004). Extinction risk from climate change. Nature 427, 145-148.

Thomas, C.D. (2000). Dispersal and extinction in fragmented landscapes. Proceedings of the Royal Society of London, Series B: Biological Sciences 267, 139-145.

Thornton, P.K. (2010). Livestock production: recent trends, future prospects. Philosophical Transactions of the Royal Society B: Biological Sciences 365, 2853-2867.

Thuiller, W., Albert, C., Araujo, M.B., Berry, P.M., Cabeza, M., Guisan, A., Hickler, T., Midgely, G.F., Paterson, J., Schurr, F.M., Sykes, M.T., Zimmermann, N.E. (2008). Predicting global change impacts on plant species' distributions: Future challenges. Perspectives in Plant Ecology, Evolution and Systematics 9, 137-152.

Thuiller, W., Broennimann, O., Hughes, G., Alkemade, J.R.M., Midgley, G.F., Corsi, F. (2006a). Vulnerability of African mammals to anthropogenic climate change under conservative land transformation assumptions. Global Change Biology 12, 424-440. 
Thuiller, W., Lavorel, S., Araujo, M.B., Sykes, M.T., Prentice, I.C. (2005). Climate change threats to plant diversity in Europe. Proceedings of the National Academy of Sciences, USA $102,8245-8250$.

Thuiller, W., Midgley, G.F., Hughes, G.O., Bomhard, B., Drew, G., Rutherford, M.C., Woodward, F.I. (2006b). Endemic species and ecosystem sensitivity to climate change in Namibia. Global Change Biology 12, 759-776.

Titeux, N., Henle, K., Mihoub, J.-B., Regos, A., Geijzendorffer, I.R., Cramer, W., Verburg, P.H., Brotons, L. (2016). Biodiversity scenarios neglect future land-use changes. Global Change Biology 22, 2505-2515.

Tittensor, D.P., Walpole, M., Hill, S.L.L., Boyce, D.G., Britten, G.L., Burgess, N.D., Butchart, S.H.M., Leadley, P.W., Regan, E.C., Alkemade, R., Baumung, R., Bellard, C., Bouwman, L., Bowles-Newark, N.J., Chenery, A.M., Cheung, W.W.L., Christensen, V., Cooper, H.D., Crowther, A.R., Dixon, M.J.R., Galli, A., Gaveau, V., Gregory, R.D., Gutierrez, N.L., Hirsch, T.L., Höft, R., Januchowski-Hartley, S.R., Karmann, M., Krug, C.B., Leverington, F.J., Loh, J., Lojenga, R.K., Malsch, K., Marques, A., Morgan, D.H.W., Mumby, P.J., Newbold, T., Noonan-Mooney, K., Pagad, S.N., Parks, B.C., Pereira, H.M., Robertson, T., Rondinini, C., Santini, L., Scharlemann, J.P.W., Schindler, S., Sumaila, U.R., Teh, L.S.L., Van Kolck, J., Visconti, P., Ye, Y. (2014). A mid-term analysis of progress toward international biodiversity targets. Science 346, 241-244.

TNC (2009). Terrestrial Ecoregions. The Nature Conservancy, Arlington, VA.

UNCCD (2017). Global Land Outlook. Secretariat of the United Nations Convention to Combat Desertification, Bonn, Germany.

UNEP (2012). Global Environmental Outlook 5. United Nations Environment Programme, Nairobi, Kenya.

UNEP (2014). The Emissions Gap Report 2014. United Nations Environment Programme, Nairobi, Kenya.

UNFCCC (2015). Adoption of the Paris Agreement. Report No. FCCC/CP/2015/L.9/Rev.1. UNFCCC, Bonn, http://unfccc.int/resource/docs/2015/cop21/eng/109r01.pdf.

Urban, M. (2015). Accelerating extinction risk from climate change. Science 348, 571-573.

Urban, M., Bocedi, G., Hendry, A., Mihoub, J.-B., Pe'er, G., Singer, A., Bridle, J., Crozier, L., De Meester, L., Godsoe, W., Gonzalez, A., Hellmann, J., Holt, R., Huth, A., Johst, K., Krug, C., Leadley, P., Palmer, S., Pantel, J., Schmitz, A., Zollner, P., Travis, J. (2016). Improving the forecast for biodiversity under climate change. Science 353,

van Vuuren, D., Edmonds, J., Kainuma, M., Riahi, K., Thomson, A., Hibbard, K., Hurtt, G.C., Kram, T., Krey, V., Lamarque, J.-F. (2011). The representative concentration pathways: an overview. Climatic Change 109, 5-31.

van Vuuren, D., Riahi, K., Moss, R., Edmonds, J., Thomson, A., Nakicenovic, N., Kram, T., Berkhout, F., Swart, R., Janetos, A., Rose, S.K., Arnell, N. (2012). A proposal for a new scenario framework to support research and assessment in different climate research communities. Global Environmental Change 22, 21-35.

van Vuuren, D.P., Stehfest, E., Gernaat, D.E.H.J., Doelman, J.C., van den Berg, M., Harmsen, M., de Boer, H.S., Bouwman, L.F., Daioglou, V., Edelenbosch, O.Y., Girod, B., Kram, T., Lassaletta, L., Lucas, P.L., van Meijl, H., Müller, C., van Ruijven, B.J., van der Sluis, S., Tabeau, A. (2017). Energy, land-use and greenhouse gas emissions trajectories under a green growth paradigm. Global Environmental Change 42, 237-250.

van Vuuren, D.P., Stehfest, E., Gernaat, D.E.H.J., van den Berg, M., Bijl, D.L., de Boer, H.S., Daioglou, V., Doelman, J.C., Edelenbosch, O.Y., Harmsen, M., Hof, A.F., van Sluisveld, M.A.E. (2018). Alternative pathways to the $1.5^{\circ} \mathrm{C}$ target reduce the need for negative emission technologies. Nature Climate Change 8, 391-397. 
Vellend, M., Baeten, L., Myers-Smith, I.H., Elmendorf, S.C., Beauséjour, R., Brown, C.D., De Frenne, P., Verheyen, K., Wipf, S. (2013). Global meta-analysis reveals no net change in local-scale plant biodiversity over time. Proceedings of the National Academy of Sciences 110, 19456-19459.

Vellend, M., Dornelas, M., Baeten, L., Beauséjour, R., Brown, C.D., De Frenne, P., Elmendorf, S.C., Gotelli, N.J., Moyes, F., Myers-Smith, I.H., Magurran, A.E., McGill, B.J., Shimadzu, H., Sievers, C. (2017). Estimates of local biodiversity change over time stand up to scrutiny. Ecology 98, 583-590.

Verburg, P.H., Crossman, N., Ellis, E.C., Heinimann, A., Hostert, P., Mertz, O., Nagendra, H., Sikor, T., Erb, K.-H., Golubiewski, N., Grau, R., Grove, M., Konaté, S., Meyfroidt, P., Parker, D.C., Chowdhury, R.R., Shibata, H., Thomson, A., Zhen, L. (2015). Land system science and sustainable development of the earth system: A global land project perspective. Anthropocene 12, 29-41.

Viechtbauer, W. (2010). Conducting meta-analyses in R with the metafor package. Journal of Statistical Software 36(3), 1-48.

Virkkala, R., Poyry, J., Heikkinen, R.K., Lehikoinen, A., Valkama, J. (2014). Protected areas alleviate climate change effects on northern bird species of conservation concern. Ecology and Evolution 4, 2991-3003.

Visconti, P., Bakkenes, M., Baisero, D., Brooks, T., Butchart, S.H.M., Joppa, L., Alkemade, R., Di Marco, M., Santini, L., Hoffmann, M., Maiorano, L., Pressey, R.L., Arponen, A., Boitani, L., Reside, A.E., van Vuuren, D.P., Rondinini, C. (2015). Projecting Global Biodiversity Indicators under Future Development Scenarios. Conservation Letters 9, 513.

Walpole, M., Almond, R.E.A., Besançon, C., Butchart, S.H.M., Campbell-Lendrum, D., Carr, G.M., Collen, B., Collette, L., Davidson, N.C., Dulloo, E., Fazel, A.M., Galloway, J.N., Gill, M., Goverse, T., Hockings, M., Leaman, D.J., Morgan, D.H.W., Revenga, C., Rickwood, C.J., Schutyser, F., Simons, S., Alison, J.S., Tyrrell, T.D., Vié, J.-C., Zimsky, M. (2009). Tracking Progress toward the 2010 Biodiversity Target and Beyond. Science 325, 1503-1504.

Walther, B., van Niekerk, A. (2015). Effects of climate change on species turnover and body mass frequency distributions of South African bird communities. African Journal of Ecology 53, 25-35.

Walther, G.-R., Post, E., Convey, P., Menzel, A., Parmesan, C., Beebee, T.J.C., Fromentin, J.M., Hoegh-Guldberg, O., Bairlein, F. (2002). Ecological responses to recent climate change. Nature 416, 389-395.

Warren, M., Frolking, S., Dai, Z., Kurnianto, S. (2017). Impacts of land use, restoration, and climate change on tropical peat carbon stocks in the twenty-first century: implications for climate mitigation. Mitigation and Adaptation Strategies for Global Change 22, 1041 1061 .

Warren, R., Price, J., Fischlin, A., de la Nava Santos, S., Midgley, G. (2011). Increasing impacts of climate change upon ecosystems with increasing global mean temperature rise. Climatic Change 106, 141-177.

Warren, R., Price, J., VanDerWal, J., Cornelius, S., Sohl, H. (2018). The implications of the United Nations Paris Agreement on climate change for globally significant biodiversity areas. Climatic Change 147, 395-409.

Warren, R., Vanderwal, J., Price, J., Welbergen, J.A., Atkinson, I., Ramirez-Villegas, J., Osborn, T.J., Jarvis, A., Shoo, L.P., Williams, S.E., Lowe, J. (2013). Quantifying the benefit of early climate change mitigation in avoiding biodiversity loss. Nature Climate Change 3, 678-682. 
White, S.R., Bork, E.W., Cahill, J.F. (2014). Direct and indirect drivers of plant diversity responses to climate and clipping across northern temperate grassland. Ecology 95, 30933103.

Wiens, J., Stralberg, D., Jongsomjit, D., Howell, C., Snyder, M. (2009). Niches, models, and climate change: Assessing the assumptions and uncertainties. Proceedings of the National Academy of Sciences, USA 106, 19729-19736.

Wiens, J.J. (2016). Climate-related local extinctions are already widespread among plant and animal species. PLoS Biology 14, e2001104.

Williams, S.E., Shoo, L.P., Isaac, J.L., Hoffmann, A.A., Langham, G. (2008). Towards an Integrated Framework for Assessing the Vulnerability of Species to Climate Change. PLoS Biology 6, e325.

Wilson, E.O. (1988). Biodiversity National Academy Press Washington D.C., USA.

Yu, Y., Pi, Y., Yu, X., Ta, Z., Sun, L., Disse, M., Zeng, F., Li, Y., Chen, X., Yu, R. (2019). Climate change, water resources and sustainable development in the arid and semi-arid lands of Central Asia in the past 30 years. Journal of Arid Land 11, 1-14.

Yule, C. (2008). Loss of biodiversity and ecosystem functioning in Indo-Malayan peat swamp forests.

Zhang, G., Biradar, C.M., Xiao, X., Dong, J., Zhou, Y., Qin, Y., Zhang, Y., Liu, F., Ding, M., Thomas, R.J. (2018a). Exacerbated grassland degradation and desertification in Central Asia during 2000-2014. Ecological Applications 28, 442-456.

Zhang, R., Liang, T., Guo, J., Xie, H., Feng, Q., Aimaiti, Y. (2018b). Grassland dynamics in response to climate change and human activities in Xinjiang from 2000 to 2014. Scientific Reports 8, 2888.

Zomer, R.J., Neufeldt, H., Xu, J., Ahrends, A., Bossio, D., Trabucco, A., van Noordwijk, M., Wang, M. (2016). Global Tree Cover and Biomass Carbon on Agricultural Land: The contribution of agroforestry to global and national carbon budgets. Scientific Reports 6, 29987. 



\section{Summary}

Biodiversity loss due to changes in climate and land use has been assessed recently. The earliest biodiversity assessments already showed that species are declining faster than at any time in the past and that ecosystems are rapidly deteriorating. Moreover, these assessments indicated that the projected changes in climate and land use likely drive further biodiversity losses in the 21 st century, both directly and in synergy with each other. This accumulated evidence positions climate change and land-use change among the major human-induced direct drivers of biodiversity loss. Climate change affects biodiversity as climate variables, such as temperature and precipitation, largely determine the geographical distributions of species. Hence, in areas where climate is less suitable, species shift their geographical ranges and go extinct locally. Land-use change poses immediate threats to biodiversity as the conversion of natural habitats (e.g. forests, wetlands and grasslands) into agricultural land results in populations decline and extinctions become more likely. These adverse effects consequently change ecosystems functioning and potentially affect the supply of ecosystems services and thus human well-being.

Although research on climate and land-use change impacts on biodiversity and the consequent implications was repeatedly conducted, the range of estimates for these impacts remains disturbingly large. Moreover, such research relied on climate-change scenarios that depict relatively small increases in global mean temperatures (i.e. $<2^{\circ} \mathrm{C}$ ). Nowadays, the plausibility of climate-change scenarios which overshoot the $2^{\circ} \mathrm{C}$ policy target from The Paris Agreement, is rapidly increasing. Advances are thus needed to better understand how biodiversity will respond to such larger changes, including quantifications of the expected biodiversity decline at different climate and land-use change levels, and the effect derived from interaction mechanisms between these drivers. Furthermore, the global efforts to combat climate change and to keep global average temperature to well-below $2^{\circ} \mathrm{C}$ will require large mitigation commitments from the land sector with potentially both positive and negative consequences for biodiversity. These implications of land-based mitigation efforts have to be further assessed.

$\mathrm{My} \mathrm{PhD}$ thesis therefore aimed to explore future biodiversity trends under projected direct and synergistic changes in climate and land use and to advance understanding of climate-change mitigation consequences for biodiversity. In this thesis, climate change was indicated by global mean temperature increase $\left({ }^{\circ} \mathrm{C}\right)$ and land-use change by land-use intensity levels (i.e. grazing and cropland levels) and land-cover type transitions.

In Chapter 2, I assessed the magnitude of expected changes of biodiversity by systematically reviewing studies and performing a meta-analysis of the responses of species distributions to climate change. I proposed two indicators to quantify the local response of terrestrial biodiversity to climate 
change: the fraction of remaining species (FRS) and the fraction of remaining area (FRA) with suitable habitat for each species. The FRS and FRA calculate deviations from the original biodiversity state and both they indicate biodiversity intactness. The biodiversity response was quantified for different intervals of global mean temperature increase and for different taxonomic groups and ecosystems. The results showed that projected climate-change impacts likely cause changes to the distribution of many plants and animals and this leads to severe range contractions and local extinction of some species (i.e. decreasing biodiversity). The FRS and FRA were projected to gradually decrease with significant reductions of $14 \%$ and $35 \%$ between $1{ }^{\circ} \mathrm{C}$ and $2{ }^{\circ} \mathrm{C}$ increases in global mean temperature, and $32 \%$ and $54 \%$ beyond $4{ }^{\circ} \mathrm{C}$ increase. This chapter showed that already at moderate temperature increases the original biodiversity significant decreased.

In Chapter 3, I estimated biodiversity decline from changes in climate and land use in grassland ecosystems, which are among the most extensive ecosystems in the world. The analysis was conducted in the Central Asian grasslands, which are nowadays transforming by changes in land use and climate. I used a scenario analysis based on the latest Shared Socio-Economic Pathways (SSPs) and Representative Concentration Pathways (RCPs) (i.e. SSP-RCP scenario framework) and further detail land-use scenarios for the region. I selected contrasting socio-economic and climate conditions (i.e. SSP1-RCP4.5, SSP3-RCP8.5, SSP4-RCP4.5 and SSP5-RCP8.5). In this analysis, the climate-change impact for the selected RCP4.5 and RCP8.5 was indicated by the FRS for grasslands as estimated in Chapter 2; the land-use change impact was indicated by changes in land-use intensity derived from the land-use scenarios; and the future biodiversity was indicated by the Mean Species Abundance (MSA). The MSA expresses the mean abundance of originally occurring species in disturbed conditions (e.g. after climate change) relative to their original abundance in undisturbed habitats. The contrasting scenario combinations showed that grasslands' biodiversity remained under continuous threat and will further decline under each scenario. The strongest impact on biodiversity was projected in SSP5-RCP8.5, where half of the grasslands will likely undergo a large decrease in their species abundance by 2100 . This chapter stressed the potential vulnerability of the Central Asian grasslands to increasing land-use intensity and climate change.

In Chapter 4, I explored interaction mechanisms between climate and land-use change effects on biodiversity. Climate change and land-use change are often addressed as drivers that interact synergistically in several ways and alter their mutual effects on biodiversity. I identified interaction mechanisms in which species in heavily modified landscapes may respond differently to climate change than species in pristine landscapes. These interactions arise if 1) species adapted to modified landscapes differ in their sensitivity to climate change from species adapted to natural landscapes and if 2) land-use composition restricts climate-change induced dispersal of species in fragmented landscapes. To verify these conditions, I performed systematic reviews and a meta-analysis of bioclimatic studies on species distributions in landscapes with varying proportions of cropland (first condition) and species' dispersal under climate change in fragmented landscapes (second condition). I used the FRS as the effect-size metric in this meta-analysis. Based on the results of this analysis, I 
found no significant interaction effect for the first condition. This indicates that the influence of global mean temperature increase on the FRS did not change with different cropland levels. No quantitative studies were found to verify the second condition for climate-change induced dispersal of species. This chapter emphasized the need to assess interactions between land-use and climatechange effects on biodiversity, integrating other conditions, such as spatial location, adaptive capacity and time lags.

In Chapter 5, I assessed carbon-dioxide-removal options in the Agriculture, Forestry and Other Land Use sectors (i.e. land-based mitigation options) implemented in different mitigation pathways that keep global temperature increase to well-below $2^{\circ} \mathrm{C}$ for their biodiversity impacts using the MSA indicator. Land-based mitigation options may preserve, increase or deteriorate biodiversity, because of their land-use impact. In this chapter, I reviewed climate change mitigation studies that assessed each of the selected land-based mitigation options and indicated the land transition needed to achieve a significant climate change mitigation (i.e. potential land-cover and/or land-use change). I found that reforestation of cultivated and managed areas together with restoration of wetlands deliver the largest increase of MSA, if provided the opportunity to reach mature states over time. Contrary, intensification of agricultural areas and bioenergy with carbon capture and sequestration decreased MSA locally. Options such as afforestation and reduced deforestation, either positively or negatively affect MSA. This depends on their spatial implementation and the precise forest conservation schemes. This chapter provided insights on possible synergies that emerge from certain scenarios and their benefits for current and future biodiversity conservation in regions with large land-based mitigation potential.

My $\mathrm{PhD}$ thesis advanced scientific understanding of climate and land-use change impacts on biodiversity that can feed into the current UN Conventions on Biological Diversity and Climate Change agendas. It showed future biodiversity trends and proposed methods that translate relevant information of socio-economic and climate-change drivers to assess interactions between climate and land-use change effects on biodiversity. Such knowledge is quickly becoming an important element to develop strategies for regional and global biodiversity conservation and thus to minimize biodiversity loss. I stress the importance of holding climate change well-below $2{ }^{\circ} \mathrm{C}$ as this helps to maintain the composition of local communities and their climatically suitable areas, while seeking for the desired combinations that will reduce the use of detrimental land-based mitigation options to biodiversity. 



\section{Resumen}

La pérdida de biodiversidad debido a los cambios en el clima y el uso de la tierra, recientemente ha sido evaluada. Las primeras evaluaciones de biodiversidad demostraron que las especies están disminuyendo más rápido que en cualquier otro momento en el pasado y que los ecosistemas se están deteriorando rápidamente. Además, estas evaluaciones indican que los cambios proyectados en el clima y en el uso de la tierra probablemente impulsarán más pérdidas de biodiversidad en el presente siglo, tanto directamente como en sinergia entre sí. Esta evidencia acumulada posiciona el cambio climático y el cambio en el uso de la tierra entre las principales causas de la pérdida de biodiversidad inducidas por la humanidad. En efecto, el cambio climático afecta la biodiversidad, ya que las variables climáticas, como la temperatura y la precipitación, determinan en gran medida las distribuciones geográficas de las especies. Por lo tanto, en áreas donde el clima es menos adecuado, las especies cambian sus rangos geográficos y se extinguen localmente. Por su parte, el cambio en el uso de la tierra plantea amenazas inmediatas a la biodiversidad, ya que la conversión de hábitats naturales (por ejemplo, bosques, humedales y pastizales) en tierras agrícolas hace que la población biológica disminuya y las extinciones sean más probables. En consecuencia, estos efectos adversos cambian el funcionamiento de los ecosistemas y pueden afectar la oferta de servicios de los mismos y por ende el bienestar humano.

Aunque investigaciones sobre los impactos y consecuencias sobre la diversidad por parte del cambio climático y del uso de la tierra se han llevado a cabo repetidamente, el rango de estimaciones para estos impactos sigue siendo significativamente alarmantemente. Además, dichas investigaciones se basan en escenarios de cambio climático que representan aumentos relativamente pequeños en las temperaturas medias globales (es decir, $<2^{\circ} \mathrm{C}$ ).

En la actualidad, la plausibilidad de los escenarios de cambio climático que superan el objetivo climático de $2^{\circ} \mathrm{C}$ del Acuerdo de París, está aumentando rápidamente. Por lo tanto, se necesitan avances analíticos para discernir cómo la biodiversidad responderá a estos considerables cambios, incluyendo estimaciones de la disminución esperada de la biodiversidad en diferentes rangos de cambio climático y uso de la tierra, así como por el efecto derivado de interacción entre dichas causas. Además, los esfuerzos globales para combatir el cambio climático y mantener la temperatura promedio mundial por debajo de $2^{\circ} \mathrm{C}$ requerirán grandes compromisos de mitigación basada en el uso de la tierra con posibles consecuencias tanto positivas como negativas para la biodiversidad. Estas implicaciones de los esfuerzos de mitigación en el uso de la tierra deben evaluarse más a fondo. Mi tesis doctoral, por lo tanto, tuvo como objetivo principal explorar las tendencias futuras de la biodiversidad en relación a los cambios directos y sinérgicos proyectados en el clima y el uso de la tierra, y así comprender mejor las consecuencias de la mitigación del cambio climático en la biodiversidad. 
En esta tesis, el cambio climático está indicado por el aumento de la temperatura media global $\left({ }^{\circ} \mathrm{C}\right)$ y el cambio en el uso de la tierra, por los niveles de intensidad del uso de la tierra (es decir, los niveles de pastoreo y tierras para cultivo) y las transiciones de tipo de cobertura de la tierra.

En el Capítulo 2, evalué la magnitud de los cambios esperados en la biodiversidad a través de una revisión sistemática de estudios y meta-análisis de las respuestas de las distribuciones de especies al cambio climático. Para ello, formulé dos indicadores para cuantificar la respuesta local de la biodiversidad terrestre al cambio climático: la fracción remanente de especies (FRS, por sus siglas en inglés) y la fracción remanente del área (FRA) con hábitat adecuado para cada especie. Ambas calculan las desviaciones del estado de biodiversidad original e indican la integridad de la biodiversidad. La respuesta de la biodiversidad fue cuantificada para diferentes intervalos de aumento de la temperatura media global y para diferentes grupos taxonómicos y ecosistemas. Los resultados mostraron que los impactos proyectados del cambio climático probablemente causen cambios en la distribución de muchas plantas y animales, y esto conducirá a contracciones severas y la extinción local de algunas especies (es decir, la disminución de la biodiversidad). Se espera que la FRS y la FRA disminuyan gradualmente con reducciones significativas de $14 \%$ y $35 \%$ entre los aumentos de $1^{\circ} \mathrm{C}$ y $2^{\circ} \mathrm{C}$ en la temperatura media global, y del $32 \%$ y $54 \%$ más allá del aumento de $4^{\circ} \mathrm{C}$. Este capítulo concluyó que un aumento moderado de temperatura provocará significativamente una disminución en la biodiversidad original.

En el Capítulo 3, cuantifiqué la disminución de la biodiversidad a partir de cambios en el clima y del uso de la tierra en los ecosistemas de pastizales, constituido como uno de los más extensos del mundo. El análisis se centró en los pastizales de Asia Central, que en la actualidad se están transformando por cambios en el uso de la tierra y el clima. Utilicé un análisis de basado en el más reciente marco de escenarios de Trayectorias Socioeconómicas Compartidas y Trayectorias de Concentración Representativas (SSP-RCP, por sus siglas en inglés) y más detalles de los escenarios de uso de la tierra para la región. Seleccioné condiciones socioeconómicas y climáticas contrastantes (SSP1-RCP4.5, SSP3-RCP8.5, SSP4-RCP4.5 y SSP5-RCP8.5). En este análisis, el impacto del cambio climático para RCP4.5 y RCP8.5 está indicado por la FRS para pastizales como se estimó en el Capítulo 2; el impacto del cambio en el uso de la tierra está indicado por los cambios en la intensidad del uso de la tierra derivados de los escenarios de uso de la tierra; y finalmente, la biodiversidad futura está indicada por la abundancia media de especies originales (MSA), la cual expresa la abundancia media en condiciones perturbadas (por ejemplo, después del cambio climático) en relación con su abundancia original en hábitats no perturbados. Las combinaciones de escenarios contrastantes mostraron que la biodiversidad de los pastizales permanece bajo una amenaza continua y disminuyó en cada escenario. El impacto más fuerte en la biodiversidad se espera en SSP5-RCP8.5, donde la mitad de los pastizales probablemente experimentarán una gran disminución en su abundancia de especies para el año 2100. Este capítulo enfatizó la vulnerabilidad de los pastizales de Asia Central al aumento de la intensidad del uso de la tierra y el cambio climático. 
En el Capítulo 4, exploré los mecanismos de interacción entre el clima y los efectos del cambio en el uso de la tierra sobre la biodiversidad. El cambio climático y el cambio en el uso del suelo a menudo se abordan como impulsores que interactúan sinérgicamente de varias maneras y alteran sus efectos mutuos sobre la biodiversidad. En este capítulo identifiqué mecanismos de interacción en los cuales las especies en paisajes muy modificados pueden responder de manera diferente al cambio climático que las especies en paisajes prístinos o naturales. Estas interacciones surgen si: 1) las especies adaptadas a los paisajes modificados difieren en su sensibilidad al cambio climático, de las especies adaptadas a los paisajes naturales; y 2) la composición del uso de la tierra restringe la dispersión de especies inducida por el cambio climático en paisajes fragmentados. Para verificar estas condiciones, realicé revisiones sistemáticas y un meta-análisis de estudios bioclimáticos sobre distribuciones de especies en paisajes con proporciones variables de tierras de cultivo (primera condición) y dispersión de especies bajo el cambio climático en paisajes fragmentados (segunda condición). Utilicé la FRS como la métrica del tamaño del efecto en éste meta-análisis. Basándome en los resultados de este análisis, no encontré ningún efecto de interacción significativo para la primera condición. Esto indicó que la influencia del aumento de la temperatura media global en la FRS no cambió con los diferentes niveles de cultivo. No encontré estudios cuantitativos para verificar la segunda condición de dispersión de especies inducida por el cambio climático. Este capítulo enfatizó la necesidad de evaluar las interacciones entre el uso de la tierra y los efectos del cambio climático en la biodiversidad, integrando otras condiciones, como son la ubicación espacial, la capacidad de adaptación y lapsos de tiempo para percibir dichos efectos.

En el Capítulo 5, evalué las opciones de eliminación de dióxido de carbono en los sectores de Agricultura, Silvicultura y otros usos del Suelo (AFOLU, por sus siglas en inglés) implementadas en diferentes vías de mitigación que mantienen el aumento de la temperatura global muy por debajo de $2^{\circ} \mathrm{C}$ para medir el impacto en su biodiversidad utilizando el indicador MSA. Las opciones de mitigación basadas en el uso de la tierra pueden preservar, aumentar o deteriorar la biodiversidad. En este capítulo, revisé diversos estudios de mitigación del cambio climático que evaluaron cada una de las opciones seleccionadas e indiqué la transición de la tierra necesaria para lograr una mitigación significativa del cambio climático (es decir, un posible cambio en el uso de la tierra). En este capítulo, demostré que la reforestación de áreas cultivadas junto con la restauración de humedales produce el mayor aumento de MSA, si se brinda la oportunidad de alcanzar estados maduros en el largo plazo. Al contrario, la intensificación de las áreas agrícolas y la bioenergía con la captura y el secuestro de carbono disminuyeron la MSA a nivel local. Las opciones tales como la forestación y la reducción de la deforestación, afectan positiva o negativamente a la MSA, esto dependerá de su implementación espacial y según los esquemas precisos de conservación forestal. Este capítulo analizó las compensaciones para la conservación de la biodiversidad actual y futura en regiones con un gran potencial de mitigación en tierra.

Mi tesis doctoral contribuyó en la comprensión científica de los impactos del cambio climático y del uso de la tierra en la biodiversidad que pueden contribuir a las actuales convenciones de las Naciones 
Unidas sobre la diversidad biológica y el cambio climático. En mi tesis demostré tendencias futuras de la biodiversidad y propuse métodos que traducen la información relevante de los factores socioeconómicos y de cambio climático para evaluar las interacciones entre el clima y los efectos del cambio de uso de la tierra sobre la biodiversidad. Este conocimiento se está convirtiendo rápidamente en un elemento importante para desarrollar estrategias para la conservación de la biodiversidad a nivel regional y mundial y, por lo tanto, para minimizar la pérdida de biodiversidad. Finalmente, destaco la importancia de mantener el cambio climático muy por debajo de $\operatorname{los} 2^{\circ} \mathrm{C}$, ya que esto ayudará a mantener la composición de las comunidades biológicas locales y sus áreas climáticamente adecuadas, al mismo tiempo que se buscan las combinaciones deseadas que reducirán el uso de las opciones de mitigación perjudiciales para la biodiversidad basadas en la tierra. 


\section{Acknowledgements}

I am happily closing another chapter of my life: my $\mathrm{PhD}$. Achieving this degree would not have been possible without the support of many people. Thus I take advantage of this space to thank these people who substantially contributed to develop each piece of my research and made this journey more enjoyable and satisfying.

First, I thank my promotors Rik Leemans and Rob Alkemade my co-promotor Kasper Kok for giving me the opportunity to take-up the challenge of this $\mathrm{PhD}$ position and to immerse deeply in two timely important scientific fields: climate change and biodiversity loss. Looking back at those first days of my $\mathrm{PhD}$ and the many questions I had, I feel extremely grateful for your support, guidance, the plentiful discussion sessions and constructive feedbacks that led to answer those questions and to wrap the results in this thesis book.

I gratefully acknowledge funding of my $\mathrm{PhD}$ research by the EU FP7 funded "Impacts and Risks from High-End Scenarios: Strategies for Innovative Solutions (IMPRESSIONS)" project. Being part of the IMPRESSIONS project was a challenging but gratifying experience. I learned so much from each of the work package meetings, assemblies, break-out sessions, not only content-wise but also about the enormous potential that the science-policy platform has to positively impact the world. Many thanks to Paula Harrison, coordinator of IMPRESSIONS, and the rest of the team for the multiple collaborations to accomplish project deliverables and publications.

I thank people from the PBL-Netherlands Environmental Assessment Agency for the opportunity to exchange knowledge through discussions, trainings, symposiums, etc. along these $\mathrm{PhD}$ years. Particularly many thanks to Johan Meijer for guiding me through the GLOBIO3 model and dealing with all sort of software problems that I faced at different times.

Working at ESA group was a really good experience, not only because it was located in the most wonderful building on Campus (Lumen), but also for all the nice people that I met. I enjoyed since the very beginning the activities as a group: coffee breaks, Sinterklaas celebrations, annual outings, borrels, etc. Thanks to all ESA colleagues: Mathilde, Karen, Nynke, Lenny, Marjolein, Lars, Dolf, Sophie, Bas, Niklas, Wim, Wichertje, André, Arnold, Jana, Hidde, Gerbert and Jesse. Many thanks to all the current PhD students: Anna, Maddy, Jerry, Saritha, Lena, Eka, Dan, Siatwiinda, Ilan, Gabriela, Jillian, Joyce, Dian, Adil, Donghao, Xingjuan and Nancy, and the former ones: Confidence, Aritta, Kanokwan, Maryna, Mengru, Lucie, Halima, Leonardo, Roy, Alexey, Momo, Julia and Shahid. I enjoyed our exceptionally international $\mathrm{PhD}$ dinners with never less than 10 different nationalities, writing weeks, ice-cream afternoons and more! Special thanks to Anna and Maddy for being my paranymphs. 
Thanks to my friends from my MSc time who for different reasons stayed in the Netherlands: Alvaro, Roula, Charlotte and Luz. Thanks to other friends with whom I accumulated memorable moments of the WUR life: Simona, Lingtong, Alessandra, Linda, Claudia, Silvia, Giuliana, Sean, the Honduran community \& Co. and the Zamoranos. Also thanks to the Peyresq people for an unforgettable ALTER-Net Summer School 2015 in the French Alps, and especially to my dear Peyresq girls Alice, Julia, Klara, Eerica, Karla and Tanya for keeping in touch sharing news and achievements. You all helped to make this journey a lot more entertaining and sweet. Also, many thanks to my beloved friends who despite being thousands of kilometres away, always found the way to cheer me up: Lorena, Eva, Lila and Tuti. A big thanks to Alvaro for your help in solving the silly and not so silly $\mathrm{R}$ troubles.

My family was a cornerstone in this journey. My parents, Fernán and Telma, and my brothers, Alan and David, have always been there to support each of my crazy decisions and help me fulfil my ambitions. No tengo palabras que describan mi sentimiento de felicidad por todo lo que hacemos juntos desde dos tierras separadas por un gran océano. Gracias mi hermosa familia por el amor y apoyo, por luchar junto a mí por mis metas, este logro es de ustedes también! I also thank my sweet Velbert family, especially to Sonia and Jörg for adopting me as your daughter. The vicinity of Velbert was just perfect these years! And a very, very, very special thanks to my mom and to my parents-inlaw, Karen and Hans, for the time spent in Wageningen and your support during the last, hectic stretch of the $\mathrm{PhD}$.

My last, and perhaps the most special thanks goes to you, Anton, my love, my partner, my husband, for your understanding, patience, support, and to you my little love, Clementina, for your unique way to shake my whole world with every single development of your own life! We did it my loves! 


\section{About the author}

Sarahi Nuñez Ramos was born on 9 November 1985 in Tegucigalpa, Honduras. After completing her primary and secondary education, Sarahi faced the first of many major decisions in her life and asked herself: "what do I want to study?". She started the green path of environmental studies at the Escuela Agrícola Panamerica El Zamorano, Honduras. In 2006, after four years of 'learning-by-doing', she completed her BSc in Socio-economic development and Environment. This BSc allowed her to understand the natural and social systems and the complexity that surrounds the management and

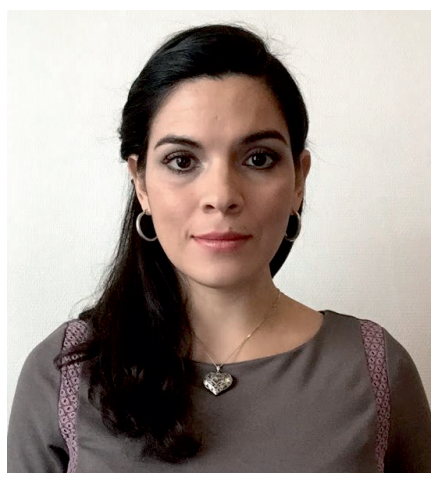
conservation of natural resources. After her BSc, she started working in different consultancy projects, in Tegucigalpa, Honduras. In 2008, she decided to pursue a Master in Project Management, which successfully completed with Master Cum Laude Honors by the Central American Technological University in Honduras in 2009. In 2010, she started a Visiting Scholar Programme in the Department of Horticulture and Crop Science at the Ohio State University in the US. This was a life changing experience for her. After almost two years of field work in the forests and metro parks of the Midwest US and learning from her mentors, she realised that an MSc was the next step in her life. In 2012, Sarahi was awarded a NFP Scholarship NUFFIC to pursue an MSc in Environmental Sciences at Wageningen University and Research, The Netherlands. She travelled to the Netherlands, where she continued her academic career. In 2014, she completed her MSc thesis in the group Environmental Economics and Natural Resources on assessing the effects of renewable energies on climate change mitigation. Her MSc strengthened her motivation and desire to solve socio-economic and environmental problems to contribute to develop solutions for a sustainable future. She wanted to continue paving her green path. Right after her MSc, Sarahi was granted the opportunity to conduct a $\mathrm{PhD}$ research to assess the consequences of high-end climate scenarios on biodiversity within the EU FP7 IMPRESSIONS project under the supervision of Prof. Dr Leemans, Prof. Dr Alkemade and Dr Kok. She conducted her research in the group Environmental Systems Analysis. Sarahi is ready to ask herself one more time: "what is my next step?". 



\section{List of publications}

Peer-reviewed publications

Nunez, S., Arets, E., Alkemade, R., Verwer, C., Leemans, R. (2019). Assessing the impacts of climate change on biodiversity: is below $2^{\circ} \mathrm{C}$ enough? Climatic Change. $154,351-365$. DOI: 10.1007/s10584-019-02420-x

Fronzek, S., Carter, T.R., Pirttioja, N., Alkemade, R., Audsley, E., Bugmann, H., Flörke, M., Holman, I., Honda, Y., Ito, A. and Janes-Bassett, V., Lafond, V., Leemans, R., Mokrech, M., Nunez, S., Sandars, D., Snell, R., Takahashi, K., Tanaka, A., Wimmer, F., Yoshikawa, M. (2019). Determining sectoral and regional sensitivity to climate and socio-economic change in Europe using impact response surfaces. Regional Environmental Change 19, 679693. DOI: $10.1007 / \mathrm{s} 10113-018-1421-8$

Other publications

IMPRESSIONS deliverables

Holman, I., Audsley, Eric., Berry, P., Brown, C., Bugmann, H., Clarke, L., Cojocaru, G., Dunford, R., Fronzek, S., Harrison, P., Honda, Y., Janes, V., Kovats, S., Lafond, V., Lobanova, A., Sloth Madsen, M., Mokrech, M., Nunez, S., Pedde, S., Sandars, D., Savin, C. , Wimmer, F. (2017) Modelling Climate Change Impacts, Adaptation and Vulnerability in Europe. IMPRESSIONS deliverable Available in:

http://www.impressions-project.eu/documents/1/

Carter, T., Fronzek, S., Alkemade, R., Holman, I., Honda, Y., Ito, A., Leemans, R., Nunez, S., Oka, K., O'Neil, B., Onigkeit, J., Pedde, S., Rounsevell, M., Takahashi, K., Wimmer, F., Yoshikawa, M. (2016) Global Scale Application of Climate Change Impact, Adaptation and Vulnerability (CCIAV) models. IMPRESSIONS deliverable D3A.1. Available in: http://www.impressions-project.eu/documents/1/

Kok, K., Sloth Madsen, M., Pedde, S., Christensen, J., Fronzek, S., Nunez, S., Gramberger, M., Jäger, J., Cojocaru, G., Frantzeskaki, N., Hölscher, K., Tabara, D., Harrison, P. (2018). Set of integrated high-end, multi-scale scenarios. IMPRESSIONS deliverable D2.4. Available in: http://www.impressions-project.eu/documents/1/ 



\section{SENSE}

Netherlands Research School for the

Socio-Economic and Natural Sciences of the Environment

\section{I P L O M A}

For specialised PhD training

The Netherlands Research School for the Socio-Economic and Natural Sciences of the Environment

(SENSE) declares that

\section{Sarahi Elizabeth Nuñez Ramos}

born on 9 November 1985 in Tegucigalpa, Honduras

has successfully fulfilled all requirements of the Educational Programme of SENSE.

Wageningen, 9 October 2019

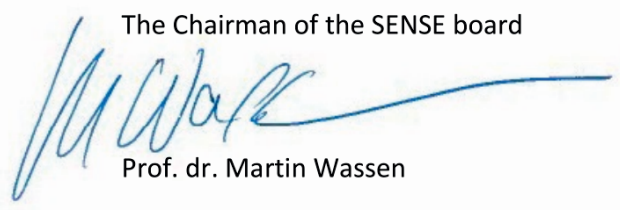

the SENSE Director of Education

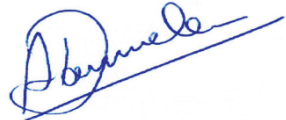

Dr. Ad van Dommelen

The SENSE Research School has been accredited by the Royal Netherlands Academy of Arts and Sciences (KNAW)

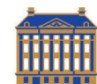

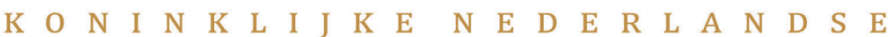

$\begin{array}{lllllllllllllllllllllllll}\text { A } & \text { K } & \text { A } & \text { D } & \text { E } & \text { M } & \text { I } & \text { E } & \text { V } & \text { A } & \text { N } & \text { W } & \text { E } & \text { T } & \text { E } & \text { N } & \text { S } & C & \text { H } & \text { A } & \text { P } & \text { P } & \text { E } & N\end{array}$ 


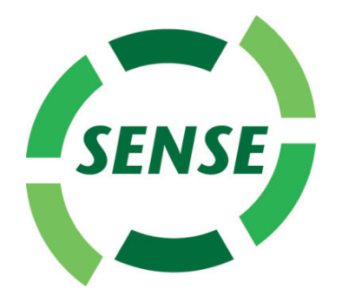

The SENSE Research School declares that Sarahi Elizabeth Nuñez Ramos has successfully fulfilled all requirements of the Educational PhD Programme of SENSE with a work load of $41.0 \mathrm{EC}$, including the following activities:

\section{SENSE PhD Courses}

- Environmental Research in Context (2015)

Project and Time Management (2015)

- Data Management Planning (2015)

- Introduction to R (2016)

- Techniques for Writing and Presenting a Scientific Paper (2016)

- Research in Context Activity: 'Communicating on PhD research for a wider audience in TV interview and sharing research results on drivers of biodiversity loss, including climate change in accessible press release' (2019)

\section{Selection of other PhD and Advanced MSc Courses}

- ALTER-Net Summer School on Biodiversity and Ecosystem Services, France (2015)

- The Choice: personal leadership (2017)

- Environmental Impact Assessment of Livestock Systems, WIAS, Wageningen University (2019)

\section{External training at a foreign research institute}

- Getting acquainted with the GLOBIO model, Netherlands Environmental Assessment Agency (2014)

\section{Management and Didactic Skills Training}

- Supervising MSc students in writing scientific essays - 'Seminar Interdisciplinarity in Scientific Research and Education', 'Introduction to Global Change', and 'Environmental Quality and Governance' (2014-2017)

- Organiser of Research Presentations and Discussion at the Environmental Systems Analysis group (2016-2018)

\section{Oral Presentations}

- Role of biodiversity and ecosystem services in climate adaptation and mitigation strategies. Adaptation Futures 2016: Practices and Solutions, 10-12 May 2016, Rotterdam, The Netherlands

- Biodiversity's response to climate change. Wageningen PhD symposium, 3 May 2017, Wageningen, The Netherlands

SENSE Coordinator PhD Education

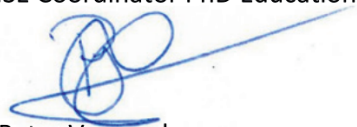

Dr. Peter Vermeulen 
The research described in this thesis was financially supported by the "Impacts and Risks from HighEnd Scenarios: Strategies for Innovative Solutions (IMPRESSIONS)" project (Grant Agreement 603416) from the EU FP7 programme. Financial support from Wageningen University and Research for printing this thesis is gratefully acknowledged.

Cover design by Tania Erazo Ramos | Printed by Proefschrift Maken. 



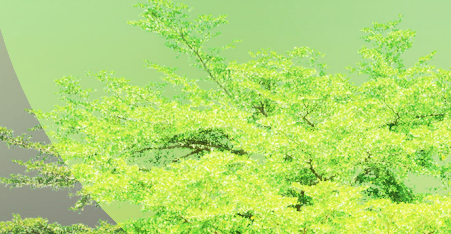

whand

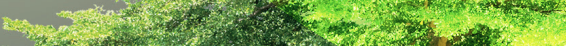
$(4,4)$

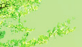

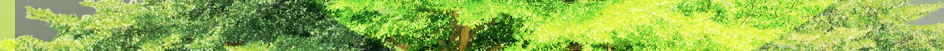

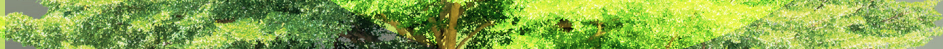
An

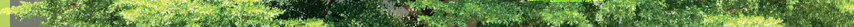

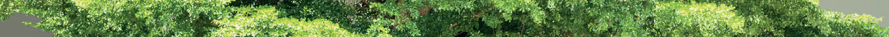

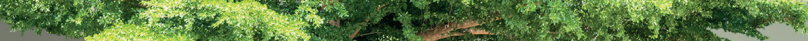

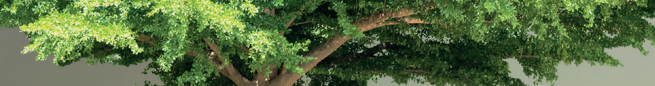
$-x^{2}+x^{2}+x^{2}+x^{2}$ 